\title{
The kindness of strangers : studies on customer behavior in commercial virtual communities
}

Citation for published version (APA):

Wiertz, C. (2005). The kindness of strangers : studies on customer behavior in commercial virtual communities. [Doctoral Thesis, Maastricht University]. [s.n.]. https://doi.org/10.26481/dis.20051208cw

Document status and date:

Published: 01/01/2005

DOI:

$10.26481 /$ dis.20051208cw

Document Version:

Publisher's PDF, also known as Version of record

\section{Please check the document version of this publication:}

- A submitted manuscript is the version of the article upon submission and before peer-review. There can be important differences between the submitted version and the official published version of record.

People interested in the research are advised to contact the author for the final version of the publication, or visit the DOI to the publisher's website.

- The final author version and the galley proof are versions of the publication after peer review.

- The final published version features the final layout of the paper including the volume, issue and page numbers.

Link to publication

\footnotetext{
General rights rights.

- You may freely distribute the URL identifying the publication in the public portal. please follow below link for the End User Agreement:

www.umlib.nl/taverne-license

Take down policy

If you believe that this document breaches copyright please contact us at:

repository@maastrichtuniversity.nl

providing details and we will investigate your claim.
}

Copyright and moral rights for the publications made accessible in the public portal are retained by the authors and/or other copyright owners and it is a condition of accessing publications that users recognise and abide by the legal requirements associated with these

- Users may download and print one copy of any publication from the public portal for the purpose of private study or research.

- You may not further distribute the material or use it for any profit-making activity or commercial gain

If the publication is distributed under the terms of Article $25 \mathrm{fa}$ of the Dutch Copyright Act, indicated by the "Taverne" license above, 


\section{THE KINDNESS OF StRANGERS}

Studies on Customer Behavior in Commercial Virtual Communities 
(c) 2005, Carolline Wiertz, Maastricht.

All rights reserved. No part of this publication may be reprinted or utilized in any form or by any electronic, mechanical or other means, now known, or hereafter invented, including photocopying and recording, or in any information storage or retrieval system, without written permission from the copyright owner.

Cover Design: Christian Petermann

ISBN-10: 90-9020089-4

ISBN-13: $97-8909020-0897$

Printed by: B+W Computerformulare 


\section{THE Kindness of StRangers}

Studies on Customer Behavior in Commercial Virtual Communities

\section{PROEFSCHRIFT}

ter verkrijging van de graad van doctor

aan de Universiteit Maasitricht,

op gezarg van de Rector Magnificus, Prof. Mr. G.P.M.F. Mols,

volgens het besluit van het College van Decanen,

in het openbaar te verdedigen

op donderdag 8 december 2005 om 16.00 uur

door

Caroline Wiertz 


\section{Promotor:}

Prof. Dr. 1.C. de Ruyter

\section{Beoordelingscomissie:}

Prof. Dr. Ir. B.G.C. Dellaert (voorzitter)

Dr. C. Mathwick (Portland State University, Oregon, US)

Prof. Dr. R. Muller 
Für meine Eltern,

Sylvie und Winand Wiertz 
(2) 


\section{ACKNOWLEDGEMENTS}


A wise man once said that the only good dissertation is a finished one. Finishing is much harder than one might think, and without the kindness of many people surrounding me, I would have never achleved this goal.

I am most thankful to my "promotor" Ko de Ruyter for not only being a great supervisor, but also a friend. He inspired me to start the PhD program in the first place, gave me guldance and counsel along the way, and always had confidence in my abilities. I greatly admire his creativity and enthuslasm for research, which he couples with a healthy ability to see things in perspective. In addition, I value his appreclation of the good things in life. His motto "work had, play hard" resulted in a host of memorable trips and culinary experiences. Thanks for everything!

I would also like to express my gratitude to the members of my committee who have provided valuable advice and feedback on my work. I am deeply indebted to Benedict Dellaert for always making time for me and getting back to me quickly. He has the rare ability to give incredibly detailed and critical feedback in such a nice way that one does not even mind having to rewrite an entire paper. I would like to thank Charla Mathwick, "my American", for her involvement in my dissertation and all the professional and personal support she has given me over the years. Our cooperation has been very enjoyable and productive, and we have had great times visiting each other in Maastricht and Portland. I am also grateful to Rudolf Müller for his helpful comments on my dissertation and his unparalleled flexibility with regards to reading it quickly. Without him, a defense in December would not have been possible.

Moreover, I would like to acknowledge the priceless help of Claudia Ulirich who has ensured that my research makes sense from a business perspective and has enabled part of my data collection.

I am also grateful to Patrick Ventker and Christian Petermann for their input in and the actual design of my book cover.

I have been fortunate to have great colleagues, both at my former and my new workplace. Many thanks to everyone in the marketing department in Maastricht for providing such a collegial environment. I would especially like to thank Jos Lemmink, my former department head, for always having an open ear 
for my problems and for his great sense of humor. Thanks to Mark Arts for knowing the answer to all possible problems and making great online quiestionnairres. I am also grateful to Sandra Streukens and Martin Wetzels for their support in statistical matters. Many thanks to Jill Lei for giving great feedback on work and life in general, and making sure that I eat enough healthy Chinese food. Most importantly, this dissertation would not have been possible without the moral support, invaluable advice, and great friendship of my "paranimfen" Vera Blazevic and Lisa Deutskens. We shared the best and the worst times, and will continue to do so in the future. They are the best friends one can wish for!

I would also like to thank my new colleagues at Cass Business School for welcoming me so cordially and making me feel at home. A special thanks to my new "bosses" Georges Selim and Vince Mitchell, and my mentor George Balabanis for the understanding, time, and support they have dedicated to me during the past year. I also thank Natasha Munshi, my partner in crime, for being such a good friend and helping me to get settled quickly in London. Also thanks to the other "Cass girls" Joelle Miffre and Tuba Üstüner for the many interesting conversations and fun times we are thaving together.

There are a few more people in my private life to whom I would like to express my special gratitude. I am grateful to my godmother Odette Pierron for her moral and financial support throughout the years. I thank my childhood friend Gwendolyne Tanguy for always being there and succeeding in not making me think about work for a while. I am deeply thankful to my boyfriend Maarten Petermann for his love and unconditional faith in me. This last year together in London has brought us even closer, and I could not have taken this final hurdle without his support! I thank my big brother Jan for being so proud of me and making the best coffee and cake in world. Last but not least, I would like to thank my parents for their ongoing love and support. They have inspired me to follow my dreams while ensuring that my feet stay firmly on the ground. Therefore, I dedicate this dissertation to them. 
TABle of Contents 
Iril Table of Contents

INTRODUCTION

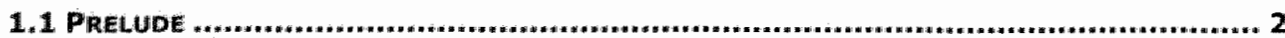

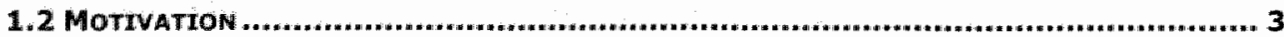

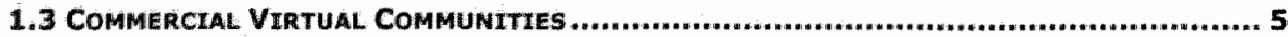

1.3.1 BACKGROUND ...

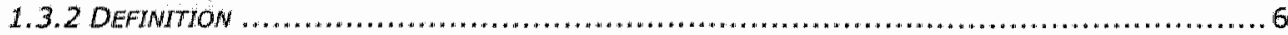

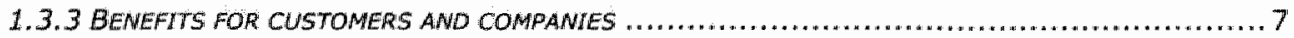

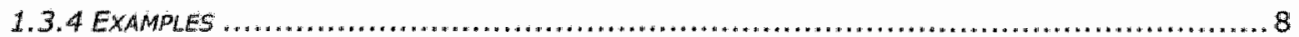

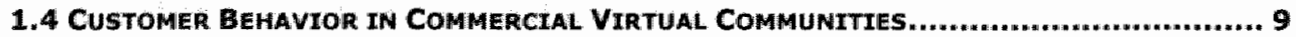

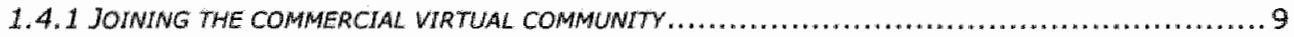

1.4.2 BEIMG ACTIVE AND MELPFUL IN THE COMMERCIAL WIRTUAL COMMUNITY........................ 10

1.4.3 CONTINUING MEMEERSHIP IN THE COMHERCIAL VRTUAL COMMUNTTY ........................... 12

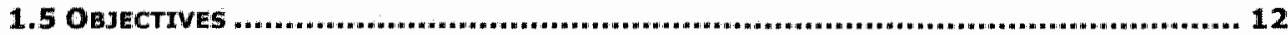

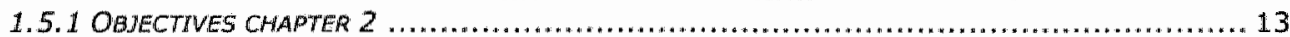

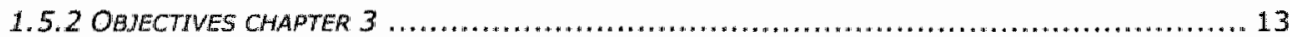

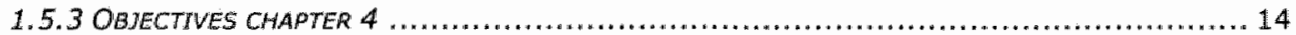

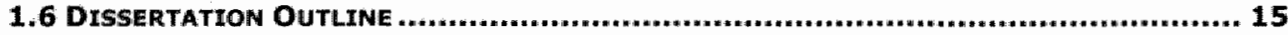

THE VALUE FORMATION PROCESS REVISITED: COST-BENEFIT TRADE-OFFS IN

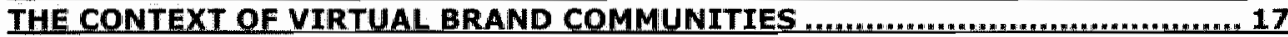

2.1 INTRODUCTION ....... nn

2.2 Value Formation and ONLINe BRANid COMMUNITY MEMBERSHIP............................. 21

2.2.1 THE COSTS AND BENEFITS OF ANTICTPATEO BRAND COMMUNITY MEMBERSHIP . .................. 21

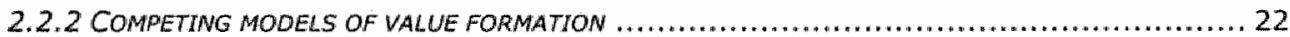

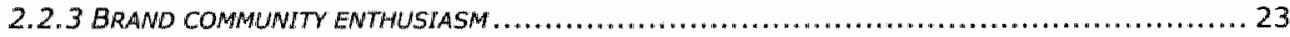

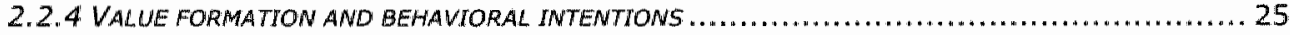

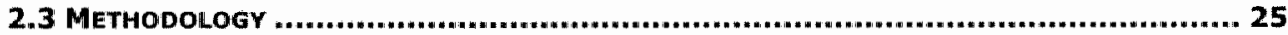

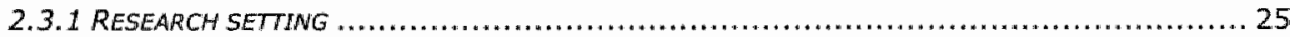

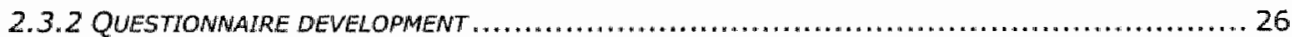

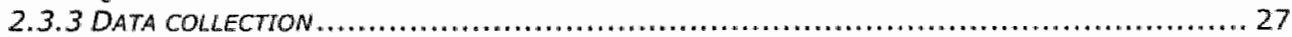

2.3 .4 ANALYSIS PLAN ...

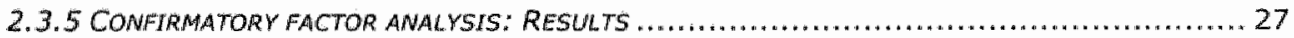

2.3.6 TEST OF THE DRRET EFFECTS VERSUS THE MEDIATED MODEL OF VALUE FORMATION .............28

2.3.7 ESTIMATING THE COMPLETE MODEL OF VALUE FORMATHON.......................................29

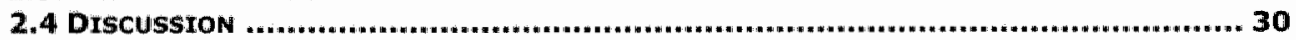

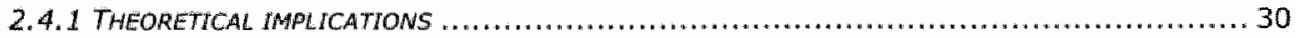

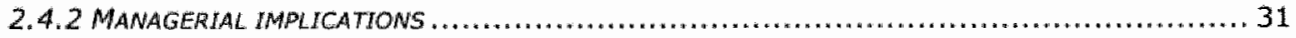

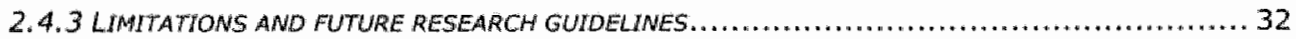

BEYOND THE CALL OF DUTY: NORMATIVE INFLUENCES IN COMMERCIAL

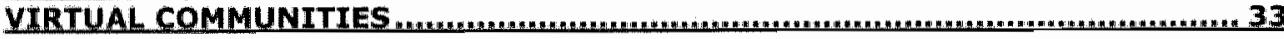

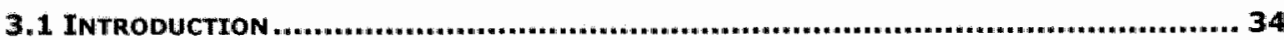

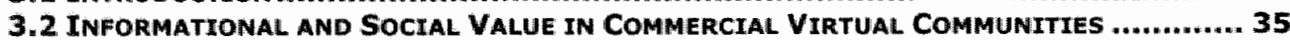

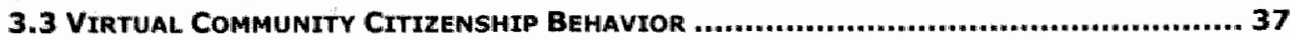

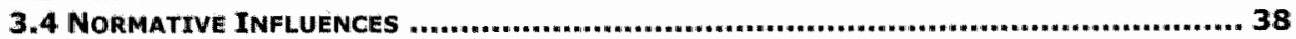

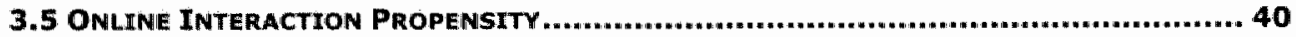

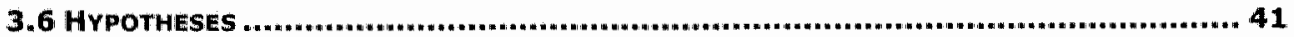

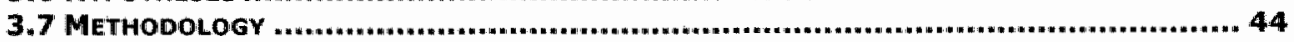

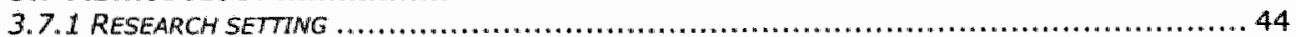




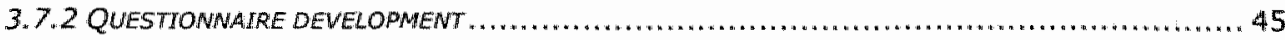

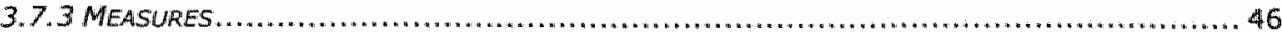

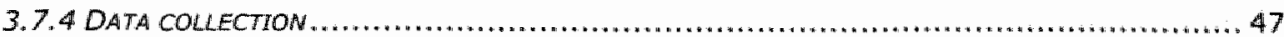

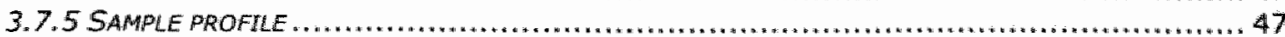

3.8 RESULTS

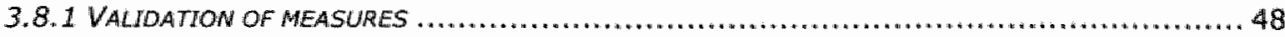

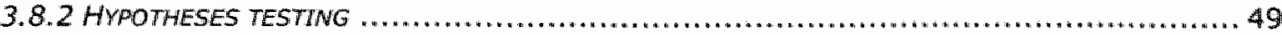

3.9 DISCUSSION .........nnw.......

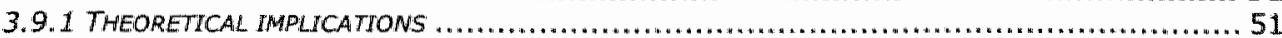

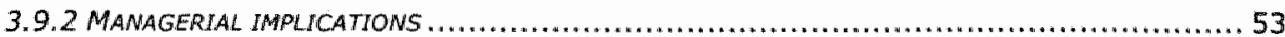

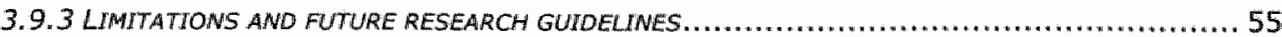

\section{THE DRIVERS AND MARKETING IMPLICATIONS OF CUSTOMERS CTTIZENSHIP} BEHAVIOR IN VIRTUAL COMMUNITIES FOR SERVICE SUPPORT

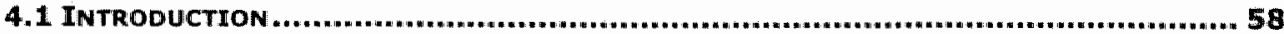

4.2 CONCEPTUAL FOUNDATIONS .

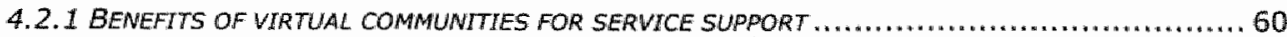

4.2.2 FROM SELF-SERWING BEHAVIOR TO VIRTUAL COMMUNITY CITZENSHIP BEHAWTOR ................ 61

4.3 ANTECEDENTS OF VIRTUAL COMMUNITY CITIZENSHIP BEHAVIOR ............................... 65

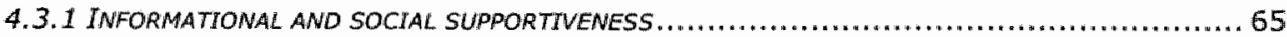

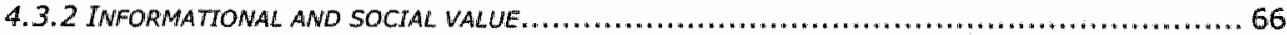

4.4 MARKETING IMPLICATIONS OF VIRTUAL COMMUNITY CITIZENSHIP BeHAVIOR .............. 68

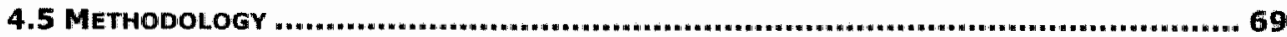

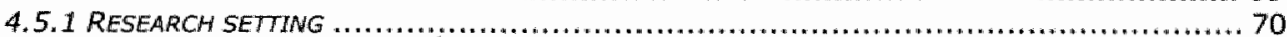

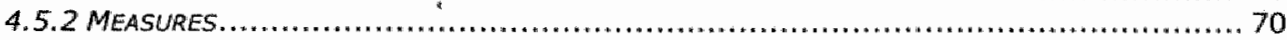

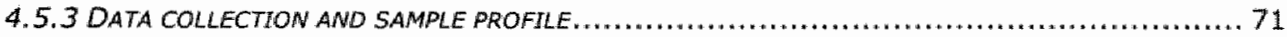

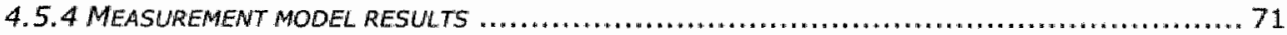

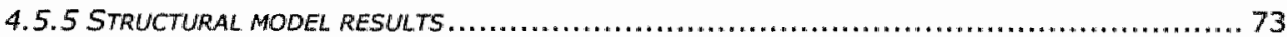

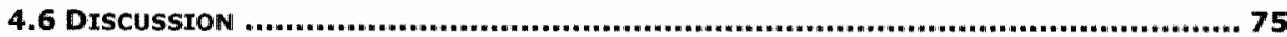

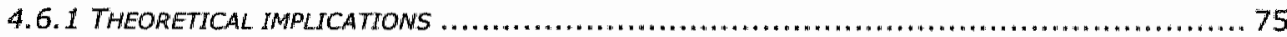

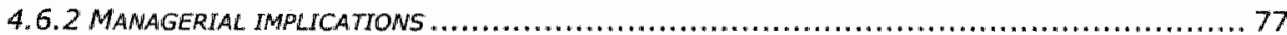

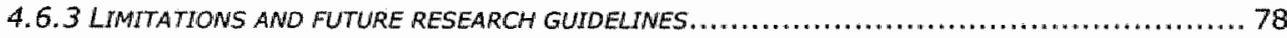

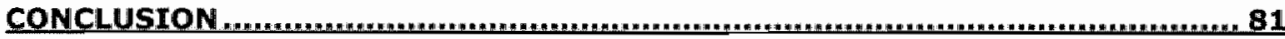

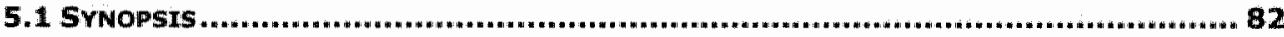

5.2 JOINING THE COMMERCIAL VIRTUAL COMMUNITY ............................................. 83

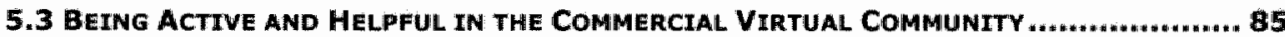

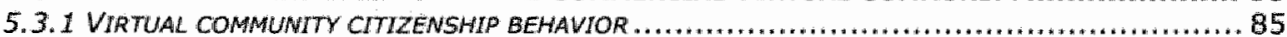

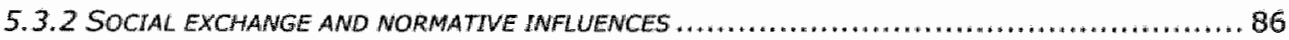

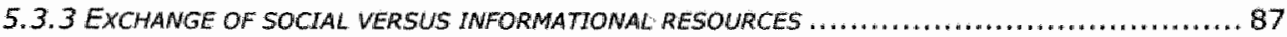

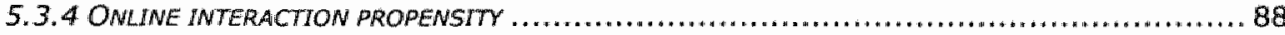

5.4 Continuing Membership in the Commercial Virtual Community........................8B

5.5 A PeRSPECTIVE ON FUTURE ReSEARCH .........................................................89

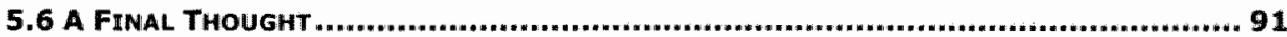

REFERENCES

APPENDICES. ......

CURRTCULUM VITAE _. 


$$
\vdots
$$


Chapter 1

\section{INTRODUCTION}




\subsection{Prelude}

The kindness of strangers is ours to give and to take; we shape the world with each embrace. (George 2003, p. 10)

In 2003, Lonely Planet's travell writer Don George edited a book containing the tales of travelers about the kindness of strangers they experienced on the road. The optimistic morale of the book is that human beings care about each other and ultimately want to be good to others. The websilte of Lonely Planet offers another example of this kindness of strangers: in the online travel community, almost three hundred thousand registered users exchange travel advice and help each other plan their next trips. This is just one example of a typical conversation:

Thread Title: Isiolo to Moyale Road (Kenya)

Date Posted: Mon July 18, 2005 8:32 AM

Posted By: Cailtiln 303

Does anyone know about the Isiolo to Moyale road for travelers in Kenya? Trying to get to Ethiopia, but don't know about security? Any alternative legal routes?

\section{Reply: 1}

Date Posted: Mon July 18, 2005 8:56 AM

Posted By: mad_paddler

I know you said legal, but this is what we did. We headed up to Lake Turkana and crossed the border beyond Illaret. It is not official, but we simply went to Immigration in Addis and they stamped our passports for us with no hassle. You do need a vehicle for this route.

\section{Reply: 2}

Date Posted: Mon Jully 18, 2005 9:39 AM

Posted By: jimmad

Just a note on the Turkana route...

This is the most spectacullar part of the continent I've seen, I can't say enough about how wild and awesome the place is. However, bear in mind that it is tough to say the least...I was alone on a bike with no GPS and felt very alone out there. The roads are very bad, the last part after Illoret basically has no road to follow. Public transport is not an option. The Moyale route is much safer than before and often used by travelers [...].

Enjoy 
Even though mad_paddler and jimmad do not know Caitlin 303, they invest time and effort to give her valuable advice. They, together with the thousands of other Lonely Planet community members, engage in this helpful behavior without reaping any apparent economic benefits in return of their investment. Such kindness of strangers in the online world lies at the heart of this dissertation.

\subsection{Motivation}

The global penetration of Internet technologies has profoundly changed the scope and boundaries of social and economic interactions. Nowadays, an estimated one billion users regularly access the Internet to find information, connect with others, entertain themselves, and complete transactions, unconstrained by distances in time and space (Computer Industry Almanac Inc. 2003; Fallows 2004). From a marketing perspective, one of the most interesting aspects of the Internet is the ease with which consumers can communicate with each other online to exchange their opinions about and experiences with products and services. The online gathering spaces in which these consumer-toconsumer exchanges take place are called "virtual communities." Organized around a certain topic of interest (e.g., travel), virtual communities are online groupings that form and develop entirely through communication between group members. The Pew Internet \& American Life Project estimates that $84 \%$ of US Internet users, or some 100 million people, are members of an online group (Rainie and Horrigan 2005), and 44\% of US Internet users have actively created content for the online world (Lenhart, Horrigan, and Fallows 2004). Many of the topics discussed in virtual communities are directly or indirectly related to the consumption of products and services, as it is the case in the Lonely Planet travel community. If Caitlin 303 decides to indeed go to Kenya and travel up to Ethiopia, she could book her flight, accommodation, and rental car immediately via the Lonely Planet website, and even purchase a Lonely Planet guide about East Africa. As such, not only Caitlin 303 as an individual, but also Lonely Planet as a company benefits from the efficient peer-to-peer advice exchanged in the virtual travel community. Thus, commercial virtual communities enable the harmonious 
interplay between the economic and social objectives of both consumers and marketers (Balasubramanian and Mahajan 2001).

Lke Lonely Planet, many companies have recognized the potential of virtual communities as a marketing tool and integrated them into their internet strategy. Regardless of whether the company hopes to strengthen its brand, build stronger relationships with its customers, conduct transactions, or reduce service costs, commerclally-orlented virtual communities have pervaded most industries. Not all of these virtual community ventures, however, turn out to be successful. The two most common problems are deserted virtual communities with no members and consequently no content, and virtual communities in which members misbehave and act anti-socially towards other members and/or the sponsoring company (e.g., Papadakis 2003). Hence, it is clear that the success of a commercial virtual community entirely depends on the behavior of its members. First of all, a sufficient amount of people must join the virtual community and become regular members. Second, these members must be willing to be "kind" to strangers by providing information and advice, as the real lifeblood of the community is sustained interaction that creates content (Bagozzi and Dholakia 2002). Finally, a sufficient amount of members must continue their membership and participation to ensure the successful future of the virtual community (Algesheimer, Dholakia, and Herrmann 2005). A particularly interesting feature of commercial virtual communities is that these members are in fact customers of the company that sponsors or hosits the virtual community. Thus, their contributions not only benefit other customers, but ultimately also the sponsoring company.

Despite the surge of practitioners' interest in virtual communities (e.g., Hagel and Armstrong 1997; Shuman and Twombly 2001; Williams and Cothrel 2000 ), there is a paucity of research on the role of commercial virtual communities in marketing (Bagozzi and Dholakia 2002). The phenomenon of virtual communities has received some attention in the sociology and social psychology, as well as information systems literature. While they provide valuable insights, most studies in sociology and social psychology focus on the question whether or not online communities conform to the traditional understanding of "community" (e.g., Etzioni and Etzioni 1999; Fernback and 
Thompson 1995), and what their impact on offline social relations and behavior is (e.g., Cummings, Sproull, and Kiesler 2002; Kraut et al. 2002). In addition, information systems research has examined questions related to the optimal design of virtual communities (e.g., Preece 2000; Preece, Rogers, and Sharp 2002), and to the exchange of knowledge in professional electronic networks (e.g., Faraj and Sproull 2000; Teïgland and McLure Wasko 2003). In marketing, most research efforts have focused on introducing and describing the concept of brand communities which can be both real and virtual (McAlexander, Schouten, and Koenig 2002; Muniz and O'Guinn 2001). To our knowledge, only the work by Dholakia and associates $(2002,2004$ and 2005) has started to examine member behavior in virtual communities from a marketing perspective. Hence, especially in the context of commercially-oriented virtual communities, the behavior of customers remains largely unexplored. This dlssertation contributes to the understanding of commercial virtual communities by investigating different types of customer behavior in these communities, the drivers of this behavior, and its marketing consequences.

The remainder of this chapter shortly introduces the main concept of commercial virtual communities and describes the relevant customer behavior in these communities. Furthermore, the objectives and detailed research questions of each chapter will be outlined.

\subsection{Commercial Virtual Communities}

\subsubsection{Background}

While the offline community phenomenon has for long been the focus of sociological inquiry, it has also been one of its most elusive concepts (Bell and Newby 1974; Etzioni and Etzioni 1999; Fernback and Thompson 1995; Puddifoot 1995; Rothaermel and Sugiyama 2001). Even though numerous articles and books have been dedicated to the collection and analysis of differing definitions and typologies of community (e.g., Hillery 1955; Porter 2004), consensus about a definite theory has not been reached. One of the earliest and probably most influential researchers who studied the community phenomenon was the German sociologist Ferdinand Tönnies (1887). He made a basic distinction between 
Gemeinschaft, a small, intimate and exclusive community, and Gesellschaft, the larger, rational, individualistic society, and claimed that industrialization and modernity fostered Gesellschaft to the ravage of traditional communities. Contemporary researchers examining virtual communities argue that their rapid growth is a consequence of a sense of loss at the personal and business level triggered by the destruction of Gemeinschaft and the resulting shift to Gesellschaft (Fernback and Thompson 1995; Muniz and O'Guinn 2001; Rheingold 1993). In order to anchor themselves, find support, and regain a sense of identity, people cluster online with similar others and support each other by exchanging information and frlendship (Bressier and Grantham 2000; Fernback and Thompson, 1995). In this way, virtual communities origlnally began to form as social entities with the aim to bring back a sense of Gemeinschaft.

The commercial possibilities of virtual communities due to their potential to integrate social and economic objectives were soon recognized by practitioners and widely propagated in Hagel and Armstong's seminal book Net Gain (1997). They propose that commercial virtual communities should fulfill four types of consumer needs: the sharing of a specific interest (e.g., on LUGNET'M, a virtual community for $L E G O B$ builders), the building of relationships (e.g., on weightwatchers, where members support each other to lose weight), the experience of fantasy (e.g. in the popular Lord of the Rings or Harry Potter communities), and the conduct of transactions (e.g. at E-bay). As the four needs are clearly not mutually exclusive, community sponsors should try to meet all of them simultaneously wherever possible (Hagel and Armstrong, 1997).

\subsubsection{Definition}

Due to the diversity of communities which can be found on the Internet, the attempt to define the term "virtual community" evokes at least as much disagreement as the definition of traditional face-to-face communities. For the purpose of this dissertation - which focuses on communities sponsored by companies - we define commercial virtual communities as "company-endorsed online aggregations of customers who collectively co-produce and consume 
content about a commercial activity that is central to their interest by exchanging informational and social resources."

\subsubsection{Benefits for customers and companies}

Commercial virtual communities provide important benefits to both the participating customers and the sponsoring company.

For participating customers, the inherent benefits of virtual communities are the social and affective components which add to the traditionally impersonal self-service technologies which are characteristic in many online environments. While many companies have successfully implemented online self-service options to increase customization and flexibility, the need of consumers for human contact with like-minded others can only be met through interactive services. Virtual communities offer the potential of collaborative exchanges by allowing for customer-to-customer communication, which adds experiential value to simple online transactions (Mathwick, Malhotra and Rigdon 2001). Second, customers participating in commercial virtual communities get access to a wealth of information in the form of member-generated content. Members with diverse backgrounds and knowledge intensities answer each other"s questions and exchange advice, best practices, and experiences. As all discussions are textual and logged, these interactions create a formidable knowledge resource. In addition to being diverse, this member-generated information is also regarded as more credible than information generated by marketers and as more useful, as it Is given from a user perspective.

Also the company that sponsors the commercial virtual community for its customers benefits in several ways. In addition to increasing loyalty to the brand, virtual communities allow for more effective segmentation and stronger relationship bullding (Algesheimer et al. 2005; McAlexander et al. 2002; McWilliam 2000; Muniz and O'Guinn 2001). Furthermore, the company has the opportunity to monitor the ongoing peer-to-peer conversations in order to gather insights about the ideas, trends and problems that their customers deal with, as well as collect information about how its customers evaluate the products and services offered by the sponsor as well as the competition. As such, virtual 
communities are a valuable source of market intelligence. Finally, by solving each other's problems in the virtual community, customers essentially take over service functions traditionally performed by service employees. This free labor provided by customers can result in significant reductions of service costs (Lovelock and Young 1979).

\subsubsection{Examples}

According to recent US statistics, the most popular types of online groups can be classified into two main categories: virtual brand communities and virtual communities for service support (professional and hobby) (Rainie and Horrigan 2005).

As the name implles, brand communities are built around a specific brand, and the members of the community share a passion for this brand. Prominent examples of such brand communities can be found in the automotive industry, where almost all major car brands attract a group of loyal brand enthusilasts. The Mini Owners' Club, for instance, provides its members with the opportunity to meet other dedicated Mini drivers online and exchange experiences and insights. The main purpose of these virtual brand communities is the affiliation with a group of similar others, and the celebration of the brand (Muniz and O"Guinn 2001).

Virtual communities for service support, on the other hand, focus on problem-solving, and are often the only free-of-charge support channel available to customers. Notable examples of these service-oriented virtual communities are the Dell communities for computer support, or the iPod Apple communities. Customers in this type of community mainly focus on providing solutions to each other's specific problems, but they also engage in social interaction. The Lonely Planet travel community described in the prelude is another example of a virtual community for service support.

Whereas virtual brand communities have recelved some attention from marketing academics (e.g., Algesheimer et al. 2005; Muniz and O'Guinn 2001), virtual communities for service support remain largely unexplored. Moreover, as opposed to member-initiated communities, the general category of company- 
sponsored virtual communities has so far been neglected in marketing research (Porter 2004). As a result, this dissertation will examine both companysponsored virtual brand communities, as well as company-sponsored virtual communities for service support.

\subsection{Customer Behavior in Commercial Virtual Communities}

Companies sponsor commercial virtual communities as online meeting places for their customers, who are the main beneficiaries as well as the main actors in the community. As a result, their behavior is crucial to a virtual community's success. The virtual community can only be sustained if a critical mass of people join, actively participate in the discussions and contribute content, and stay members in the future. Thus, once the customer has come in touch with the virtual community for the first time, s/he has to make three sequential choices: whether to join, actively participate, and continue membership.

\subsubsection{Joining the commercial virtual community}

At the most basic level, upon exposure to the virtual community, the customer has to decide whether to join and become a member or not. Most virtual communities require some form of registration that a customer has to go through before being able to access the community's resources. As this registration process requires effort, some customers might be discouraged from joining. But if, on the other hand, the expected benefits of community membership outweigh the necessary effort investments, they might well decide to go through the registration process. It is very important for marketers to understand how customers make this basic decision, both in terms of which attributes they trade off and how these attributes are traded off, so that they can adapt the design of the community to make it as attractive as possible. Despite the relevance of this initial customer behavior, very few studies have empirically investigated why people join virtual communities in the first place. A notable exception is a recent study by Ridings and Gefen (2004), who found that the 
10 | Chapter 1

most popular reason for being a member in a community is access to information, followed by social interaction. Despite this laudable effort which has ldentified the main benefits of vitual community membership, there is a lack of research on the sacrifices that customers have to make in order to join, and more importantly on the trade-off process of these benefits and sacrifices.

\subsubsection{Being active and helpful in the commercial virtual community}

Once a customer has joined a commercial virtual community, s/he is confronted with the decision of whether or not to contribute to the community. Membership grants access to the virtual community's informational and social resources, which are created entirely through the interaction between virtual community participants. Hence, these resources have the qualities of public goods which are available to every virtual community member, no matter whether s/he has contributed to their creation and development. As a result, a member coulld decide to "free-ride" and just benefit from the resources created by others without ever actively contributing anything her/himself (McLure Wasko and Faraj 2000). This behavior would be in line with neoclassical economic theory, which posits that individuals act as rational agents who strive to maximize their economic benefits (Balasubramanian and Mahajan 2001). And indeed, the majority of virtual community members are "lurkers," who only read the discusslons of others and retrieve information, without producing content themselves. Some statistics estimate that as much as $90 \%$ of members mainly engage in lurking, and only $10 \%$ actively particlpate in online discussions (Cothrel and Williams 1999; Preece and Nonnecke 2004). However, without a critical mass of members who actively participate and create informational and social content, the virtual community would soon lose its attractiveness and be deserted. It is therefore crucial to understand why virtual community members, given their propensity to act out of self-interest, are willing to actively engage in online discussions and help other members. This question is particularly Intriguing in the context of commercial virtual communities, as the members are customers of the sponsoring company who are benefiting other customers. As such, active commercial virtual community members actually act as "partial 
employees ${ }^{\prime \prime}$ of the sponsoring company (e.g., Mills and Morris 1986), who are providing a free service to fellow customers. Due to this similarity with service employees, we draw on organizational literature (e.g., Organ 1988) and intraduce the concept of virtual community citizenship behavior to capture the beneficial behavior of customers in commercial virtual communities.

Why do customers engage in this beneficial citizenship behavior? Does Don George of Lonely Planet rightly conclude in his book that people Indeed act out of pure kindness and simply want to be good to others? This conclusion would not only be at odds with neoclassical economic theory, but also with the dominant view in Western thought on "kindness." According to leading thinkers such as Freud (1930), Machiavelli (1515), and Nietzsche (1910), "all prosocial behavior, regardless how noble in appearance, is ultimately motivated by some form of self-benefit" (Batson 1987, p. 66). However, this self-benefit does not necessarily have to take the form of economic rewards, but could also take the form of social or personal rewards. For example, a person who was kind to someone usually feels good about her/himself, and is recognized by others for this kindness. In addition, the benefactor can expect the recipient of her/his kindness to reciprocate in the future. Hence, the beneficial citizenship behavior of customers in commercial virtual communities might be explained not by economic theory, but rather by social exchange and norm theory (e.g., Blau 1964; Gouldner 1960; Schwartz 1977), which posit that behavior is influenced by self-expectations and expectations of the social group, and that people generaily reciprocate received favors to avoid becoming indebted to others. But due to the anonymity of virtual community participants, there have been doubts about the applicability of such theorles in online environments (e.g., Alonzo and Alken 2004).

Despite the crucial importance of understanding the active and helpful participation behavior of virtual community members, only three studies in marketing have so far made attempts to empirically address this question (Bagozzi and Dholakia 2002; Dholakla et al. 2004; Algesheimer et al. 2005). However, none of these was conducted in the context of commercial virtual communities, in which the customers of the sponsoring company act as "partial 
12 Chaipter 1

employees," and dominant theories, such as social exchange and norm theory, have been neglected.

\subsubsection{Continuing membership in the commercial virtual community}

Finally, a commercial virtual community cannot be sustained if most of its members are fleeting participants who quilckly lose interest and abandon their membership. Therefore, the last behavioral choice a customer has to make is whether or not to stay an active member in the community. As a commercial virtual community is always organized around a commercial activity (i.e., a brand, product, or service), membership goes hand in hand with the continuous involvement with this commercial activity. As a result, continued membership in a virtual community can also affect future purchase behavior of members. Even though both membership continuance and purchase behavior are clearly in the interest of the company that sponsors the commercial virtual community, the motivations of this behavior have hardly received any attention in the marketing literature to date (with the notable exception of the recent study by Algesheimer et al. 2005).

\subsection{Objectives}

The objective of this dissertation is to address the outlined gaps in the marketing literature on virtual communities by studying the different types, motivations, and consequences of customer behavior in commerciall virtual communities. Thus, the central research question is as follows:

What are the different types of customer behavior in commercial virtual communities, the motivations of this behavior, and its marketing consequences?

In order to answer this central research question, three quantitative studies that address different types of customer behavior in the context of commercial virtual communities have been conducted. The first study explores how customers make the initial decision to join a virtual brand community. The 
second and third study, conducted in the context of virtual communities for service support, identify the drivers of the active and helpful behavior of customers and investigate the consequences of this behavior in terms of membership continuance and purchase intentions. The three studies are described in the chapters 2,3, and 4 , and their specific objectives are outlined below.

\subsubsection{Objectives chapter 2}

The basic research question investigated in chapter 2 is why customers decide to join a commercial virtual community in the first place, and which cognitive process they use to make this choice. Based on value theory, we develop a framework including informational and social benefits of virtual community membership, as well as costs in terms of investment in cognitive effort. Traditional value theory posits that these benefits and costs are traded off simultaneously as direct effects to derive a value judgment. Due to the specific nature of highly experiential Internet services, such as a virtual brand community, we argue for an alternative model in which benefits and costs are traded off sequentially to derive a final value judgment. In addition, we also consider the influence of enthuslasm for the brand community on this trade-off process. Consequently, the specific objectives of this chapter are: (1) to identify the attributes that customers consider in deciding whether or not to join a virtual brand community, (2) to understand how customers make this decision by contrasting two competing models of value formation, and (3) to consider the influence of important individual differences, such as enthusiasm for the brand community, on this process.

\subsubsection{Objectives chapter 3}

Chapter 3 turns to the next facet of customer behavior in commercial virtual communities, and makes an attempt to find answers to the cruclal question why customers are willing to activelly participate and help other customers in commercial virtual communities. We introduce and develop the 
notion of virtual community citizenship behavior to capture this beneficial customer behavior and establish a framework based on norm theory to explain it. Previous research had argued that due to the anonymity of actors, normative Influences did not play an important role in governing behavior online $(e . g .$, Alonzo and Aiken 2004). Furthermore, we draw attention to potential differences in customers' predisposition to engage in online interactions (i.e., online interaction propensity), and investigate the effect of this variable on virtual cornmunity citizenship behavior. More specifically, the objectives of this chapter are: (1) to identify the antecedents of virtual community citizenship behavior, (2) to investigate whether normative influences do operate in the online environment, and (3) to introduce an important behavioral orientation with regards to online communication, called online interaction propensity, and examine its influence on virtual community citizenship behavior.

\subsubsection{Objectives chapter 4}

Chapter 4 again addresses the question why customers actively participate and help other customers in commercial virtual communities, but this time with a specific focus on the differential impact of the two main exchange processes taking place between community members: the exchange of informational resources and the exchange of social resources. A main objective is to examine potential cross-over effects of these two processes. For example, does social interaction support or hinder information exchange? Furthermore, the marketing implications of virtual community citizenship behavior in terms of membership continuance and purchase intentions are considered. Thus, the objectives of this chapter are: (1) to make a distinction between the exchange processes of informational resources versus social resources, (2) to examine their unique influence on virtual community citizenship behavior, and (3) to consider the marketing consequences of virtual community citizenship behavior. 


\subsection{Dissertation Outline}

This dissertation is based upon three empirical studies that are reported in chapters 2, 3, and 4 (see figure 1.1). These chapters are inter-related, but may also be read separately. Each chapter addresses one facet of customer behavior that is essential to the success of commercial virtual communities.

Chapter 2 addresses the main question why customers join a commercial virtual community, and through which cognitive process they derive this decision. The empirical study was conducted in the context of a virtual brand community.

Chapter 3 explores possible drivers of the active and helpful behavior of customers directed toward other customers in commercial virtual communities. The data collection for this study took place in a virtual community for service support.

Chapter 4 reports on a study that examines the specific impact of the information exchange process and the social interaction process on the beneficial behavior of customers, and the consequences of this behavior in terms of intentions to continue membership in the commercial virtual community and purchase more products and services of the sponsoring company. The research context for this study was again a virtual community for service support.

Chapter 5 concludes with a synopsis of the main findings about the motivations and consequences of different types of customer behavior in commercial virtual communities, and outines the implications as well as guidelines for future research. 
$16 \mid$ Chapter 1

Figure 1.1 - Dissertation Outline

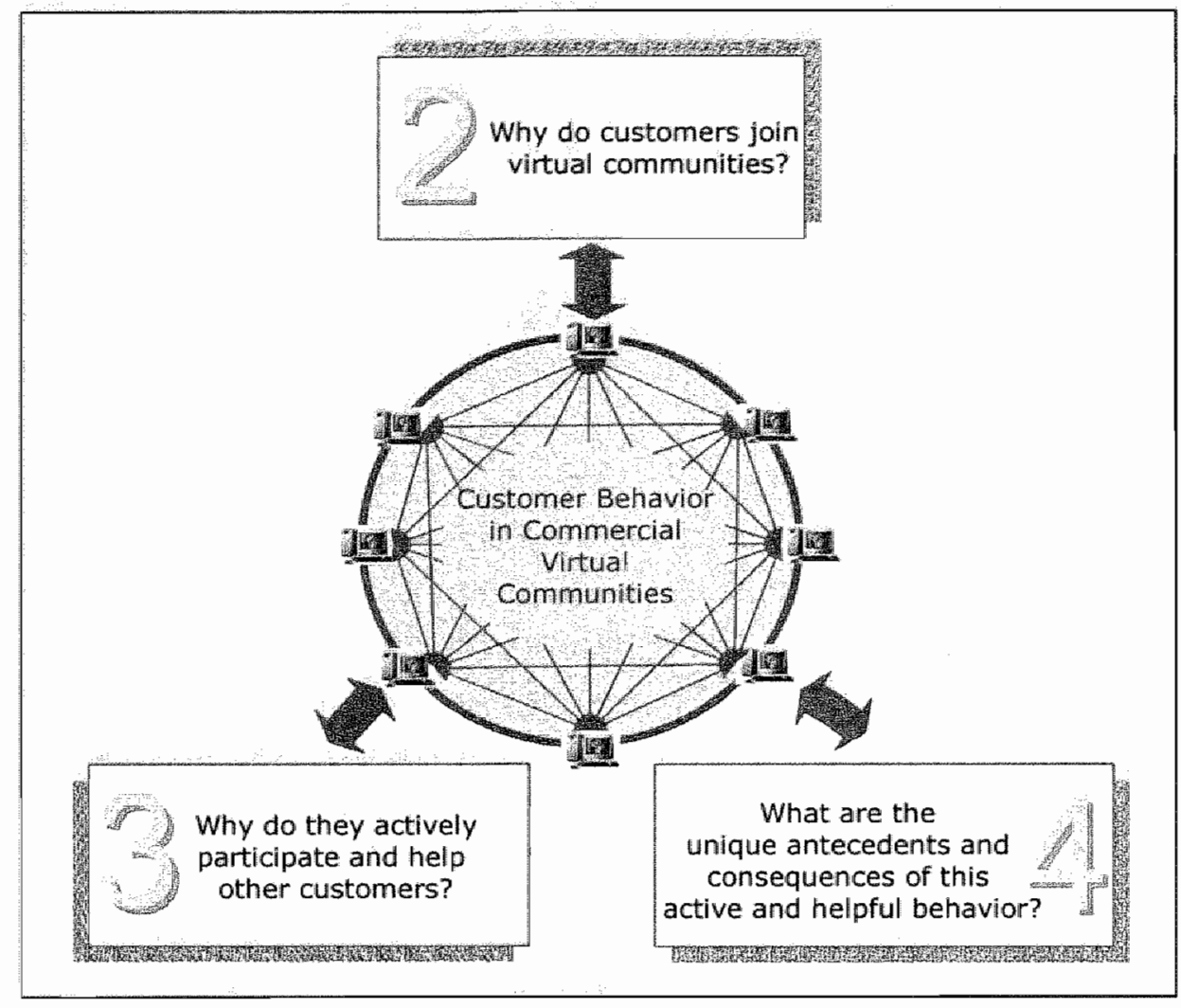


CHAPTER 2

\title{
The Value formation Process Revisited: Cost-Benefit Trade- Offs in the Context of Virtual Brand Communities
}

\begin{abstract}
The value formation process has been conceptualized as a trade-off between costs and benefits. Empirical tests using a direct effects model of value formation, however, have found inconsistent results. Therefore, we propose and test an alternate model of value formation in a highly participatory e-service setting: a virtual brand community. This alternate model, which provides superior fit to the data, specifies benefits as key mediators of the cost - value relationship. In addition, brand community enthusiasm, a state of impassioned interest in the brand and its surrounding community, is found to be al significant predictor of value expectations.
\end{abstract}




\subsection{Introduction}

Electronic services (e-services) have become an integral part of many companles' service dellvery strategy and constitute the fastest growing segment of online business (www.census.gov). At the same time, researchers have come to recognize that the potentiall of e-services has not been fully realized due to inadequate e-service designs and offerings (Xue, Heim and Harker 2005). A distinguishing feature of many e-services is the active participation that is required from the consumer to successfully deliver the service. For example, consumers can gather information about a travel destination in an online community like virtualtourist.com, design customized stationary on businesscards.com, or manage a stock portfolio on firstdirect.com. In each case, the consumer has to put effort into understanding and interacting with the technological interface before s/he can reap the benefits of the e-service. In addition, many e-services are designed to offer initial free trial periods which eliminate all but the non-monetary costs. Given the overwhelming number of free choices and competing offers available online, e-services should be designed in ways that entice potential customers to expend effort in order to use the eservice. To that end, it is important for service companies to understand what drives consumers' intentions to try new e-services that require their active participation.

An extensive body of literature has established value as a key driver of behavioral intentions. In this literature, value has been defined as a trade-off between what the consumer receives and what $s /$ he has to give up to acquire a product or service (Woodruff 1997; Zeithaml 1988). In other words, consumers derive a value judgment by weighing the expected costs of acquiring a product or service against the expected benefits. Empirically, this trade-off has been represented as a direct effects model in which costs and benefits simultaneously predict value. This model, however, has exhibited unstable results in several empirical studies (Cronin et al. 1997; Brady and Robertson 1999; Cronin, Brady, and Hult 2000).

These unexpected results may be due to the fact that the value formation process can vary across purchase settings and consumer segments (Bolton and 
Drew 1991; Brady and Robertson 1999; Chen and Dubinsky 2003; Zeitham: 1988). Thus, in e-service settings where the service cost is characterized by demands for extensive consumer participation, the value formation process will likely change. The customer first has to master the technological interface before obtaining the desired benefits from the e-service. This sequentiall e-service consumption experience fundamentally changes the value formation process. Hence, there are empirical as well as conceptual reasons to suspect that the traditional direct effects model might not adequately capture the value formation process in the context of e-service consumption. Beyond the consumption setting, the overall value attached to an e-service may also be influenced by individual consumer differences (Bolton and Drew 1991). For example, consumers who are enthusiastic about a certain e-service would expect more value from its use than less enthused customers.

In light of these potential influences, we seek to contribute to the value literature in two important ways. First, we contrast the traditional value model with an alternate model of value formation in the context of an e-service that requires high customer participation: an online brand community. This alternate model is based on the argument that benefits depend on costs rather than combine as simultaneous direct effects. Second, we investigate whether the degree of enthusiasm for the online brand community has an influence on value formation. Both madels are illustrated in Figure 2.1. 
Figure 2.1: Competing Models of Value Formation

\section{Traditional direct effects model}

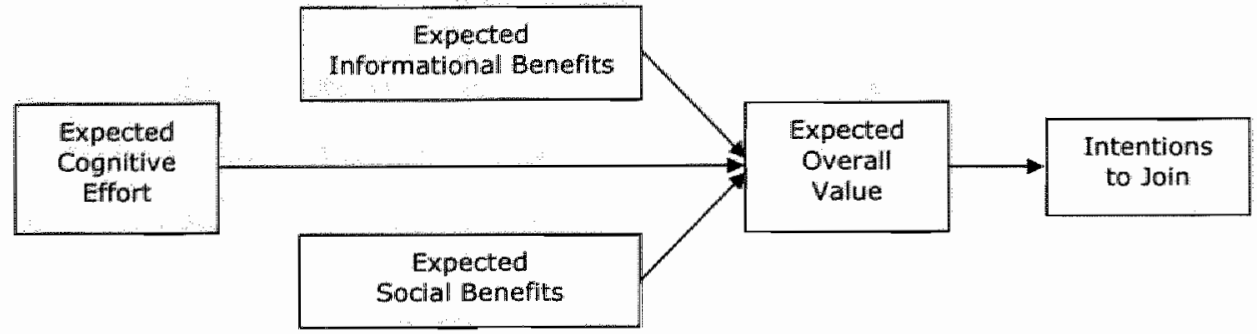

Alternate mediated madel

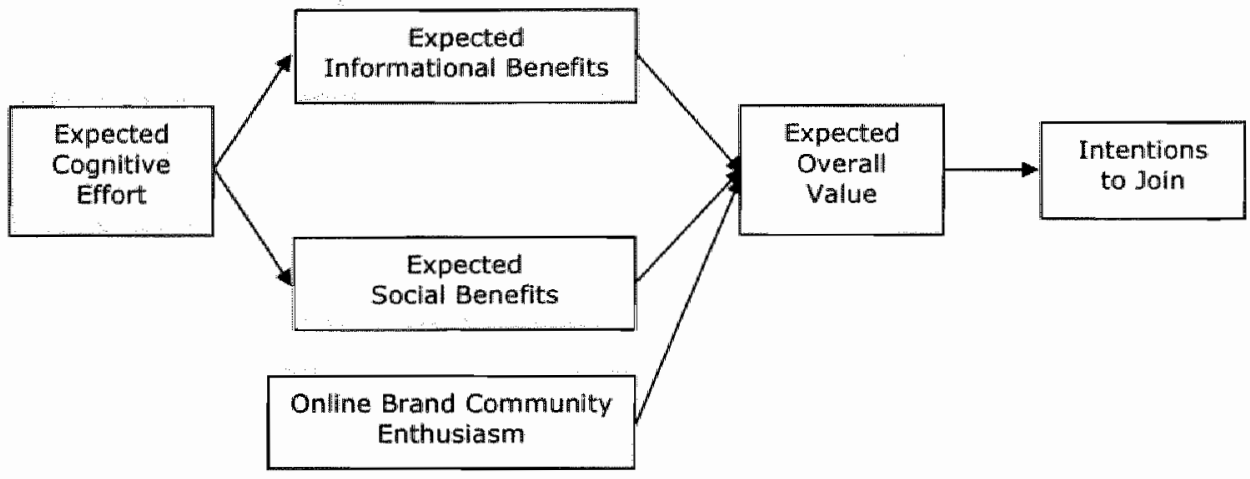

The chapter begins with a discussion of the sources of costs and benefits specific to an online brand community. We proceed with a review of the literature on value theory, contrasting two competing models of value formation. We then Introduce brand community enthusiasm and investigate its influence on value formation. We point out the implications for theory and practice and conclude the chapter with a discussion of the limitations and directions for future research. 


\subsection{Value Formation and Online Brand Community Membership}

\subsubsection{The costs and benefits of anticipated brand community membership}

When considering using a new e-service, consumers make an assessment of the expected costs, benefits, and subsequently overall value associated with its use. An online brand community is a virtual meeting space for consumers who share a strong interest in a brand, and provides an important information source as well as larger social benefits to its members. As such, the online brand community is an e-service option that provides both social and informational benefits (Burnett 2000; Muniz and O'Guinn 2001; Rheingold 1993). This distinction is in conformance with the hedonic and utilitarian nature of consumption benefits documented in the customer value literature (Holbrook and Hirschman 1982). Hedonically oriented social benefits are mainly received through the affiliation and construction of interpersonal relationships with a group of people who share similar interests. Informational benefits, which are more utilitarian in nature, arise from access to a large pool of information about the topic of interest provided by the online community.

The informational and social benefits arising from online brand community membership are balanced against consumption costs. In general, consumers attempt to minimize expenditures of money, time, and (cognitive) effort (Downs 1961), the three main categories of consumption costs. Given that most eservices are initially free and that it is hard to anticipate time investments before actuall usage, the cost most relevant to our research context is the cognitive effort necessary to join and use the proposed online brand communlty (Garbarino and Edell 1997). Cognitive effort can be defined as "the amount of cognitive capacity expended on a task" (Petty and Cacioppo 1986, p. 14). Most online brand communities initially require some form of registration, the use of interactive technologies, and occasionally the downloading of software. Consequently, potential members have to invest significant cognitive effort in order to join the online brand community and subsequently use it. The cognitive effort expended to join an online brand community, therefore, represents the cost that is traded-off against social and informational benefits, to arrive at an overall value expectation. 
The empirical literature suggests this trade-off process should be modeled by directly weighing the cognitive effort against the anticipated informational and social benefits. In the following section, we discuss potential flaws in the traditional direct effects model and propose an alternate model of value formation in the context of e-services.

\subsubsection{Competing models of value formation}

While there is general agreement in the conceptual literature on value formation that costs and benefits are traded off in order to derive an overall value judgment, several empirical studies report mixed results when using a direct effects model to capture this trade-off process. For example, Cronin, Brady, and Hult (2000) model value formation in six service contexts and find that only one of the six contexts exhibits the hypothesized direct structure. In the other five contexts, benefits alone appear to define value, suggesting that costs are absent from the trade-off process. These surprising findings lead Cronin, Brady, and Hult (2000) to conclude "service customers seem to place greater importance on quality (benefits) than on costs" (p. 209). In earlier chapters, Cronin et al. (1997) and Brady and Robertson (1999) found similar results. These findings imply that the get side of the value equation is transformed into an overall value perception, without significant influence from the give side. These results oppose the conceptual value theory and are counterintuitive. It is hard to imagine that consumers purely rely on the expected benefits of a new service, absent consideration of associated costs. Thus, the Insignificant path between cost and value as reported in the empirical literature, points to the possibllity that a direct cost-benefit trade-off does not adequately capture the value formation process in all consumption contexts.

The context-dependent nature of value is well established in both conceptual and empirical research (Bolton and Drew 1991; Chen and Dubinsky 2003; Zelithaml 1988). In the context of highly participatory e-services, service evaluation is typically framed by the expectation that consumption benefits will offset, and hopefully outweigh, transactional costs. These costs have to be incurred in order to obtain the benefits. For example, in the case of an online 
brand community, the customer has to invest cognitive effort to join the community, learn to navigate its website, and contribute to community dialog before s/he can enjoy the informational and social benefits arising from membership. This necessary cognitive effort may actually have a negative impact on the expected benefits. In other words, the potential benefits depend to a certain extent on the expected cognitive effort necessary to join and use the community. Rather than combining costs and benefits simultaneously, consumers appear to evaluate e-services sequentially. The trade-off referred to in the conceptual literature on value is believed to occur at the point benefits are realized. This sequential evaluative process suggests costs may exert a direct impact on benefits while only indirectly influencing value (Baron and Kenmy 1986). Therefore, we believe that a medlated model of value formation - rather than a direct effects model - captures this sequential evaluation process.

$\mathrm{H}_{1}$ : Cognitive effort indirectly influences value through its impact on informational and social benefits.

\subsubsection{Brand community enthusiasm}

Bolton and Drew (1991) proposed that value formation varies not only across consumption settings, but also across individuals. Therefore, they included costs and benefits as well as customer characteristics in the value function to find a direct effect of customer characteristics on value. In line with this approach, we propose individual differences related to brand community enthusiasm will also exert a direct Impact on value expectations.

Brand community enthusiasm is a state of impassioned interest in a brand and the community of users surrounding it. Online brand communitles offer information to potential members and enable contact to other consumers who share similar interest in a brand. The online brand community literature identifles opinion leadership, information seeking, and social identification as key characteristics of community membership (Hagel and Armstrong 1997; Bagozzl and Dholakia 2002). Individuals who manifest these characteristics are likely to be enthusiastic about joining an online brand community. 
Opinion leaders are consumers whose advice is commonly sought by others in their peer groups because of their knowledge and expertise about a certain product, service, or brand (Grewal, Mehta, and Kardes 2000). They act as important channels of information and have significant social influence on the buying decision of others (Feick and Price 1987). Furthermore, they enjoy communicating their knowledge about the brand to others. Membership in an online brand community provides access to a whole new audience in which the opinion leader can establish him/herself as an expert. In fact, Hagel and Armstrong (1997) have described opinion leaders as vital components of online communities.

In addition, information seekers are attracted to online brand communities by the unique nature of its member-generated content (Hagel and Armstrong 1997; Burnett 2000). The member-generated content augments traditional marketer-generated information with customer insights and word-of-mouth communication that enhances the credibility of the resource. As such, the online community facilitates the information seeking process by providing access to the community-generated information resources.

Finally, online brand communities are unique in that they offer the opportunity to find a sense of belonging and identity with a group of similar others (Hagel and Armstrong 1997). Social identification implies that consumers derive part of their self-worth from affiliation with groups important to them (Ashforth and Mael 1989). Affiliation provides the opportunity to associate themselves with the desirable characteristics attributed to the members of this group. Online brand communities enhance social ldentification by bringing together people who share interest in a speciflc brand (Bagozzi and Dholakia 2002). Thus, a consumer who seeks social identification with other brand admirers is likely to be enthusiastic about joining the online brand community. In short we expect that brand community enthuslasm is reflected in the dimensions of opinion leadership, information seeking, and social identification.

$\mathrm{H}_{2}: \quad$ Brand community enthusiasm is a state manifest in opinion leadership, information seeking, and social identification. 
In lime with Bolton and Drew (1991), we propose that a consumer characteristic such as brand community enthusiasm directly influences value expectations. If a consumer is enthusiastic about the idea of participating in a specific online brand community, s/he will expect that membership in this community will be valuable.

$\mathbb{H}_{3}$ : $\quad$ Brand community enthusiasm will exert a positive influence on expected overall value.

\subsubsection{Value formation and behavioral intentions}

Numerous studies have used value judgments to successfully predict behavioral intentions (Brady and Robertson 1999; Cronin et al. 1997" Cronin, Brady, and Hult 2000). We believe that the intentions to join an online brand community will also be explained by the expected overall value of community membership.

$\mathrm{H}_{4}$ : The expected overall value of the online brand community will have a positive influence on intentions to join that same community.

\subsection{Methodology}

\subsubsection{Research setting}

In order to empirically test our hypotheses, we conducted a quantitative study among the visitors to the homepage of a compact car manufacturer. We chose a car brand as the specific context of our investigation because high involvement products, such as cars, are products that are prone to become the center of an online brand community. We chose this compact car brand, in panticular, because it is a relatively new brand with a very strong image as a lifestyle product. Its target group is defined not according to demographics, but according to an innovative, unconventional, extroverted, and young-at-heart lifestyle. At the point in time when our study was conducted, the car manufacturer was investigating the opportunities to bulld an online portal with elaborate community functions around its brand. A trial version, explaining and demonstrating the registration, the different services, and the interactive communication channels, was developed for demonstration purposes. In the 
proposed oniline brand community, potential members could not only interact via email, discussion boards, and chat, but also upload pictures of their car and themselves, exchange anecdotes via personal columns, and even exchange spare parts with other car owners.

\subsubsection{Questionnaire development}

The measurement instrument was developed in an iterative process, in which a series of established scales were refined through feedback obtained from structured interviews with consumers of the focal product and marketing managers from the car manufacturer. Furthermore, the relevance of opinion leadership, information seeking, and social identification to capture brand community enthusiasm was confirmed in 15 in-depth interviews with consumers. We then conducted a quantitative pre-test of the preliminary questionnaire with 78 visitors of a car dealership. As a consequence, several items were reworded or deleted, resulting in a final list of 26 questions.

Each construct in this study was measured using multiple-item scales with a five-point Likert type response format. Opinion leadership was measured with three items adapted from Grewal et al. (2000), information seeking consisted of three items adapted from Bloch, Sherrell, and Ridgway (1986), and social Identification was measured with three items based on Bagozzi and Dholakia (2002). The expected cognitive effort to join and use the online brand community consisted of a three-item scale adapted from Menon (1997). To measure both expected informational benefits and expected social benefits, we adapted three Items from Okleshen and Grossbart (1998) and from McLure Wasko and Faraj (2000) respectively. Finally, the measure for the overall value of the online brand community consisted of a three-item scale adapted from Cronin et al. (1997) and Cronin et al. (2000), while the three-item measure of the intentions to join the online community was adapted from Garbarino and Johnson (1999). Finally, the online questionnaire was used to collect information on the age and gender of the respondent. 


\subsubsection{Data collection}

Data were collected during one week via an online questionnaire that was linked to the section "What"s New" on the general homepage of the car manufacturer. Visitors who clicked on the link were automatically sent to an introductory page explaining the idea of the new online brand community and the rationale of the study. Next, the participants were introduced to the trial version of the community by taking a virtual guided tour. Afterwards, they were led to the online questionnaire in which they were asked to evaluate the proposed new online community. Date and time of completion of the survey, as well as the remote user name, were captured to exclude the possibility of double entries. During the week of our data collection, 1,141 of the 12,363 visitors to the general homepage of the car manufacturer clicked on the section "What's New." Of these, 391 clicked on the link to the questionnalire, but five respondents abandoned the study after the introductory page. In total, 386 questionnaires were completed, resulting in a response rate of $34 \%$. The large majority of respondents $(63 \%)$ were in the age group of 18 to 34 years, with $43 \%$ female and $57 \%$ male. These characteristics are representative of the demographics of the average driver of the car brand investigated.

\subsubsection{Analysis plan}

A confirmatory factor analysis (CFA) was conducted to test the measurement model. Structural equation modeling (SEM) techniques were empiloyed to compare the traditional direct effects model of value formation with the alternate mediated model (hypothesis 1). SEM was also used to test the structure of brand community enthusiasm within the mediated model (hypotheses 2 and 3), and to examine the impact of overall value expectations on intentions to join the online brand community (hypothesis 4 ).

\subsubsection{Confirmatory factor analysis: Results}

Prior to hypotheses testing, a CFA was conducted on the full data set to examine the psychometric properties of the administered scales. The initial 
measurement model yielded an acceptable model fit $\left(\chi^{2}=510.84\right.$ (224 df), RMSEA $=0.057 ; C F I=0.95$ ). Other than the fixed factor loadings, each item evidenced highly significant $t$-values ( $t$-value $>6.00$ ), which suggest convergent validity. Furthermore, the variables in this study met or exceeded the threshold for composite reliability (Fornell and Larcker 1981). The CFA table including the questionnaire items, their loadings, and respective t-values is included in Appendix A.

\subsubsection{Test of the direct effects versus the mediated model of value formation}

To test hypothesis 1 , we examined the structural relationships between cognitive effort, informational benefits, social benefits and overall value. The initial step was to estimate the traditional direct effects model, which served as a baseline for the analysis. In this model, cost and benefits were specified as direct predictors of overall value. The results yielded an acceptable model fit $\left(\chi^{2}=\right.$ $173.36(50 \mathrm{df}) ;$ RMSEA $=0.076 ;$ CFI $=0.96)$. Consistent with the findings reported by Cronin et al. (1997) and Cronin, Brady, and Hult (2000), the cost varlable in this model, cognitive effort, exerted a non-significant influence on overall value. Informational and social benefits, on the other hand, were both significant predictors of overall value $(B=0.28$; $t$-value $=4.89$ and $B=0.50$; $t$ value $=8.46$, respectively) .

As a second step, we specified the alternate mediated model in which the path between cognitive effort and informational benefits, as well the path between cognitive effort and social benefits were freed for estimation. A comparison of the chi-square statistic resulting from this mediated model $\left[\left(\chi^{2}=\right.\right.$ 163.67 (48 df); RMSEA $=0.075 ; C F I=0.96$ ] indicated a highly significant improvement in model fit ( $\chi^{2}$ change $=9.69(2 \mathrm{df}) ; p<0.01$ ) relative to the direct effects model tested previously. Informational and social benefits completely medlate the relationship between cognitive effort and overall value. ${ }^{1}$ Cognitive effort exerts a negative influence on informational and social benefits $(B=-0.18 ; \mathrm{t}$-value $=-2.79$ and $B=-0.16 ; \mathrm{t}$-value $=-2.54$, respectively $)$.

\footnotetext{
A formal mediation test following the Maxham and Netemeyer (2003) procedure indicated that all four conditions of mediation were satisfied. The results of this test are available upon request.
} 
Informational benefits positively impact overall value $(B=0.28$; $t$-value $=4.82)$, as do social benefits $(B=0.50 ;$ t-value $=8.42$ ). These findings support hypothesis 1 .

\subsubsection{Estimating the complete model of value formation}

To test the remaining hypotheses, brand community enthusiasm was introduced to the mediated model as a predictor of overall value, which then predicts intentions to join the online brand community. This final specification achieved an acceptable model fit $\left(\chi^{2}=660.35\right.$ (241 df); RMSEA $=0.066$; CFI $=$ 0.93). Brand community enthusiasm was specified as a latent variable reflected in the three hypothesized underlying dimensions. The completely standandized factor loadings for opinion leadership $(B=0.89 ; t$-value $=8.88)$, social identification $(B=0.74 ; \mathrm{t}$-value $=8.92)$, and information seeking $(B=0.70 ; t$ value $=$ fixed to 1.00 ) were all highly significant, supporting hypothesis 2 . The brand community enthusiasm construct exerts a positive influence on overall value $(B=0.33 ; t$-value $=6.22)$, providing support for hypothesis 3 . In addition, overall value significantly impacts intentions to join the online brand community $(B=0.87 ;$ t-value $=15.97)$, as put forward in hypothesis 4 . Consistent with the initial analysis of the mediated model, cognitive effort negatively impacts informational benefits $(B=-0.18 ;$ t-value $=2.79)$ and social benefits $(B=-0.16$; $\mathrm{t}$-value $=2.54)$, which in turn predict overall value $(B=0.29 ; \mathrm{t}$-value $=5.03$ and $B=0.43 ;$ t-value $=7.43$, respectively). Figure 2.2 graphically illustrates these results. 
Figure 2:2: Results of the Complete Model of Value Formation

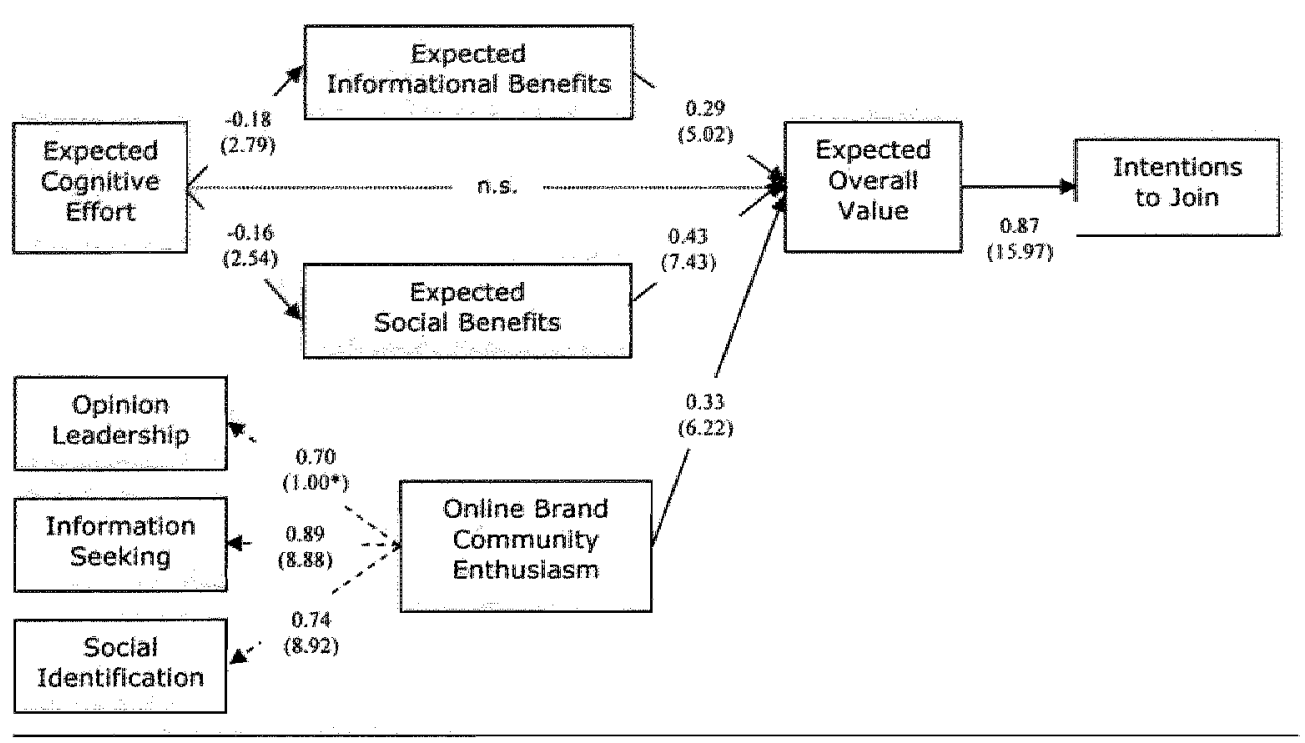

Notes: Completely standardized betas; t-walues in parentheses

\subsection{Discussion}

\subsubsection{Theoretical implications}

The majority of e-services require active participation of consumers for successful service delivery (Xue, Heim and Harker 2005). Given their many alternatives, consumers will invest the required effort needed to participate only when they expect the e-service to be valuable. It is therefore important for service managers to understand how consumers derive a value judgment of a new e-service prior to usage. Empirically, value perceptions have been modeled as a direct combination of costs and benefits. Yet, past value studies have failed to fully support this model, as costs often had an insignificant impact on value, with benefits defining value alone. A mediated model of value formation, as proposed in this study, appears to better capture the value formation process in a highly participatory e-service setting. This alternative model is based on the argument that when initially using an e-service (in our case an online brand 
community), the consumer first has to invest cognitive effort to learn how to use the service before s/he can obtain the desired benefits. Such a sequential evaluation process is best represented by a mediated model in which value expectations are influenced by benefits that are conditioned on costs. Our empirical results find support for this mediated model, as indicated by the significant improvement in model fit relative to the direct effects model. The value formation process is not only influenced by the consumption context, but also by relevant consumer characteristics (Bolton and Drew 1991). We find that enthusiasm for the e-service positively affects value expectations. Brand community enthusiasm is reflected in the dimensions opinion leadership, information seeking, and social identification. In summary, our study demonstrates that the value formation process surrounding a highly participatory e-service is best captured by a mediated model in which costs and benefits are traded off sequentially rather than simultaneously "Moreover, value expectations are strongly influenced by consumer enthusiasm for the e-service.

\subsubsection{Managerial implications}

From a managerial viewpoint, our study points to several important marketing and design issues that service companies should consider when developing new or re-evaluating old e-service offerings. The sequential nature of e-service evaluation implies that non-monetary costs (which may be regarded as minor by managers) can actually represent formidable barriers to trial. If the consumer expects to invest a lot of cognitive effort, the potential benefits and ultimately the overall value expectation of the e-service will be reduced. Therefore, initial entry barriers, even when non-monetary, should be minimized. Furthermore, marketing efforts should specifically target consumers who are enthusiastic about the new e-service. In the case of online brand communities, these target consumers can be identified by their level of brand-specific opinion leadership and information seeking, as well as their level of social identification with other users of the brand. 


\subsubsection{Limitations and future research guidelines}

The findings of this study should be read with the understanding that Iimitations exist. In first instance, our study was conducted in the context of an online brand community. It should be noted that this particular e-service requires a considerable amount of particlpation from the consumer. Future research should investigate whether the findings of this study generalize to other service settings. Furthermore, due to the anonymity of the visitors to the website featured in this study, we cannot make any statements about the characteristics that distinguish respondents from non-respondents. Finally, the data are crosssectional, reflecting a point in time prior to full launch of the online brand community. The process of value formation modeled here is therefore comparable to a cost-benefit trade-off made in a pre-purchase situation. It might be interesting to study changes in the value formation process over time. 
CHAPTER 3

\title{
Beyond the Call of Duty: Normative Influences in COMmERCIAL VIRTUAL COMmUNities
}

\begin{abstract}
The key success factor of a commercial virtual community for customers is the pro-social behavior of its members, manifested in what we call virtual community citizenship behavior. In this chapter, we report the results of an empirical study that attempts to model antecedents of three types of virtual community citizenship behavior - helping, civic virtue, and sportsmanship - in the context of a commercial virtual community. We demonstrate that the theory of norms can be extended to online contexts and that the virtual community members' propensity to engage in online interactions has a strong impact on helping behavior and civic virtue.
\end{abstract}




\subsection{Introduction}

Virtual communities represent one of the most interesting phenomena of the Internet (Ballasubramanian and Mahajan 2001; Rothaermel and Sugiyama 2001). Through the support of textual "conversations," a virtual community functions as a gathering space where like-minded individuals actively exchange Information and engage in social interaction (Burnett 2000). Companies Increasingly use virtual communities internally for the purpose of facilitating knowledge exchange between employees, and externally for the purpose of building relationships with their customers, getting their feedback, strengthening the brand, and reducing their service costs by enabing peer-to-peer problem solving. These external virtual communities of customers that provide a commercial benefit to the organization are the focus of this chapter. The success of both internal and external virtual communities obviously depends on a critical mass of members who actively participate and help other members. Whereas theories of organizational motivation help to explain why emplovees participate in internal virtual communities, it is less clear why the customers of an organization are willing to answer "the call of duty" and actively engage in commercial virtual communities, helping other customers. As customers become "partial emplloyees" of the organization, we term their pro-social behavior in commercial virtual communitles virtual community citizenship behavior, and draw on norm theory to explain this type of customer behavior (Gouldner 1960; Schwartz 1977).

Norm theory posits that individuals behave in ways that conform to the expectations of a social group (social norms) and of themselves (personal norms). Pro-social behavior that is beneficial to individuals and the social group as a whole (e.g., virtual community citizenship behavior) is strongly driven by the desire to conform to normative expectations. There are competing views, however, regarding the strength of norms in the online environment. Whille several scholars propose that the absence of social and contextual cues on the Internet leads to a reduced impact of norms and fosters conditions that promote less socially oriented behavior (Alonzo and Aiken 2004; Preece 2004; Utz 2000), other studies adhere to an opposite point of view, suggesting that norms do 
maintain their important influence on behavior on the Internet (McLure Wasko and Faraj 2000; Ridings, Gefen, and Arinze 2002). One objective of this chapter is to empirically investigate whether traditional norm theory can be extended to explain the citizenship behavior of customers in the context of commercial virtual communities. Specifically we are interested in studying the influence of social and personal norms on three types of virtual community citizenship behavior: helping, civic virtue, and sportsmanship.

In addition to normative influences, also differences in individual dispositions of customers might affect their virtual community citizenship behavior. Hence, a second objective is to introduce an individual disposition variable that seems highly relevant in the context of online communication and examine its influence. We conceptually develop online interaction propensity, which describes an individual's general tendency to engage in online interactions, and investigate whether this variable directly influences virtual community citizenship behavior.

\subsection{Informational and Social Value in Commercial Virtual Communities}

Virtual communities originally began to form as social entities with the alm of bringing back a sense of bellonging that was lost during the shift from community to society. More and more private indlviduals clustered online with similar others to anchor themselves, support each other, and exchange information (Bressler and Grantham 2000). By the mid-1990s, the commerclal potential of such online groups was strongly propagated in the popular literature (e.g., Hagel and Armstrong 1997), with the result that numerous companies started to explore the opportunities for building their own virtual community. Virtual communities that are set-up by companies generally take two forms: internal and external. Internal virtual communities facilitate the exchange of knowledge between employees within different parts of the organization. External virtual communities, on the other hand, try to attract a collective of customers of the organization in order to achieve a commercial benefit. Such commercial benefits include, for example, brand building, relationship bullding, market research through "listening in," and the reduction of service costs. These 
commercial virtual communities of customers are the research context of this chapter. Due to the diversity of communities that can be found on the Internet, no generally agreed-upon definition of the term "virtual community" has yet emerged. For the purpose of this dissertation, we define commercial virtual communities as company-endorsed online aggregations of customers who collectively co-produce and consume content about a commercial activity that is central to their interest by exchanging informational and social resources.

Like all virtual communities, a commercial virtual community consists of informational and social content, both created and exchanged through interaction (Bagozzl and Dhollakla 2002; Rheingald 1993). Research has shown that most people take part in a virtual community because they want to receive highquality information and exchange ideas and solutions (McLure Wasko and Faraj 2000; Ridings and Gefen 2004). In addition, people participate in virtual communities to develop valuable interpersonal relationships and engage in social interactions with like-minded others (Burnett 2000). This social component is likely to be more important for customers than for employees, who usually keep their online interaction in internal virtual communities "down-to-business" (Constant, Sproull, and Klesler 1996). But in the context of commercial virtual communities, the value of both the information and the social interaction that a customer gets out of the community is the main attraction of membership. In line with Babin et al. (1994), we define value broadly as the objective and subjective criteria that make up the entire experience in the virtual community. Informational value refers to the personal evaluation of the information quality the community provides to a customer, whereas social value captures the evaluative judgment a customer makes about the social support received. It is important to note that the informational and socilal resources of the virtual community have the quality of public goods that are visible and accessible to all members of the community, regardless of whether they have actively contributed to their production (Mclure Wasko and Faraj 2000). Consequently, there is ample opportunity for members to "lurk" (i.e., read the discussion without contributing) and free-ride. A functioning virtual community, however, needs a balanced proportion of members who do not only selfishly benefit from 
the content created by others, but who are willing to help other members and actively contribute to the community:

\subsection{Virtual Community Citizenship Behavior}

In the context of company-internal virtual communities, this active and helpful member behavior has been shown to result from a strong organizational orientation of employees and an organizational culture that encourages information sharing (Constant et al. 1996). As such, participating in an internal virtual community is part of an employee's organizational citizenship behavior $(O C B)$. $O C B$ is defined as "behavior(s) of a discretionary nature that are not part of the employee's formal role requirements ${ }_{r}$ but nevertheless promote the effective functioning of the organization" (Organ 1988, p. 4). As such, OCB is largely pro-social in nature. Interestingly, it seems that in the context of external commercial virtual communities, the organization's customers engage in a similar type of behavior. Whereas customers are traditilonally rather passive recipients of products and services, they actively contribute to their experience in the commercial virtual community and even take over service functions by attempting to solve the problems of other customers. As such, the customers actually go beyond their traditional role requirements and become 'partial employees" of the organization. Therefore, pro-social citizenship behavior observed among regular employees can be expected to also exist among customers in commercial virtual communities. We term this customer behavior virtual community citizenship behavior (vCCB) in order to differentiate it from OCB and emphasize its context. It is this pro-social behavior of customers (as opposed to employees) that we aim to ultimately explain in this chapter.

The original OCB construct, as suggested by Organ (1988), encompasses five underlying dimensions. However, empirical research has indicated that respondents often have difficulties to recognize the fine distinctions between the various dimensions. As a result, Podsakoff, Ahearne and Mackenzie (1997) developed a condensed OCB scale that comprises only three distinct subdimensions. In line with this study, we conceptualize VCCB as consisting of the dimensions helping ("those voluntary actions that help another person with a 
problem"), civic virtue ("behavior indicating that a person responsibly participates in and is concerned about the life of the community as a whole ${ }^{x p}$ ) and sportsmanship ("the willingness to tolerate less than ideal circumstance without complaining") (Podsakoff et al. 1997, p. 263).

While theories of organizational motivation successfully explain the OCB of employees, the motivations of customers to display VCCB and benefit other customers are less clear. In order to explain why customers in commercial virtual communities behave like helpful, active, and tolerant citizens, we turn to norm theory.

\subsection{Normative Influences}

In the last decade, an accumulative body of literature in social psychology and marketing has recognized that pro-social behavior of customers, such as donating money (Diamond and Kashyap 1997), helping (Price, Feick, and Guskey 1995), or volunteering (Fisher and Ackerman 1998), is largely driven by social and personal norms. Norms specify expectations about how an individual should or ought to behave, and are enforced by the promise of rewards and the threat of sanctions (Cialdini, Kallgren, and Reno 1991). These rewards or sanctions can either be administered by a social group or by an individual (Schwartz 1977). Therefore, norm theory distinguishes between social and personal norms.

Social norms are characterized by perceptions, attitudes and values that are commonly accepted by a soclal group. Although they are usually not explicitly stated, social norms have a strong influence on behavior, especially when this behavior is visible to other group members (Feldman 1984). It has been argued that especially the social norm of reciprocity plays a major role in Initiating pro-social behavior (Gouldner 1960; Schwartz 1977). The norm of reciprocity specifies that people should help those who have helped them by returning equivalent benefits. Reciplents of beneficial actions feel a sense of indebtedness, which leads to a motivation to alleviate this indebtedness through reciprocation.

In addition to soclal norms, also personal norms are important determinants of pro-social behavior. Schwartz (1977) conceptualized personal 
norms as internalized values that are expressed as self-expectations regarding appropriate behavior in particular situations. This appropriate behavior is motivated by the desire to act in ways consistent with the personal value system, regardless of external reinforcement (Schwartz 1977). Activated personal norms are experienced as feelings of moral obligation to behave in conformity to the self-concept. Consequently, obligation has been used to operationalize personal norms. Obllgation "energizes" altruistic actions (Schwartz 1977, p. 231), and therefore determines pro-social behavior.

As mentioned in the introduction, there has been considerable debate about the validity of traditional norm theory in the online environment. Several scholars purport that the lack of visual cues in virtual communities and the associated 'disembodiment' of online individuals may cause anti-normative conditions and promote less socially oriented behavior, such as free-riding or "flaming" (i.e., verbally abusing other members) (Alonzo and Alken 2004; Preece 2004; Utz 2000). Preece (2004) even warns that rude member behavior might destroy the virtual community. This problem usually does not exist in internal virtual communities, as all members are employees of the same organization and therefore operate within organizational boundaries. External commercial virtual communities of customers, however, do not share the same organizational bond and might well struggle with anti-normative member behavior.

But there is a competing stream of research that stresses the importance of norms in all types of vitual communitles. In contrast to offline soclal groups, behavior in virtual communities is visible to everyone through written text. Therefore, especially social norms have been suggested to play an Important role in online groups (Mclure Wasko and Faraj 2000; Ridings, Gefen, and Arinze 2002). In order to elucidate this ongoing debate, we investigate whether the norms of reciprocity and obligation are still prevallent in commercial virtual communities of customers that are external to the organization. Specifically, we examine the impact of reciprocity and obligation, which are elicited by the informational and social value received, on helping, civic virtue, and spoitsmanship.

In addition to social and personal norms, there might be other influences operating on VCCB. Individual dispositions of employees have been identified as 
an important group of antecedents of OCB (Podsakoff et al. 2000). Likewise, individual dispositions of customers might impact their citizenship behavior in commercial virtual communities. Since VCCB accurs in an online environment, a customer's general disposition towards online communication is likely to play an important role.

\subsection{Online Interaction Propensity}

It is a common observation in virtual communities that members strongly differ in their interaction frequency (e.g., Burnett 2000; Hammond 2000). For example, Hammond (2000) concludes from his qualitative work that there are two types of membership in virtual groups: communicative membership, in which individuals interact frequently, articulate concerns, and respond to messages; and quiet membership, in which individuals read messages but rarely send/post messages of their own. Based on a review of the communication literature, we propose that the type of membership that an individual displays may be explained by the presence (or lack) of a general disposition to engage in online interactions. In the traditional communication and psychology disciplines, which deal with face-to-face interactions, it is well known that individuals have different propensities to communicate with others (Liu 2003). This personality trait has been called "(un)willingness to communicate" and describes a general tendency to approach or avoid communication (Burgoon 1976; McCroskey and Richmond 1985 ).

But as all Interaction on the Internet is mediated by technology, it is profoundly different from face-to-face communication (e.g., Hoffman and Novak 1996). Online interactions are mostly asynchronous, text-based, and lack both verbal and especially non-verbal cues. In addition, due to the truly global nature of the Internet, a large percentage of online interactions occur between relative strangers. Many people who communicate with each other online have never personally met, and postings on newsgroups, discussion boards, and in online communities can have potentially global audiences. Due to these fundamental differences between offline and online communication , it is not suitable to simply transfer an offline communication trait and apply it to the online context. Rather, 
it seems necessary to investigate online interactions separately. Most research on the Internet has overlooked the existence of individual differences in online interaction preference (Liu 2003). In order to overcome this shortcoming, we propose a new behavioral disposition - online interaction propensity - that we define as a relatively stable tendency of an individual to interact with strangers (i.e., people they have never met offline) in an online environment. It is this personality trait that explains why one person will engage in online interactions and another will not under identical circumstances. We would like to emphasize that online interaction propensity is believed to be a general behavioral disposition that explains all kinds of online interactions, and not only those taking place in virtual communities. In this chapter, however, we will examine its influence on the citizenship behavior of customers in commercial virtual communities. The next section outlines our hypotheses.

\subsection{Hypotheses}

Figure 3.1 presents the conceptual framework for this study and summarizes our hypotheses.

Figure 3.1: Research Model

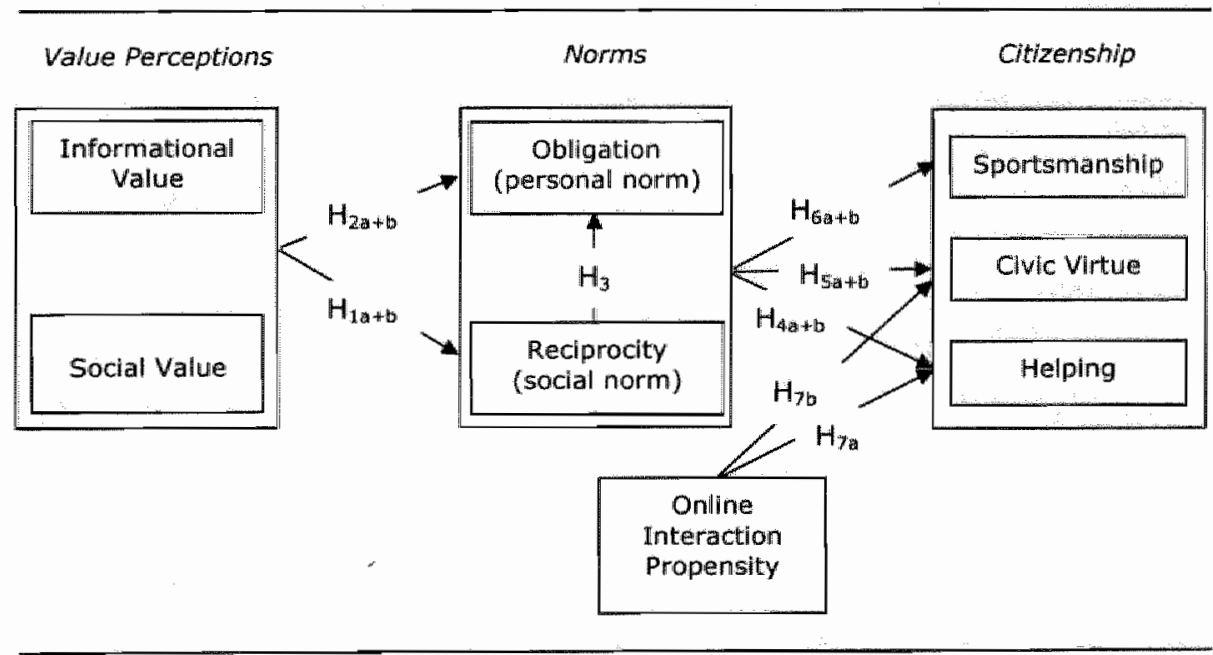


As discussed previously, the main reasons for participating in a commercial virtual community are the informational and social value received (Ridings and Gefen 2004). Both informational and social resources are created in a social space, through the exchange of favors between virtual community members. If a community member receives valuable informational or social support through the community, s/he in fact accumulates a social debt. As communication is overt in a virtual community setting and consequently visible to all members, a community member who does not pay back this debt runs the risk of being socially punished (e.g. future requests for help would be ignored). On the other hand, if a member is especially active in providing help to others, s/he is likely to be socially rewarded (e.g., by gaining status, being respected). Therefore, we expect that the consumption of both informational and social value will intensify the social norm of reciprocity (Schwartz 1977). It is important to note that virtual communities support a form of generalized reciprocity (Constant et all. 1996; Mclure Wasko and Faraj 2000), where members expect that help given to one individual will be reciprocated by someone else than the original recipient of the help. Even though the norm of reciprocity is universal (i.e., prevalent in all groups to which an individual belongs), it is not unconditional (Gouldner 1960). Rather, the intensity of the norm is "contingent upon the imputed value of the benefit previously received" (Gouldner 1960, p. 171), which in our case is the value of the information exchange and social interaction provided by the virtual community. Consequently, we propose that both the informational and social value have a positive impact on reciprocity.

$H_{1: *} \quad$ Perceived informational value has a positive impact on reciprocity.

$H_{16}$ : Perceived social value has a positive impact on reciprocity.

A member who has benefited from valuable informational and/or social support provided by the community accumulates not only a social, but also a personal debt (Schwartz 1977). If s/he now becomes aware of the need for information or social support of a fellow member, the personal norm of obligation, which is experienced as a feeling of moral obligation to return the help previously recelved, is activated. The value attributed to the information and social support received is important as "the same action can engender different 
obligations depending on the extent to which the individual targeted by the action values it" (Lambert 2000, p. 802). Therefore, we expect that the informational and social value of the virtual community, as percelved by the community members, will have a positive impact on obligation.

$\mathrm{H}_{2 \mathrm{a}}$ : Perceived informational value has a positive impact on abligation.

$\mathrm{H}_{2 b}$ : Perceived social value has a positive impact on obligation.

Previous research indicates that social norms form the basis of personal norms. As stated by Gouldner (1960) and Schwartz (1977), the internallzation of the norm of reciprocity morally obliges a person to give back benefits received from another party. In a virtual community, members spend time and effort to communicate with other members by posting messages on discussion boards. Often, members respond to specific requests for information, help, or support, even though they do not receive an immediate economic benefit in return. Rather, they display these altruistic behaviors because they have been helped by the community before and feel that they have to "give back" (McLure Wasko and Faraj 2000, p. 169). This desire for reciprocity generates an obligatory impetus to actively care for the community. Therefore, we propose that also in the context of virtual communities, reciprocity leads to direct feelings of obligation.

$\mathrm{H}_{3}$ : Reciprocity has a positive impact on obligation.

Reciprocity and obligation are two well-documented antecedents of prosocial behavior. Pro-social behavior of customers in our commercial virtual community setting is conceptualized by VCCB. If a virtual community member has accumulated a social and/or personal debt towards the virtual community, his/her feelings of both reciprocity and obligation will urge him/her to repay this debt through VCCB. Lambert even states that citizenship behavior is the "currency" of reciprocity (2000, p. 802). Therefore, we propose that members who feel a sense of reciprocity and obligation will act like good virtual community citizens by engaging in three types of behavior: returning the help previously received, actively participating and taking an interest in the virtuall community, and tolerating minor imperfections.

$\mathrm{H}_{4 a}$ : Reciprocity has a positive impact on helping. 
$H_{4 b}$ : Obligation has a positive impact on helping.

$H_{5 a:}$ : Reciprocity has a positive impact on civic wirtue.

$H_{5 b}$ : Obligation has a positive impact on civic virtue.

$H_{\text {sal }}$ : Reciprocity has a positive impact on sportsmanship.

$H_{6 b}$ : Obligation has a positive impact on sportsmanship.

In addition to normative influences, VCCB could also be affected by individual dispositions of customers. By definition, VCCB occurs in an online environment in which at least two citizenship behaviors - namely helping and civic virtue - require action from virtual community members. This action takes the form of supportive online communication. In the offline communication literature, the trait willingness to communicate has been shown to directly predict actual communication behavior, for example the likellihood of students to verbally participate in class (Chan and McCroskey 1987). Likewise, a customer's behavioral tendency to engage in online interactions will have an important influence on his/her helping behavior and active participation in a commercial virtual community.

$\mathrm{H}_{\text {3a: }}$ Online interaction propensity has a positive impact on helping.

$\mathrm{H}_{7 b}$ : Online interaction propensity has a positive impact on civic virtue.

\subsection{Methodology}

\subsubsection{Research setting}

In order to empirically test our hypotheses, we conducted a quantitative study among the members of a virtual technical support community hosted and moderated by a large computer hard- and software supplier. The primary commerclall benefit of this virtual community is service cost reduction, and to a lesser extent brand building and "istening in." The community is available on a world-wide basis, and the language for content is English. Furthermore, it is entirely based on asynchronous discussion boards. Hence, information exchange is not "real time", although most posts receive a reaction within minutes. All member-generated content is stored and, due to a powerful search engine, easily accessible at all times. As a free-of-charge e-support service, the community is 
accessible to all of the hosting company's customers, but its main users are IT professionals. The goal of the community is to provide a platform where likeminded professionals can interact and engage in peer-to-peer technical support and knowledge sharing. Consequently, the majority of member interaction focuses on information exchange about technical problems. The value of this information exchange is demonstrated by the hosting organization's estimate that at least $35 \%$ of the problems posted in this virtual community are completely solved by other members. In addition, members also converse about social topics, which range from exchanging system-administrator jokes to discussing the isolation and frustration that some experience at their workplace.

As mentioned before, the online community is moderated by employees of the hosting organization. These moderators practice a "hands off" approach and usually do not answer technical questions. Their role is to facilitate member interactions, and as such, they mainly guilde new members and gather feedback from existing ones. They only interfere in the discussions if members display disruptive behaviors, as outlined in a community "code of conduct." In order to use the online technical support community, members have to register to the site by choosing a user name and password. In this process, an accurate email address has to be provided, but the hosting organization commits to not use or disclose this email address without the consent of the member. Hence, real names and email addresses are not visible online unless the member chooses to disclose them. While several thousand people have at some point registered for the community, the hosting organization estimates that there are roughly 750 active members who regularly spend several hours per week in the online community.

\subsubsection{Questionnaire development}

Each study variable is measured using a multiple-item measurement scale. All measures use a seven-point Likert type response format, with "strongly disagree" and "strongly agree" as the anchors. Except for online interaction propensity, we only used scales that have been validated by previous empirical research. Items were selected and adapted to the specific characteristics of our 
research setting on the basis of interviews with three academic experts and three service support managers of the virtual community under investigation. To pretest the resulting questionnaire, it was administered to 127 undergraduate business students in an e-laboratory setting. To get familliar with the virtual community under investigation, the students first were asked to browse through several representative discussion threads. They were then guided to the preliminary questionnaire. As a consequence of this pre-test, several items were reworded or deleted.

In addition, we had to develop a scale for the individual difference variable online interaction propensity. We followed the procedure proposed by Churchill (1979) and conducted in total two qualitative and three quantitative studies to develop and validate a scale. In the qualitative studies, we established the domain of our construct, generated an initial pool of 54 items, and selected the 30 most representative items for further quantitative analysis. In the first quantitative study ( $n=287$ ), we reduced the scale to eight items by randomly splitting the sample in half and using exploratory and confirmatory factor analysis. In the following study $(\mathrm{n}=308)$, we evaluated discriminant validity by assessing the final eight-item scale together with conceptually close constructs and response set bias. Finally, we established nomonological validity in the fifth study ( $n=195$ ) by demonstrating the ability of the online interaction propensity scale to explain communication behavior in an online discussion board setting.

\subsubsection{Measures}

The final questionnaire consists of 30 items. Perceived informational value is measured by three items that are based on Okleshen and Grossbart (1998), while social value consists of three items adapted from McLure Wasko and Faraj (2000). Reciprocity and obligation both consist of a four-item scale, which we adapted from de Ruyter and Wetzels (2000) and McLure Wasko and Faraj (2000). Each of the community citizenship behaviors (helping, clvic virtue, and sportsmanship) is measured with four items respectively, adapted from Podsakoff et al. (1997). Finally, the online interaction propensity scale consists of eight newly developed items. 


\subsubsection{Data collection}

Due to the unavailability of personal email of the virtual community members, a link to the online questionnaire was posted in a discussion thread in the forum about "general matters." We introduced ourselves as independent researchers, explained the purpose of the study, and invited virtual community members to participate. In order to capture both intrinsically and extrinsically motivated respondents in our sample, we provided two types of incentives. On the one hand, we promised to publish the aggregated results in the community, and on the other hand, we offered a lottery to win one of 100 Amazon.com vouchers. In total, we received 203 usablle responses. As we do not know how many community members have read the thread featuring our survey, but decided not to respond, we cannot estimate a precise response rate. In order to avold double entries, date and time of completion, as well as the remote user name were captured.

\subsubsection{Sample profile}

The 203 respondents we considered in our analysis are predominantly male $(92.5 \%)$ and relatively young ( $71.5 \%$ below 45 years), which is not surprising in the IT industry. They live in 33 different countries, but most respondents come from the US (40\%) and the UK (10\%). The majority $(68 \%)$ is already member in this virtual community since more than one year, and respondents spend on average 5.5 hours per week in the community. They estimate that $67.2 \%$ of the problems they post in the community are completely solved, which is much higher than estimated by the hosting organization. Finally, we were able to not only capture very active particlpants in our sample, but also the so-called "lurkers," who only read the virtual community diallogue without contributing. Overall, $16.7 \%$ of our respondents indicated that they have not yet posted anything on the discussion boards. 
48 Chapter 3

\subsection{Results}

\subsection{Validation of measures}

We examined the psychometric properties of the administered scales by conducting exploratory as well as confirmatory factor analysis. The exploratory factor analysis (using principle component analysis with varimax rotation) found an eight-factor solution that explains $75.6 \%$ of the total variance. The eight factors corresponded to the eight constructs investigated in our study. After inspection of the individual item loadings, we deleted three items with loadings lower than 0.40 and two items with significant cross-loadings from further analysis. See Appendix B for all questionnaire items, their individual loadings, and $t$-values.

We then submitted the data to confirmatory factor analysis (CFA), using LISREL version 8.70 (Jöreskog and Sörbom 1999). The measurement model yielded an acceptable fit $\left(x^{2}=486.38\right.$ (349 df); RMSEA $=0.040 ;$ NNFI $=0.98$; CFI $=0.98)$. The individual item loadings were all highly significant ( $t$-value $>$ 8.00) and substantial in size. Furthermore, both composite reliabilities and average variances extracted exceeded the recommended cut-off values of 0.70 and 0.50, respectively (Fornell and Larcker 1981; Nunally and Bernstein 1994). Hence, we established the convergent validity of our scales. To assess discriminant validity, we compared the square root of the average variance extracted with the correlation between two latent constructs (Fornell and Larcker 1981). Discrimant validity is supported when the square root of the average variance extracted exceeds this correlation, which is the case for all possible pairs of constructs in this study. In addition, for each pair of constructs, we compared the chi-square statistic of a measurement model constraining the correlation to unity to a baseline model without this constraint. In each case, the chl-square statistic of the constrained model was greater than that of the free model, indicating that the free model provides a better representation of the data and thereby establlishing discriminant validity (Anderson and Gerbing 1988). Table 3.1 presents the correlation matrix and the composite reliability and average variance extracted for all study variables. It is interesting to note here that the correlations between the three types of citizenship behavior do not show 
a consistent pattern. While helping and civic virtue are relatively highly correlated ( $r=0.59$ ), as would be expected, sportsmanship does not seem to be correlated with either of the two other citizenship behaviors.

Table 3.1: Composite Reliability, Average Variance Extracted, and Correlations

\begin{tabular}{|l|c|c|c|c|c|c|c|c|c|c|}
\hline & CR & AVE & IV & SV & REC & OBL & HELP & CIVIC & SPORT & OIP \\
\hline IV** & $\mathbf{0 . 8 5}$ & $\mathbf{0 . 6 5}$ & $\mathbf{0 . 8 1 *}$ & & & & & & & \\
\hline SV & $\mathbf{0 . 9 3}$ & $\mathbf{0 . 8 0}$ & 0.16 & $\mathbf{0 . 8 9}$ & & & & & & \\
\hline REC & $\mathbf{0 . 9 4}$ & $\mathbf{0 . 8 4}$ & 0.21 & 0.28 & $\mathbf{0 . 9 2}$ & & & & & \\
\hline OBL & $\mathbf{0 . 8 7}$ & $\mathbf{0 . 7 0}$ & 0.15 & 0.22 & 0.33 & $\mathbf{0 . 8 4}$ & & & & \\
\hline HELP & $\mathbf{0 . 9 3}$ & $\mathbf{0 . 8 1}$ & 0.06 & 0.14 & 0.33 & 0.35 & $\mathbf{0 . 9 0}$ & & & \\
\hline CIVIC & $\mathbf{0 . 9 3}$ & $\mathbf{0 . 7 7}$ & -0.01 & 0.07 & 0.31 & 0.23 & 0.59 & $\mathbf{0 . 8 8}$ & & \\
\hline SPORT & $\mathbf{0 . 8 2}$ & $\mathbf{0 . 5 8}$ & 0.04 & -0.02 & -0.02 & 0.02 & -0.03 & 0.05 & $\mathbf{0 . 7 6}$ & \\
\hline OIP & $\mathbf{0 . 9 3}$ & $\mathbf{0 . 7 6}$ & $\mathbf{0 . 1 5}$ & 0.21 & 0.28 & 0.42 & 0.42 & 0.39 & 0.03 & $\mathbf{0 . 8 7}$ \\
\hline
\end{tabular}

*Numbers shown in bold on the diagonal denote the square root of the AVE

**IV = Informational Value; $S V=$ Sacial Value; $R E C=$ Reciprocity; OBL = Obligation; HELP = Helping; CIVIC $=$ Civic Virtue; SPORT $=$ Sportsmanship; OIP $=$ Online Interaction Propensity

As we collected the data on both independent and dependent variables from the same respondent, the potential for common method variance exists. In order to address this potential problem, we conducted Harman's one-factor test as recommended by Podsakoff and Organ (1986). All study variables were subjected to a principal component factor analysis, and the unrotated factor solution was examined. The analysis identified again eight distinct factors with eigenvalues over one, accounting for $76 \%$ of the total variance. As significantly more than one factor emerged from the data, and as the first factor explained only $28 \%$ of the total variance, we can conclude that common method variance does not seem to pose a problem in the data.

\subsubsection{Hypotheses testing}

Following the measurement model analysis, we estimated a full structural model in order to examine the relationships between our study varlables. The structural model achieved an acceptable model fit $\left(\alpha^{2}=567.01\right.$ (361 df); RMSEA $=0.049 ; \mathrm{NNFI}=0.97 ; \mathrm{CFI}=0.97$ ). Hypotheses $1 \mathrm{a}$ and $1 \mathrm{~b}$ are supported, as the social norm of reciprocity is indeed influenced by the perceived informational value $(B=0.19$; t-value $=2.59)$, and even more strongly by the perceived social 
value $(B=0.27$; t-value $=3.59)$ of the virtual community. The personal norm of obligation, however, is not directly affected by informational and social value. Hence, we do not find support for hypotheses $2 \mathrm{a}$ and $2 \mathrm{~b}$. Hypothesis 3, however, which states that the social norm of reciprocity may be internalized and thereby strengthens obligation, can be confirmed $(B=0.26$; $t$-value $=3.29)$.

The first citizenship behavior, helping, is strongly influenced by both types of norms (reciprocity: $B=0.20$; t-value $=2.83$; obligation: $B=0.20$; t-value $=$ 2.76), supporting hypotheses $4 \mathrm{a}$ and $4 \mathrm{~b}$. Civic virtue, the second citizenship behavior, is only impacted by the social norm of reciprocity $(B=0.19$; $t$-value = 2.59), while the personal norm of obligation does not seem to have an effect. Consequently, we can confirm hypothesis $5 a$, but have to reject hypothesis $5 \mathrm{~b}$. Next, we also investigated the influence of norms on the third citizenship behavior, sportsmanship. Surprisingly, neither social nor personal norms have an impact on this type of citizenship behavior, leading to a rejection of hypotheses $6 \mathrm{a}$ and $6 \mathrm{~b}$. In order to further investigate this surprising result, we considered the possibility that sportsmanship may not be driven by norms, but simply by the overall evaluation of the virtual community. It seems reasonable to speculate that virtual community members are more willing to tolerate small imperfections In the community if its overall value is perceived to be high. Hence, we estimated a rival model in which we freed the paths from informational value and social value to sportsmanship. But again, we found both paths to be not significant (informational value: $B=0.02$; $t$-value $=0.25$; social value: $B=-0.02 ; t$-value $=-0.28$ ). We can therefore concluide that sportsmanship is not influenced by any of our study variables.

Finally, we were interested to find out whether the citizenship behaviors that require active online participation - namely helping and civic virtue - are influenced by online interaction propensity. Indeed, online interaction propensity significantly impacts both helping $(B=0.31$; t-value $=4.24)$ and civic virtue ( $B$ $=0.34_{i}^{*} \mathrm{t}$-value $=4.61$ ), supporting hypotheses $7 \mathrm{a}$ and $7 \mathrm{~b}$. In order to investigate the importance of this influence, we estimated another rival model in which we constrained the paths from online interaction propensity to the two citizenship behaviors to zero. As expected, the free modell yielded a superior 
model fit, as evidenced by the significant chi-square change ( $x^{2}$ difference $=$ $32.92(2 \mathrm{df}) ; \mathrm{p}<0.001$ ). Table 3.2 provides an overview of these results.

Table 3.2: Beta Coefficients and t-Values

\begin{tabular}{|c|c|c|c|c|}
\hline & Hypothesis & B-coefficient & t-value & Result \\
\hline$H_{1 \mathbf{a}}$ & Info Value $\rightarrow$ Reciprocity & 0.19 & 2.59 & supported \\
\hline$H_{1 b}$ & Social Value $\rightarrow$ Reciprocity & 0.27 & 3.59 & supported \\
\hline $\mathbf{H}_{\mathbf{2 a}}$ & Info Value $\rightarrow$ Obligation & 0.08 & 1.08 & not supported \\
\hline $\mathbf{H}_{26}$ & Social Value $\rightarrow$ Obligation & 0.13 & 1.78 & not supported \\
\hline & Reciprocity $\rightarrow$ Obligation & 0.26 & 3.29 & supported \\
\hline $\mathrm{H}_{4: \text { a }}$ & Reciprocity $\rightarrow$ Helping & 0.20 & 2.83 & supported \\
\hline $\mathrm{H}_{4 \mathrm{~b}}$ & Obligation $\rightarrow$ Helping & 0.20 & 2.76 & supported \\
\hline $\mathbf{H}_{5 \mathbf{a}}$ & Reciprocity $\rightarrow$ Civic Virtue & 0.23 & 3.12 & supported \\
\hline$H_{5 b}$ & Obligation $\rightarrow$ Civic Virtue & 0.05 & 0.73 & not supported \\
\hline $\mathbf{H}_{6 \mathbf{a}}$ & Reciprocity $\rightarrow$ Sportsmanship & -0.03 & -0.41 & not supported \\
\hline $\mathbf{H}_{6 \mathrm{~b}}$ & Obligation - Sportsmanship & 0.04 & 0.51 & not supported \\
\hline$H_{7 \mathbf{a}}$ & $\begin{array}{l}\text { Online interaction Propensity } \\
\rightarrow \text { Helping }\end{array}$ & 0.31 & 4.24 & supported \\
\hline $\mathbf{H}_{\boldsymbol{r b}}$ & $\begin{array}{l}\text { Online Interaction Propensity } \\
\rightarrow \text { Civic Virtue }\end{array}$ & 0.34 & 4.61 & supported \\
\hline
\end{tabular}

Model Fit: $\chi^{2}=567.01(361 \mathrm{df}) ;$ RMSEA $=0.049 ;$ NNFI $=0.97 ;$ CFI $=0.97$

\subsection{Discussion}

\subsubsection{Theoretical implications}

The success of each virtual community depends on the citizenship behavior of its members. Meaningful content will only be created and relationships will only be forged in virtual communities in which the members contribute to the discussions on a continuous basis. Specifically in the context of commercial vilrtual communities of customers, organizations need to understand why their customers are willing to become "partial employees" and actively particlpate and help fellow customers in the virtual community. We introduced VCCB as a useful and comprehensive measure of the different facets of beneficial behavior of customers in commercial virtual communities. We investigated whether norm 
theory can be extended to the online world to successfully explain three types of VCCB: helping, civic virtue, and sportsmanship. Our results demonstrate that the two primary resources exchanged in a virtual community - information and social interaction - Intensify the social norm of reciprocity felt by community members, but do not directly impact the personal norm of obligation. Obligation is only indirectly affected by value perceptions through the internalization of the norm of reciprocity. Both feelings of reciprocity and obligation have a significant impact on helping behavior, whereas civic virtue is only influenced by reciprocity. An explanation for this discrepant result might be found in the slightly different nature of these two citizenship behaviors. Personal norms are activated when a need is perceived, such as the need for help. Civic virtue describes general active participation behavior that seems less urgent and therefore might entail a lesser moral obligation than helping. Even more surprisingly, the third citizenship behavior sportsmanship is not influenced by any of our study variables. Neither normative influences nor value perceptions are related to sportsmanship. In an attempt to understand this finding, we again inspected the nature of this citizenship behavior more closely. In contrast to helping and civic virtue, sportsmanship, which is defined as "the willingness to tolerate less than ideal circumstance without complaining" (Podsakoff et al. 1997, p. 263), does not require an active behavior from the virtual community member. Furthermore, helping and civic virtue are outwardly directed at other members, whereas sportsmanship is internally directed. The speculation that helping and civic virtue are somewhat different behaviors than sportsmanship is supported by the high correlation between helping and civic virtue, and the low correlation between sportsmanship and either other citizenship behavior. Hence, we tentatively conclude that sportsmanship might be less important to the effective functioning of a commerclal virtual community than helping and civic virtue.

In general, our findings demonstrate that the theory of norms known from traditional face-to-face communities plays a vital role in governing the behavior of customers in commercial virtual communities. Especially the social norm of reciprocity seems particularly important in our study. Our results thus contradict previous findings that reported a reduced influence of norms online. A member who has been helped in the virtual community feels a sense of indebtness to the 
entire community. Consequently, this member wants to reciprocate the favor and feels abliged to take the effort to answer someone else's posted problem, even though this action will not provide him/her with any direct economic benefits. our empirical results are in line with McLure Wasko and Faraj (2000), who concluded from their qualitative study that members of virtual communities initially participate in a virtual community because they aspire access to knowledge on a specific topic of interest, but ultimately become involved and develop the desire to help others out of a sense of moral duty and an interest to advance the community as a whole.

A second objective of this study was to develop a new and important individual disposition variable and examine its impact on VCCB. Online interaction propensity, which we define as an individual's general tendency to engage in online interactions with strangers, indeed has a strong direct impact on the two active citizenshlp behaviors helping and civic virtue. Hence, this new variable proves very useful in predicting online communication behavior and merits attention by other researchers.

\subsubsection{Managerial implications}

The conclusions drawn from this study also hold several interesting implications for companies that host external commercial virtual communities for their customers. Some of these findings will also apply to internal virtual communities for employees. Our research has pointed to a number of important determinants of active and helpfull community participation that can be directly or indirectly influenced by the community host. While social and personal norms, which are the main determinants of VCCB, are difficult to influence directly, they are impacted by the value of the information exchange and the social interaction. Accordingly, if the perceived value of these two aspects Increases, also the feelings of reciprocity and obligation of the members become stronger, ultimately strengthening VCCB. Thus, a community sponsor should try to stimulate community members to provilde valuable information and social interaction. We would like to emphasize here the importance of social value in commercial virtual communities. While social interaction is usually avoided in internal virtual 
communities (Constant et al. 1996), it plays a very important role in stimulating feelings of reciprocity in external customer communities. In fact, social vallue is a more important driver of reciprocity than informational value, which suggests that customer communities are slightly less "work-oriented" and require a stronger social component than internal employee communities.

The goal of increasing the perceived value of the community can be achieved, for example, through the use of 'point reward systems.' Each community member is awarded points for his/her answers to a previous post by the poster of the original question based on the usefulness or helpfulness of the answer. With a certain amount of points, the community member receives a degree or upgrade. This degree is visible to all other members and provides status, stimulating others to receive the same kind of degree or to surpass other members. This visibillty effect is particularly important considering that in our study, the social norm influenced most VCCBs. As a result, such a point system not only stimulates the frequency of interaction, but also the quality of the postings. To further increase the quality of the information exchange and social interaction, the sponsoring company can also try to recruit experts for the virtual community, which can be either professional community moderators, very knowledgeable customers, or other industry experts. If these experts can be convinced to join the virtual community, their contributions will certainly add to and stimulate the community discussions, resulting in higher informational and social value for other members.

A method to make the desired pro-social behavior more visible and explicit is the establishment of a 'netiquette," a code of conduct explicitly stating the rules of community membership. Most netiquettes only list the behaviors that are obviously unacceptable, such as posting threatening or verbally abusive comments, but few also emphasize the desired behaviors, such as helping and civic virtue. If the community netiquette outlining both negative and positive behavior is known to every member, the expectations of social and personal norms, and consequently their enforcement by the group and the self, are stronger. As a result, if reciprocity and obligation are increased, also VCCB will be positively affected. 
Finally, it is also important for organizations hosting a virtual community to realize that a certain percentage of customers, those who have a low online interaction propensity, may never become active contributing members of the virtual community. It might be worthwhile to attempt identifying the level of online interaction propensity upon registration to the virtual community in order to better understand subsequent communication activity.

\subsubsection{Limitations and future research guidelines}

Our findings can only be interpreted in the light of certain limitations. To begin with, our core framework focuses on the mediating role of social and personal norms in the formation of VCCB. Clearly, other constructs may be relevant in this context. For example, several researchers have alluded to the role of self-esteem and self-representation in motivating active contributions in computer networks (e.g., Constant et al. 1996). In addition, one of the VCCBs, sportsmanship, could not be explained by either norms or perceived community value. Future research should be directed at investigating the importance of this citizenship behavior to the effective functioning of an online community, and if worthwhile, its specific drivers. Moreover, the individual disposition online interaction propensity exhibits a strong direct effect on CCB. This suggests that it may be interesting to consider additional individual disposition variables when attempting to explain online behavior. Furthermore, our study assumes that members have certain perceptions of the informational and social value provided by the virtual community. It would be interesting to investigate how these perceptions are formed, in other words, what the antecedents of informational and social value are. Finally, all concepts and relationships were measured at one point in time, thus essentially from a static perspective. It may be worthwhile to study especially the relationships between social and personal norms and prosocial behavior over time. This consideration seems important because norms are likely to strengthen during the socialization process of a new member. 

CHAPTER 4

\title{
The Drivers and Marketing Implications of Customers" Citizenship Behavior in Virtual Communities for Service SUPPORT
}

\begin{abstract}
Companies increasingly use their customers as productive resources and outsource part of the service function to virtual communities of service support, in which customers help each other to solve their service problems. We introduce the notion of virtual community citizenship behavior to capture this unusual customer-to-customer service behavior and empirlcally investigate its unique antecedents as well as marketing consequences with a sample of 203 members of a virtual community for technical service support. We pay specific attention to the potentially differentiai influence of the social versus informational resource exchange process in motivating virtual community citizenship behavior.
\end{abstract}




\subsection{Introduction}

The rapid growth of new communication technollogies and the expansion of the Internet have created possibilities for self-service that did not exist before. One of the most remarkable developments is the virtual community, an aggregation of people who meet and interact online "for the sake of achieving personal as well as shared goals of their members" (Dholakia, Bagozzi, and Klein Pearo 2004, p. 242). Numerous companies have realized the commercial potentlial of these virtual communities and have created their own virtual communities for service support. Such a virtual community enables customers to meet like-minded peers, share information and best practices and help solve each other's service problems. Using their customers as service providers, companies can achieve significant savings in service costs while maintaining service quality. Prominent examples of such service-oriented communities are LUGNET $^{\text {TM }}$ sponsored by LEGOß, the IT Resource Center sponsored by Hewlett Packard, and the Dell Technical Support Communities. Through these virtual communitles, companies in fact "outsource" the service function to their own customers, who end up providing an efficient support service to each other.

This customer-to-customer service behavior takes the notion of customer participation to a new level. Customer participation in service delivery as such is not a new concept in the services marketing field and has been addressed, albeit not extensively, in previous research (e.g., Bendapudi and Leone 2004; Meuter and Bitner 1998; Prahalad and Ramaswamy 2004, Risch Rodie and Schultz Kleine 2000). However, all of these studies have addressed participative customer behavior necessary to produce a service for personal consumption. To our knowledge, no previous research has yet investigated participative customer behavior aimed at producing a service for other customers, as it is the case in virtual communities for service support. As customers take on the rolle of service employees, we draw comparisons to the organizational literature and introduce virtual community citizenship behavior (VCCB) to embody this form of community service. Clearly, VCCB goes beyond simple customer participation. While service companies have come to expect their customers will engage in the necessary co-production behavior when interacting with a self-service 
technology, it is not so clear why a customer would invest time and effort to serve other customers and solve their problems in a virtual community.

This question is made more interesting by the fact that in virtual communities, customers not only exchange information necessary to solve factual probiems, but supplement this utilitarian information exchange with social interaction (Fischer, Bristor and Gainer 1996; Ridings and Gefen 2004). Whereas some researchers have acknowledged the importance of differentiating between informational and social processes in knowledge exchange and problem solving (Kreijns et al. 2004), no research known to us has identified their unique impact on behavior, particularly in the context of customers solving other customers" informational and social problems. In addition, little is known about the outcomes of VCCB. There is some evidence that customer participation generally leads to increased loyalty to the service provider (Gupta and Vajic 2000; Risch Rodie and Schultz Kleine 2000), but these studies have always assumed that the service delivered with the participation of the customer was being produced for personal consumption. The marketing implications of customers serving other customers in virtual communities, however, have not yet been explored.

Hence, our research has three main objectives. First, we extend the customer particypation literature by introducing and elaborating on the concept of informational and social virtual community citizenship behavior (VCCB). We establish the relevance of VCCB for describing customer-to-customer service behavior in virtual communities. Second, we draw on theories of interpersonal support and social exchange to identify the specific informational and social drivers of VCCB. Finally, we investigate the marketing implications of informational and social VCCB for both the virtual community and the sponsoring company in terms of customers' membership continuance and purchase intentions. We develop a theoretical framework and test our hypotheses quantitatively with survey data from a sample of onilne technical support community members. 
$60 \mid$ Chapter 4

\subsection{Conceptual Foundations}

\subsubsection{Benefits of virtual communities for service support}

In 2004, customer service and support costs reached $\$ 100$ billion (www.whatis.com), and made up for as much as $60 \%$ of a high-tech company's total cost (Patsuris 2005). Faced with pressures to reduce these service costs while simultaneously maintaining service quality and customer satisfaction, a growing number of companies have introduced virtual communities as an additional service channel for their customers. For example, nearly all large computer hardware and software manufacturers, such as Dell, Apple, Hewlett Packard, and Microsoft, sponsor service-oriented virtual communities as the only free-of-charge option for technical service support. But virtual communities for service support also prosper in non-technical business segments: members of LUGNET $^{T M}$ give each other advice on how to build $\angle E G O B$ constructions, customers of Traxxas help each other with problems related to their remotecontrolled mini Hummer-cars, and travelers using Lonely Planet or Frommers travel guides share information regarding travel routes and accommodation. Regardless of whether the community focuses on software problems or on problems with planning a vacation, the important common feature of all virtual communities for service support is that their main purpose is problem-solving, and therefore information exchange ${ }^{2}$.

Some statistics indicate that virtual support communities can reduce the volume of service calls by $30 \%$. Considering that the cost of a transaction handled online is only $\$ 0.10$ as opposed to $\$ 7$ in a call center, the cost savings are significant (The Economist 2004). Hence, the Gartner Group estimates that by the end of 2005, more than $50 \%$ of companies will include community features In their customer support strategy (Harris 2001). But companies do not onlly benefit financially from sponsoring virtual communities for service support. The logged discussions between customers provide a valuable source of market intelligence, supplying extensive feedback about the company's and its competitors' products and services. In addition, the sponsoring company's

\footnotetext{
${ }^{2}$ It is important to point out here that virtual communitles for service support are different from open-source communities. The latter are NOT sponsored by companles but are set up by individuals as independent software development projects (Moon and Sprouill 2000) and are usually very small in size, with a median amount of members ranging form 6.5 to 8 per group (Krishnamurthy 2002).
} 
customers can easily be contacted through the online community, for example for the purpose of concept testing. Finally, the ongoing dialogue between the customers and sponsoring company eventually leads to stronger relationship building and future loyalty.

While it is clear that virtual communities for service support are very beneficial for the company that sponsors them, they would not exist if they were not also valuable to the customers. In an environment that is easily accessible around the clock and free-of-charge, virtual communities provide two main resources: information and social support. The information exchanged in the community is particularly valuable because it combines knowledge from many diverse individuals. Furthermore, users of these virtual communities share enthusiasm for the same product or activity. The community thus offers social value by providing a platform that allows customers to meet like-minded others and develop a sense of belonging and identification with the social group (Rothaermil and Sugyama 2001).

\subsubsection{From self-serving behavior to virtual community citizenship behavior}

We extend previous work by Meuter and Bitner (1998) who evaluate the evolution of service delivery as technology has been integrated into the delivery process. Central to this evolution has been the increasing participation of the customer. At its most basic level, service is delivered by the firm alone, as in the case of utility services. Joint production relles on input from both the firm and the service customer, as demonstrated in healthcare and educational services. Finally, self-service technologies enable customer production during which the customer only interacts with a technological interface instead of a service employee. In each of these contexts, the service is produced for personal consumption.

A unique feature of virtual communities for service support, on the other hand, is that customers augment this pure self-serving behavior by providing a support service to fellow customers. Hence, this adds a second dimension to the service delivery evolution, by supplementing self-serving behavior with community service aimed at other customers. Whereas firm, joint, and customer 
production focus on satisfying the service requirements of an individual customer, this next step in the service delivery evolution, which we refer to as community production, satisfies the service requirements not only of the individual, but also the collective (see figure 4.1).

Figure 4.1: Extended Customer Participation Continuum

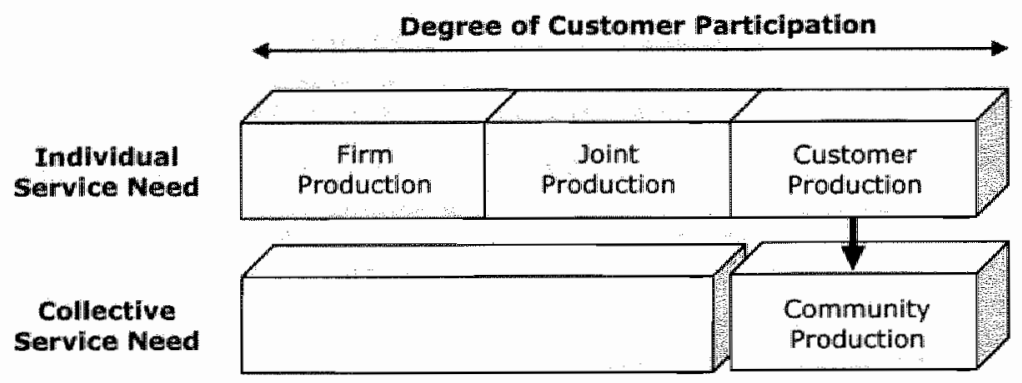

When a customer solves another customer's problem in a virtual community, $5 /$ he is engaging in a discretionary helpfull behavior that lies outside of traditional customer role requirements. As the customer essentially provides free labor in these service-oriented virtual communities, we build upon the analogy of the "partiall employee" (e.g., Mills and Morris 1986) and draw comparisons to the organizational literature on employee motivation.

In this literature, the discretionary and helpful behavior of employees has been labeled organizational citizenship behavior (OCB). OCB goes beyond the formal role requirements of employees and is therefore not formally recognized by reward systems. Nevertheless, the importance of OCB is evident, as it has been shown to promote the effective functioning of the organization by increasing stabillty and decreasing employee turnover (Chen, Hul and Sego 1998; Organ 1988; Podsakoff et al. 2000). As such, it "presents the glue which holds collective endeavors together" (Brief and Motowidlo 1986, p. 712). This is probably even more true for virtual communities than for organizations. While customers' traditional role requirements do certainly not include service provision 
for other customers, virtual communities for service support could not exist without the willingness of a critical mass of people to share information with other customers and help solve their problems.

Hence, we introduce the term virtual community citizenship behavior (VCCB) to capture the different facets of beneficial behavior that customers direct towards other customers in virtual communities for service support.

A recent stream of literature proposes that $O C B$ can be categorized according to the intended target of the behavior (Anderson and Williams 1996; Williams and Anderson 1991). As a result, Settoon and Mossholder (2002) have directed attention at "interpersonal" OCB, which focuses on citizenship behavior oriented toward coworkers. This interpersonal OCB comprises the two dimensions helping and civic virtue. Helping reflects "those voluntary actions that help another person with a problem" while civic virtue describes "behavior indicating that a person responsibly participates in and is concerned about the life of the community as a whole" (Podsakoff et al. 1997, p. 263). Furthermore, interpersonal $O C B$ is either focused on tasks or persons. Task-focused interpersonal $O C B$ relates to the exchange of job-related resources, such as information, whereas person-focused interpersonal $O C B$ is concerned with providing support for personal problems. As VCCB is also interpersonal (directed at other customers), we conceptualize it in line with Settoon and Mossholder (2002) as comprising the helping and civic virtue sub-dimensions. Given that the resources exchanged among virtual community members are informational and social in nature, we distinguish between informational VCCB that is task-focused, and social VCCB that is person-focused.

We believe that the introduction of the informational and social VCCB concept provides a valuable contribution to the understanding of customer participation behavior in commercial virtual communities. Research on virtual communities is in general scarce in marketing, and only three studies (Algesheimer et al. 2005; Bagozzi and Dholakia 2002; Dholakla et al. 2004) have so far considered the participation behavior of community members. However, this participation behavior has so far been conceptualized and measured as frequency of participation. This basic conceptualization does not take into account that the contributions to a virtual community can have different natures, 
reflecting the goals that community members want to achieve with their participation. For example, a virtual community member can participate with the goal of being helpful to a specific person, or with the goal of advancing the community as a whole. Furthermore, s/he might participate in a social discussion or in a discussion focused on information exchange. The concept of VCCB captures these fine distinctions in participation goals and therefore provides a more complete conceptualization of participatory behavior than simple frequency.

In the next section, we develop hypotheses about the specific social and informational antecedents of VCCB, and its marketing consequences for the virtual community and the sponsoring company. Figure 4.2 summarizes the proposed research model.

Figure 4.2: Hypothesized Framework

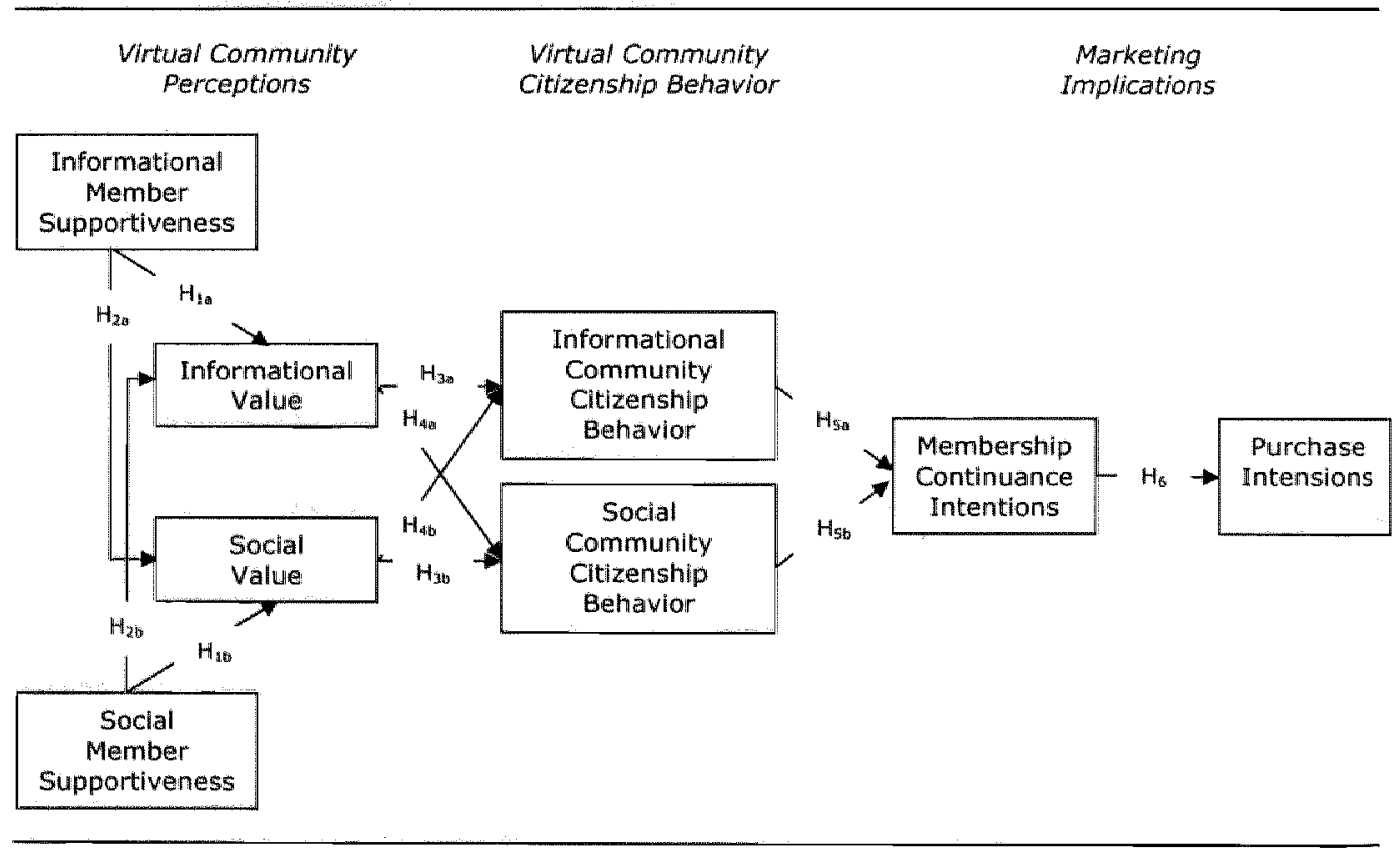




\subsection{Antecedents of Virtual Community Citizenship Behavior}

The perceived supportiveness of fellow community members and the value that results from it are hypothesized to drive VCCB. Prior to providing the rationale for these relationships, we would like to point out that these antecedents of VCCB are perceptions of the virtual community as a whole that arise from experience with that community.

Existing literature indicates that people participate in virtual communities for two main reasons: informational and social resources (Bumett 2000; Fischer, Bristor and Gainer 1996; McLure Wasko and Faraj 2000). In fact, a recent study by Ridings and Gefen (2004) empirically demonstrates that information exchange is indeed the most popular and social interaction the second most popular reason for membership in a virtuall community. In the context of service-oriented virtual communities, the same two resources are of primary importance. The main purpose of these communities clearly is peer-to-peer problem solving and the exchange of knowledge. But customers also engage in a surprising amount of social talk, for example thanking and complementing each other, cheering each other up, and so on. Experiencing these interactions over time combines to create a perception of member supportiveness that generates value in the community. Thus, the starting point of our model is the individual member's perceptual reaction to the virtual community as a whole. This perceptual reaction is what triggers individual behavior.

\subsubsection{Informational and social supportiveness}

According to the Interpersonal Support Evaluation List by Cohen et al. (1985), interpersonal supportiveness is multi-dimensional. Informational supportiveness refers to the avallability of an information provider and the quality of the obtained information. Social supportiveness, on the other hand, is experienced when individuals feel respected and part of the group. If customers in service-oriented virtual communities provide these two types of supportiveness to each other, the perceived informational and social value of the community as a whole will be positively affected. 
$H_{1 .}$ : The informational supportiveness provided by members positively influences the informational value of the virtual community.

Hib: The social supportiveness provided by members positively influences the social value of the virtual community.

In addition to drect effects, there might also be cross-over effects. Recent research in the field of collaborative learning has pointed to the importance of social interaction in supporting knowledge exchange (Kreigns et al. 2004). Hence, the value of the avalable information may be augmented if the members of the virtual community maintain good social relations with their peers. Moreover, the social value of the community may also be increased by informational supportiveness, as members experience a sense of camaraderie when receiving informational support from others. We therefore propose possible cross-over effects between the informational and social supportiveness of members and the informational and social overall value of the virtual community.

$H_{2 a}$ : The informational supportiveness provided by members positively influences the social value of the virtual community.

$\mathrm{H}_{2 \mathrm{~b}}$ : The social supportiveness provided by members positively influences the informational value of the virtual community.

\subsubsection{Informational and social value}

As discussed previousily, the main attraction for customers participating in a service-oriented virtual community is the informational and social value they receive through their membershlp. In fact, according to social exchange theory, this perceived informational and social value might explain why customers not only selfishly use the community as an information resource, but also actively participate and help others, thus engaging in VCCB. Sociall exchange is defined as "voluntary actions of individuals that are motivated by the returns they are expected to bring" (Blau 1964, p. 91). Hence, if one individual helps another, $s /$ he expects a return at some point in the future. In contrast to economic exchange, social exchange entalls diffuse, unspecified future obligations whose exact nature cannot be stipulated in advance. Although left to the discretion of 
the indebted individual, the return is expected to be of equal value to the help received. If that is not the case, the social exchange relationship between these individuals would not be continued. Specifically, Blau (1964, pp. 89-90) states that if both parties in a social exchange relationship "value what they receive from the other, both are prone to supply more of their own service to provide incentives for the other to increase his supply and avold becoming indebted to him." Accordingly, if a customer values the service received through the virtual community in terms of informational and social resources, $s$ /he has an interest to continue the relationship with the community and receive even more services in the future. But in order to maintain the soclal exchange relationship, s/he needs to return his/her obligation to the virtual community, which is achieved by helping other customers. Therefore, based on social exchange theory, we positt that VCCB is positively influenced by the informational and social value that the customer obtains from the virtual community for service support.

$H_{3 a}$ : The informational value of the virtual community positiveiy influences informational VCCB.

$\mathrm{H}_{36}$ : The social value of the virtual community positively influences social VCCB.

The virtual community becomes socially valuable to a customer by providing a feeling of belonging and camaraderie. As such, the virtual community is a "sound social space" which promotes open dialogue and information sharing (Kreijns et al. 2004, p. 156). Consequently, social value may also induce informational VCCB. Informational value, on the other hand, might impact social VCCB simply by motivating customers to give back to the community in exchange for the valuable information received, without differentiating between help in informational or social matters. Similar cross-over effects have been found by Settoon and Mossholder (2002) where the task antecedents of taskfocused interpersonal OCB influence person-focused interpersomal OCB. The social antecedents also-influence task-focused interpersonal OCB. Given these findings, Settoon and Mossholder (2002) conclude that social and task antecedents are "not easily teased apart" (p. 264). Furthermore, they explain that "whereas task activities directly influence the technlcal core, interpersonal 
actwites shape the environment in which the technical core must function" (pp. 264-265). The same is true in the context of virtual communities for service support, where the social interaction creates an environment that facilitates information exchange. We therefore propose that the informational and social value of the virtual community has cross-over effects on informational and social VCCB.

$H_{48}:$ The informationa value of the virtual community positively influences social VCCB.

$H_{4 b}$ : The social value of the virtual community positively influences informational VCCB.

\subsection{Marketing Implications of Virtual Community Citizenship Behavior}

Virtual communities for service support constitute a very unusual service delivery environment in so far as customers, instead of employees, provide service to other customers. This remarkable customer-to-customer service behavior has not yet been explored in the marketing literature, and its consequences remain unknown to the marketer. Research on customer participation in services which are consumed by the participating customer as well as jointly produced with the service company, provides some scarce evidence that active participation can increase loyalty towards the service provider, particularly in the case of highly experiential services (Gupta and Vajic 2000; Rlsch Rodie and Schultz Kleine 2000). The reasoning for this conclusion relies on the argument that participation itself provides experiential benefits to the consumer, resulting in a positive evaluation of the overall service experience. In the organizational literature, another argument is used to explain the influence of OCB on turnover intentions. If employees have contributed to shaping their work environment through their helpful $O C B$, they are more committed to the organization and want to benefit from this positive environment in the future. Therefore, the higher an employee's OCB, the lower her/his turnover intentions and vice versa (Chen, Hui and Sego 1998). Based on these indications, we expect that customers who help other customers and actively participate in the service-oriented virtual community are likely to have 
intentions to continue their community membership in order to enjoy the positive outcomes of their behavior. Accordingly, we expect that informational and social WCCB increases membership continuance intentions.

\section{$\mathrm{H}_{5 a}$ : Informational VCCB positively influences membership continuance intentions.}

$H_{5 b}$ : Social VCCB positively influences membership continuance intentions.

Membership continuance intentions are very important from a marketing point of view, because only a virtual community with sustained membership can fulfill an effective service function in the long run. As such, high levels of membership continuance intentions ensure that the sponsoring company can benefit from the cost savings achieved through the virtual community in the future. But continued membership in the service-oriented virtual community should also affect the purchase behavior of customers. At the heart of the service-oriented virtual community lies always a product or service, such as an Apple computer, or a holiday trip. If customers did not purchase these products or services, they could not be a member of that community and enjoy the informational and social benefits provided. In a recent study of brand communities, Algesheimer et al. (2005) argue that "a key marker of community membership is ongoing purchase and use of the brand" (p. 23). As the same argument holds in the context of virtual communities for service support, we propose that membership continuance intentions have a positive impact on purchase intentions. As such, the virtual community does not only affect the sponsor company's revenues through cost reduction, but also through increased purchase.

$\mathrm{H}_{6}:$ Membership continuance intentions positively influence purchase intentions.

\subsection{Methodology}

For an elaborate discussion of the research setting, pre-test, data collection procedure, and sample profile, we refer the reader to Chapter 3, as 
$70 \mid$ Chiapter 4

this situdy is based on the same database. Below a brief synopsis of the most salient details is given.

\subsubsection{Research setting}

In order to test the aforementioned hypotheses, we conducted an empirical study among the members of a virtual community for technical service support. This community is sponsored and moderated by a leading US-based IT company as a free-of-charge channel for peer-to-peer service support. The majority of members are IT professionals, who participate in order to find solutions to hardware, software, and network problems. Hence, most of the interaction between community members focuses on technical information exchange. But members also engage in some degree of social talk as they thank each other for help, share jokes, and exchange experiences about frustrations at their workplace. The community is very active, with several thousand registered members, even though the sponsor company estimates that slightly less than one thousand members actively participate on a regular basis.

We opted for this specific research context because we are interested in the specific role that social interaction plays in a primarily task-solving oriented virtual community. As described above, a virtual community for technical support by nature focuses on problem-solving, and finding important effects of social Interaction would be even more meaningful in this environment than, for example, a virtual travel community.

\subsubsection{Measures}

Each construct is measured with multiple items, using a seven-point Likert type response format.

Informational supportiveness and social supportiveness of members is measured with 4 items each, adapted from the ISEL (Interpersonal Support Evaluation List) scale by Cohen et all. (1985). Informational value comprises three items based on Okleshen and Grossbart (1998), and social value consists of three items based on McLure Wasko and Faraj (2000). Informational VCCB 
and social VCCB are conceptualized as second-order constructs reflecting Settoon and Mossholder's (2002) two dimensions helping and civic virtue. Each dimension is measured with four items adapted from Podsakoff et al. (1997) and Settoon and Mossholder (2002). Membership continuance intentions comprises four items based on Garbarino and Johnson (1999), and purchase intentions three items adapted from Swinyard (1993). Finally, the questionnaire also included several demographic questions.

\subsubsection{Data collection and sample profile}

In order to collect our data, we started a new discussion thread in the above-described virtual community for technical service support, containing a short invitation to participate and a link to our online questionnaire. The link guided the potential respondent to an introduction page which explained the purpose of the study more elaborately. In total, we received 203 usable questionnaires. Our respondents are predominantly male, work in the IT industry, and live in 33 different countries. Furthermore, on average, they spend slightly more than 5 hours per week in the virtual community, and are members since more than one year.

\subsubsection{Measurement model results}

We conducted a confirmatory factor analysis (CFA) Using LISREL version 8.70 (Jöreskog and Sörbom 1999) on all latent constructs in order to evaluate the psychometric properties of our scales. Two items were deleted from the analysis due to factor loadings below 0.65 . One of these items ("I particlpate in the online technical support community discussion about technical matters" ) was part of the informational civic virtue scale; the other one was part of the social helping scale ("I voluntarily help new members to orient themselves in the online technical support community"). Overall, the measurement model yielded an acceptable fit $\left(x^{2}=815.91\right.$ (515 df); RMSEA $=0.054 ;$ NNFI $=0.97 ;$ CFI $\left.=0.98\right)$, even though the chi-square statistic is significant due to its sensitivity to sample size. To assess the convergent validity of our scales, we inspected the individual 
Item loadings, composite reliability, and average variance extracted. All items loaded significantly on their respective constructs $(t>9)$ and were substantial in size ( $>0.65)$. Furthermore, all composite reliabilities exceed the recommended cut-off value of 0.70 , and the average variances extracted exceed the recommended cut-off value of 0.50 (Fornell and Larcker 1981; Nunally and Bernstein 1994). Appendix $C$ presents a list of the individual scale items and their corresponding loadings and t-values.

Next, we assessed discriminant validity using two different methods. First, we compared the square root of the average variance extracted to the correlation between two latent constructs (Fornell and Larcker 1981). Discriminant validity is supported when the square root of the average variance extracted exceeds this correlation, which was the case for all possible pairs of constructs. Second, again for each pair of constructs, we compared the chisquare statistic of a measurement model constraining the correlation to unity to a baseline model without this constraint. Again, all measures achieved discriminant validity, as the chi-square statistic of the constrained model was in each case significantly greater than that of the free model, indicating that the free model has a better fit to the data (Anderson and Gerbing 1988). The composite reliabilities and average variances extracted of all constructs, as well as the correlation matrix, are summarized in table 4.1 .

Table 4.1: Composite Reliability, Average Variance Extracted, and Correlations

\begin{tabular}{|l|l|l|l|l|l|l|l|l|l|l|l|l|}
\hline & CR** & AVE & IMS & SMS & IV & SV & ICIV & IH & SCIV & SH & MCI & PUR \\
\hline IMS & $\mathbf{0 . 9 3}$ & $\mathbf{0 . 7 7}$ & $\mathbf{0 . 8 8}$ & & & & & & & & & \\
\hline SMS & $\mathbf{0 . 9 6}$ & $\mathbf{0 . 8 5}$ & 0.35 & $\mathbf{0 . 9 2}$ & & & & & & & & \\
\hline IV & $\mathbf{0 . 9 0}$ & $\mathbf{0 . 7 6}$ & 0.52 & 0.25 & $\mathbf{0 . 8 7}$ & & & & & & & \\
\hline SV & $\mathbf{0 . 8 2}$ & $\mathbf{0 . 6 0}$ & 0.30 & 0.49 & 0.30 & $\mathbf{0 . 7 8}$ & & & & & & \\
\hline ICIV & $\mathbf{0 . 8 7}$ & $\mathbf{0 . 6 9}$ & 0.29 & 0.39 & 0.43 & 0.35 & $\mathbf{0 . 8 3}$ & & & & & \\
\hline IH & $\mathbf{0 . 8 6}$ & $\mathbf{0 . 6 0}$ & 0.38 & 0.38 & 0.49 & 0.33 & 0.69 & $\mathbf{0 . 7 8}$ & & & & \\
\hline SCIV & $\mathbf{0 . 9 2}$ & $\mathbf{0 . 7 4}$ & 0.21 & 0.32 & 0.23 & 0.41 & 0.46 & 0.41 & $\mathbf{0 . 8 6}$ & & & \\
\hline SH & $\mathbf{0 . 9 2}$ & $\mathbf{0 . 7 9}$ & 0.18 & 0.29 & 0.08 & 0.42 & 0.38 & 0.43 & 0.60 & $\mathbf{0 . 8 9}$ & & \\
\hline MCI & $\mathbf{0 . 9 5}$ & $\mathbf{0 . 8 2}$ & 0.39 & 0.32 & 0.25 & 0.27 & 0.38 & 0.40 & 0.39 & 0.36 & $\mathbf{0 . 9 1}$ & \\
\hline PUR & $\mathbf{0 . 9 2}$ & $\mathbf{0 . 7 9}$ & 0.38 & 0.28 & 0.52 & 0.15 & 0.28 & 0.28 & 0.18 & 0.07 & 0.47 & $\mathbf{0 . 8 9}$ \\
\hline
\end{tabular}

*Numbers showm in bold on the diagonal denote the square root of the AVE

* $C R=$ Composite Reliabillity; $\mathrm{AVE}=$ Average Varhance Extracted; IMS = Informational Member Supportiveness; SMS = Social Member Supportiveness; IV = Informational Value; SV = Social Value; ICIV = Informational Civic Virtue; IH = Informational Helpiling; SCIV = Sociall Civic Virtue; $\mathrm{SH}=$ Social Helping; $\mathrm{MCI}=\mathrm{Membership}$ Continuance Intentions; PUR = Purchase Intentions 
All of our data were collected through self-reports because the constructs investigated would not be readily evident to an alternative rating source (Bettencourt, Meuter and Gwinner 2001). As a result, the information on independent and dependent variables was provided by the same respondent, which could lead to common method variance. We conducted Harman's onefactor test as recommended by Podsakoff and Organ (1986) to address this potential problem. We performed a principal component factor analysis on all constructs and examined the unrotated factor solution. Ten factors with eigenvalues over one emerged, accounting for $81 \%$ of the total variance. The first factor explained only $32 \%$ of the total variance. Thus, we can conclude that common method variance does not seem to pose a problem in the data.

\subsubsection{Structural model results}

We then estimated a full structural model to examine the hypothesized relationships between our constructs. The model achieved an acceptable fit $\left(X^{2}=\right.$ 947.75 (544 df); RMSEA $=0.061 ; \mathrm{NNFI}=0.97 ;$ CFI $=0.97$ ), even though the chi-square statistic is still significant due to its sensitivity to sample size.

The first set of hypotheses proposes a positive influence of informational and social supportiveness of the virtual community members on the overall informational and social value of the community. In support for hypotheses 1 a and $2 \mathrm{a}$, we find that informational supportiveness strongly impacts informational value $(B=0.50 ; t$-value $=6.36)$, and to a lesser extent social value $(B=0.18, t-$ value $=2.45$ ). Social supportiveness significantly influences social value $(B=$ $0.49 ; \mathrm{t}$-value $=5.77)$, but not informational value $(B=0.09 ; \mathrm{t}$-value $=1.26)$. Hence, we can confirm hypothesis $1 b$, but not hypothesis $2 b$.

Next, we examined the influence of value on VCCB. VCCB is conceptualized as a second-order construct consisting of the dimensions helping and civic virtue in order to capture the shared variance reflected in these underlying dimensions. All four dimensions loaded significantly on their respective construct (informational civic virtue: $B=0.89$, $t$-value $=$ fixed to 1.00 ; informational thelping: $B=0.90 ; t$-value $=8.23$; social civic virtue: $B=$ $0.81, t$-value $=$ fixed to $1.00 ;$ and social helping: $B=0.80 ; t$-value $=6.77$ ). As 
expected, informational value has a positive effect on informational VCCB $(B=$ $0.46 ; \mathrm{t}$-value $=5.87$ ), supporting hypothesis $3 \mathrm{a}$. The cross-over effect on social VCCB, however, is not significant $(B=-0.04$; $t$-value $=-0.52)$. Consequently, we have to reject hypothesis $4 \mathrm{a}$. Social value, on the other hand, significantly influences both social VCCB $(B=0.64 ; t$-value $=5.65)$ and informational VCCB $(B=0.42 ; t$-value $=5.00)$. Hence, we find support for hypotheses $3 \mathrm{~b}$ and $4 \mathrm{~b}$. Finally, both types of informational and social VCCB significantly impact membership continuance intentions $(B=0.29$; t-value $=3.67$; and $B=0.36$; $t$ value $=4.13$, respectively), confirming hypotheses $5 \mathrm{a}$ and $5 \mathrm{~b}$. Membership continuance intentions, in turn, predict purchase intentions $(B=0.51$; t-value $=$ 7.45), which provides support for hypothesis 6 . Figure 4.3 provides a graphical summary of these findings.

Flgure 4.3: Results

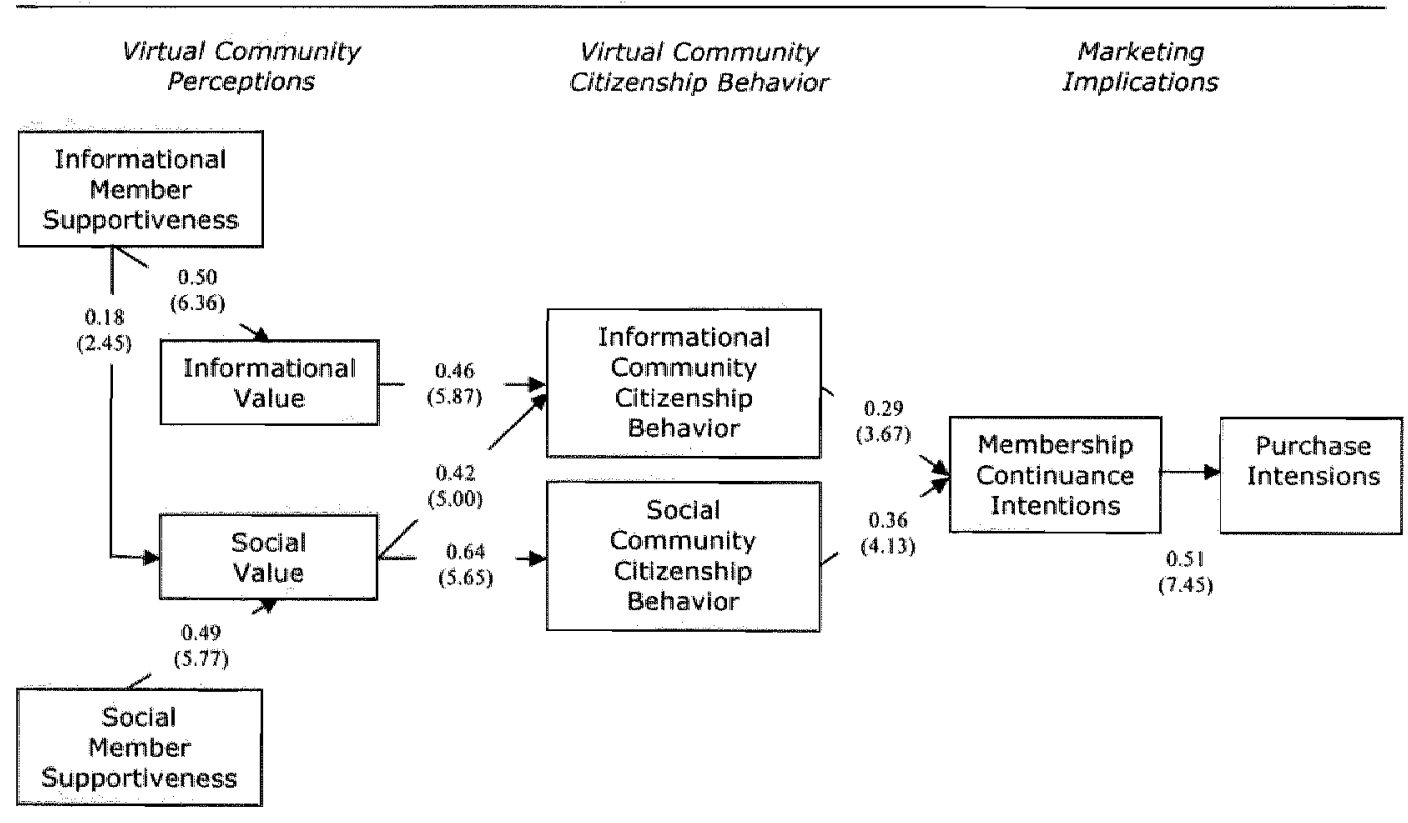

Notes: Completely standardized betas; $t$-values in parentheses 


\subsection{Discussion}

\subsubsection{Theoretical implications}

In the current research, we investigated the phenomenon of customers providing service to other customers in the context of virtual communities for service support. This investigation extends existing theory regarding customer participation in service settings. Specifically, we extend Meuter and Bitner's (1998) continuum by adding community production. Community production describes a service delivery setting in which customers do not only seek to satisfy their individual service needs, but also the service needs of the collective. The addition of the collective dimension to the existing literature on customer participation really is the primary focus of this study. As customers take over the functions of service employees to satisfy the service needs of the collective, wirtual community citizenship behavior (VCCB) is demonstrated. VCCB goes beyond the traditional customer role requirements by benefiting other customers as well as the company that sponsors the virtual community. Drawing on literature on interpersonal support, social exchange, and employee motivation, we developed a conceptual framework that identifies the antecedents and marketing consequences of VCCB. We found empirical support for most hypothesized relationships in a sample of 203 members of a virtual community for technical service support.

From a customer perspective, the attraction of service-oriented virtual communities is two-fold. Most importantly, customers galn access to a wide variety of information shared by other customers. Moreover, the virtual community provides a social environment in which customers can meet and develop social relations with like-minded athers. We were particularly interested in the unique effects of these informational and socilal processes on customer behavior and intentions. Our results confirm that the perceived informational and social supportiveness of other virtual community members is cruclal to the value of the community. The informational supportiveness plays a particularly important role, as it not only influences informational value, but also social value. Thus, we can conclude that all types of interactions are perceived as social by the virtual community members, even the act of pure information sharing. Social 
supportiveness, on the other hand, only contributes to the perceived sociall value of the virtual community. This suggests that virtual community members clearly differentiate between the two benefits they receive from their membership. Feeling respected and a part of the group (social supportiveness) apparently does not compensate for specific information needs.

Furthermore, we find that, in line with social exchange theory, the perceived value of the virtual community elicits VCCB, as customers feel they have to return the support received from others. Social VCCB is only motivated by social value, whille informational VCCB is strongly predicted by both informational and social value. This finding allows interesting insights into the mechanisms that govern the behavior in virtual communities. The usefulness of the obtained information prompts a customer to help other customers only with their technical problems, thus purely focusing on the utilitarian or task-oriented interaction in the virtual community. The feeling of group affiliation and camaraderie, on the other hand, creates a social environment which strongly motivates dlalogue and helping behavior, regardless of whether the exchange is informational or social in nature. We thus find support for Kreijns et al.'s (2004) speculation that knowledge exchange is facilitated through a "sound social space" (p. 156), especially in onlline environments.

Another main objective of our study was to identify the so far unknown marketing implications of the decision to "outsource" the service support function to customers in a virtual community. We based our hypotheses on evidence from the customer participation and employee motivation literature (e.g., Chen, Hui and Sego 1998; Risch Rodie and Schultz Kleine 2000) that customer participation and citizenship behavior can lead to loyalty. As customers invest time and effort to actively participate and help others in a service-oriented virtual community, they have a reason to stay and benefit from the positive environment that they have shaped. We can empirically conclude that both types of VCCB indeed lead to loyalty to the virtual community as reflected in membership continuance intentions. In addition, we found a strong relationship between membership continuance intentions and purchase intentions. Customers must remain users of the products or services discussed in the virtual community to make membership meaningful. Thus, the virtual community increases the purchase intentions of its 
members. These findings demonstrate that customer-to-customer service behavior in a communal environment can lead to very positive marketing outcomes.

\subsubsection{Managerial implications}

Our findings have several important implications for companies hoping to benefit from virtual communities of service support. First of all, we can conclude that customers are willing to participate and serve other customer in a virtual community, if their supportive behavior is reciprocated. The perceived value of the community is totally dependent on the input of the customers themselves. While the sponsoring company cannot directly control this behavior, it can contribute to the creation of an environment that is conducive to supportive behavior. The best way to achieve this is through paying careful attention to the feedback that the community members provide. For example, the layout and technical functionalities of the community's website have to correspond to the customers' needs. This coupled with discrete moderation by the sponsoring firm should ensure the smooth functioning of the community.

Moreover, it is interesting to point out again that all interaction, even pure information exchange, is perceived as social and contributes to the building of a sound social space, which in turn encourages active participation and helping. This finding suggests that even in virtual communities with a strong focus on information and knowledge sharing, social interaction is extremely important to the functioning of the community. Consequently, instead of trying to oppress social talk, companies sponsoring a virtual community should allow and encourage its customers to converse freely about social matters.

Another important conclusion is that the necessary active participation of customers is not percelved negatively and on the contrary even leads to positive outcomes. In addition to serving as a tool for service cost reduction, virtual communities ultimately have the potential to increase revenues through higher purchase intentions of community members. Thus, it is important for companies to recognize the strategic importance of virtual communities for service support in their overall service strategy and make sure to carefully manage them. 
The most important message to companies is that they can leverage their customers as productive resources in wirtual communities for service support and enjoy the resulting benefits, as long as they do not forget that these virtual communities first and foremost have to provide value to their customers.

\subsubsection{Limitations and future research guidelines}

Despite the interesting insights that our study offers, we have to acknowledge the limitations of this research. First of all, we collected data only at one point in time, therefore, our study suffers from the common limitations of cross-sectional fleld research, including the inability to make causal inferences. Due to the nature of the constructs we investigated, we had to use self-reported measures which might introduce problems of common-method variance. Even though Harman's one-factor test indicated that common-method variance is not causing severe problems in our data, we have to interpret our results with caution.

Second, we only studied one virtual community which provides a specific, albeit relatively common, service: technical support. While we believe that our findings will generally hold in non-technical service-oriented communities, such as LUGNET ${ }^{T M}$, the specific importance of social interaction versus information exchange might be affected. Also, our specific respondent group of IT professionals might introduce a bias, as these knowledge workers have to look beyond their organizational boundaries for information and might therefore attribute more value and interest to a virtual community for technical service support than other customer groups. Thus, it would be worthwhile to investigate different types of virtual communities for service support to see whether our results can be replicated.

Third, we have focused our investigation of the marketing consequences of VCCB on only two variables: membership continuance intentions and purchase intentions. An interesting avenue for future research might be to investigate whether VCCB also has an influence on other important marketing variables, such as perceived service quality and satisfaction. On a similar note, an examination of the impact of VCCB on online and offline word-of-mouth behavior 
might also offer further insights into the consequences of this interesting phenomenon.

Finally, due to our focus on the informational and social processes operating in the virtual community, we have not considered any situational or personality variables that might exert direct of moderating effects on our constructs and relationships. An interesting situational variable in the context of virtual communities for service support would be work-based support (Wiesenfeld, Raghuram and Garud 2001), as it provides an indication to the extent a customer is integrated in her/his work place and has to rely on external sources of information, such as a virtual community. Moreover, two personality variables seem relevant in our research context. Online interaction propensity, which refers to the generall tendency of an individual to converse online, has been shown to affect online communication behavior. Furthermore, some customers might engage in online information exchange to get a positive reaction that builds their self-esteem. Hence, need for recognition (Ruch and Hehl 1993) might be another variable worthwhile investigating in future research. 
CHAPTER 5

CONCLUSION

i: 


\subsection{Synopsis}

More than two millennia ago, Cicero declared that "we were born to unite with our fellow men, and to join in community with the human race ${ }^{a r}$ (106-43 BC). His quote seems more appropriate than ever in today"s networked economy, which allows people from all over the globe to join in "virtual" community, free of time and space restrictions. In these virtuall communities, people meet online to chat, argue, and exchange information about a topic they are strongly interested in. The tremendous growth and popularity of virtual communities soon triggered the interest of marketers and resulted in the proliferation of commercial virtual communities, which are company-sponsored communities of customers. These commercial virtual communities were the focus of this dissertation. More specifically, research in marketing and related fields has so far neglected the important question of what motivates different customer behaviors in these communities. Therefore, the central research question of this dissertation was:

What are the different types of customer behavior in commercial virtual communities, the motivations of this behavior, and its marketing consequences?

This central research question was addressed in three empirical studies. Each study was described in one chapter of the dissertation. The first study, conducted in the context of a virtual brand community, investigated the main question of why customers join such a community in the first place, and how exactly they derive that decision. Based on value theory, we identified the expected costs and benefits of virtual community membership and found that they are traded off sequentially rather than simultaneously in order to make an overall value judgment. This final value judgment, in turn, was also impacted by enthusiasim for the brand community.

The third chapter described study 2 , in which we attempted to explain the "kindness of strangers" - the active and helpful behavior of customers, conceptualized as virtual community citizenship behavior. This study was conducted in a virtual community for service support. We found that norm theory 
could be extended to the context of virtual communities, and that especially social, but also personal norms have a strong influence on active participation and helping behavior. This behavior is also strongly predicted by a customer's online interaction propensity. Surprisingly, sportsmanship, the tolerance of imperfections of the virtual community, could not be explained by any of the study variables and does not seem to be very important in the context of commercial virtual communities.

Finally, chapter 4 described the last study, in which we investigated the unique influence of the exchange processes of informational resources and social resources between community members on virtual community citizenship behavior. Again, we studied a virtual community for service support. One of the most interesting findings is that any type of interaction, even if it purely focuses on information exchange, contributes to the perceived social value of the community. Conversely, the social value is very important in motivating any kind of active participation and helping behavior, no matter whether this behavior is focused on social support or informational support. Furthermore, we also learned that virtual community citizenship behavior has very positive marketing outcomes, as it leads to sustained community membership and eventually to heightened purchase intentions.

Overall, this dissertation focused on three types of customer behavior: (1) joining the commercial virtual community, (2) being an active and helpful participant, and (3) continuing being a member in the virtual community. The remainder of this chapter provides an integrated perspective on customer behavior in commercial virtual communities by detailing the theoretical and practical implications of the three studies for each customer behavior. Finally, the chapter concludes with general suggestions for future research in the field of commercial virtual communities.

\subsection{Joining the Commercial Virtual Community}

A commercial virtual community benefits from network effects (at least until a point of saturation), which means that the more members join, the more diverse knowledge will be contributed and the more informational and social 
resources will be created, which in turn advantages all members. Hence, it is important for the success of a commercial virtual community to continuously attract new members. Behavioral intentions, such as the intention to join a virtual community, have been successfully predicted by value theory. The expected benefits and costs of community membership are traded off in order to derive an overall value judgment. The more positive this overall evaluation, the higher are the intentions to join. We have studied this value formation process in a virtual brand community built around an automotive brand. Highly interactive and experiential electronic services, such as a virtual brand community, require the active participation of customers to register for the community and learn how to correctly use the technological interface, as well as the implicit rules of communication specific to every virtual community. This initial joining process requires cognitive effort from the customer, which constitutes the most important cost of joining. The expected benefits of virtual community membership, on the other hand, are the access to a formidable information source (informational benefit), and the affilliation with like-minded others (social benefit). In contrast to traditional value theory, which models value as a simultaneous weighing of costs and benefits, we find that the cost-benefit tradeoff in the context of a virtual brand community follows a sequential process. Customers first have to expend the cognitive effort necessary to join before they can enjoy the informational and social benefits of the virtual community. We show that such a sequential trade-off process is best represented by a mediated model in which costs exert a direct negative impact on benefits while only Indirectly affecting value. This implies that the expected cognitive effort to join which might be considered as a minor cost by managers, since it is nonmonetary - can actually form an important barrier to trial. It is therefore imperative to minimize initial entry barriers for potential new virtual community members. Furthermore, enthusiasm for the brand community, which is reflected In the level of brand-specific opinion leadership and information seeking of customers, as well as their level of social identification with other users of the brand, has an important positive impact on the expected overall value of the virtual brand community and hence the likelihood to join. Thus, a company 
sponsoring a brand community should identify these enthusiastic customers and promate the virtual brand community among them.

\subsection{Beïng Active and Helpful in the Commercial Virtual Community}

\subsubsection{Virtual community citizenship behavior}

Once a customer has joined the commercial virtual community, s/he gains access to the informational and social resources that are exchanged between community members. Many virtual communities suffer from a free-rider problem, as the majority of members just consume the content generated by a minority. Without a critical mass of members who are willing to actively participate and help others in the virtual community, and as such contribute to the generation of the community's resources, the content of the community will become outdated and lase its attraction to current and future members. Since customers are contributing to the communal resources by helping and solving the probllems of other customers in commercial virtual communities, they are functioning as "partial employees" of the company that sponsors the community. This is especially true in virtual communities for technical service support, which form the research context for the studies investigating this customer behavior. Hence, we draw on the organizational literature on employee motivation and introduce the concept of virtual community citizenship behavior (VCCB) to capture this important active and helpfull behavior that benefits other customers. Initlally, we defined VCCB in line with Podsakoff et al. (1997) as being reflected in the dimensions helping, civic virtue (active contribution), and sportsmanship (tolerance of minor imperfections). We find, however, that the last dimension, sportsmanship, does not play an important role in virtual communities. The explanation for this may be that VCCB is an active, interpersonal behavior oriented toward other customers, whereas sportsmanship is directed at the whole virtual community and does not necessitate active behavior. 


\subsubsection{Social exchange and normative influences}

In order to explain the "kindness of strangers" in commercial virtual communities and answer the question of why customers engage in VCCB, we apply two interrelated theoretical frameworks to the context of commercial virtual communities: social exchange theory and norm theory. Social exchange theory proposes that people engage in voluntary actions (such as helping) for two reasons: in order to create a debt with the beneficiary of these actions, or reduce a debt previously incurred. Hence, if a customer's problem is solved by another customer in a virtulal community, s/he has become indebted to the community and "owes a favor." The desire to alleviate this debt will motivate this customer to return the help received the next time s/he reads a posted problem in the community to which s/he knows the answer. While the exact nature of the favors that people exchange is not specified, they are expected to be of equal value. Therefore, if customers perceive the value of social and informational resources they receive in the virtual community as high, they feel more compelled to engage in VCCB in order to "give back" to the community. Our studies show indeed that the informational and social value of the virtual community, which is created through the supportive contributions of community members, is the most important driver of VCCB. From a managerial perspective, it is consequently very important to ensure that the quality of the member contributions is perceived as valuable. Even though companies cannot control the behavior of their community's members, they can try to influence it. Valuable contributions, for example, can be supported through a "point reward system," with which members recognize each other's contributions and gain status and esteem within the community the more points they receive. Furthermore, the perceived value of the communal resources can also be enhanced by actively recruiting experts to the virtual community who are likely to add valuable content.

The need to alleviate the debt one incurs when receiving help, as described previously, can be explained by norm theory. Norms govern behavior by specifying expectations about how a person ought to behave, and these expectations are enforced through rewards (being recognized, feeling good about oneself) or sanctions (being ignored, feeling guilty) by either the social group or 
the self. According to the social norm of reciprocity, people should reciprocate the help they have received from others. In a commercial virtual community, all interactions are textual and therefore visible to the social group, which increases the pressure on members to conform to the norm and return help. Furthermore, if the norm of reciprocity is internalized, it becomes a personal norm that expresses itself in a feeling of moral obligation to return the help received from other community members. As such, the social norm of reciprocity and the personal norm of obligation are the mechanism through which the social exchange process operates. Social exchange, in turn, energizes the beneficlal VCCB that customers demonstrate in commercial virtual communities. Our studies show that while both social and personal norms are essential, the norm of reciprocity is especially important in initiating both active participation and helping. As mentioned above, this finding can be explained with the textual nature of the exchanges taking place in the virtual community, which makes all contributions of all members visible to the whole community. It is therefore reasonable that the social pressure to engage in beneficial citizenship belhavior is higher in commercial virtual communities than the personal pressure. Hence, contrary to previous research, we find that normative influences do play an important role online. One way to actively support the awareness of the specific norms that govern the behavior in a commercial virtual community is the establishment of a "netiquette" that outlines the desired code of conduct.

\subsubsection{Exchange of social versus informational resources}

In order to explore the issue of VCCB motivation even further, we distinguished between social VCCB, aimed at persons, and informational VCCB, aimed at tasks and problem-solving, and investigated their unique antecedents. Our results indicate that all forms of interaction, even if solely focused on information exchange, are perceived to contribute to the social value of the virtual community, and this social value is the most important driver of both types of VCCB, also VCCB that is only aimed at problem solwing. This result is very important in the context of virtual communities for service support, whose main purpose is information exchange and problem-solving. Even though social 
interaction is not task-focused and might be considered as distracting or even disruptive by the company that sponsors the virtual community, it is an essential basis for information exchange and should therefore be not only tolerated, it should be encouraged.

\subsubsection{Online interaction propensity}

Finally, since VCCB is expressed through online interactions between customers, we also considered the influence of an individual's tendency to engage in online interactions. Therefore, we introduced and developed an individual difference variable which we call online interaction propensity, and examined its impact on VCCB. Our findings demonstrate that indeed, virtual community members who are very prone to engage in online interaction display higher levels of VCCB. As a consequence, a certain percentage of customers, those who are not online interaction prone, may never become actively participating community members. Identifying the level of online interaction propensity of customers will help sponsoring companies to better understand the preferred patterns of interaction in their virtual community.

\subsection{Continuing Membership in the Commercial Virtual Community}

The final important customer behavior addressed in this dissertation is the membership continuance in the commerclal virtual community. This behavior was again examined in the context of a virtual community for service support. To sustain the critical mass of active and helpful members necessary to generate valuable content, a sufficient amount of customers must have the intention to remain a contributor to the virtual community in the future. Our research shows that these membership continuance intentions are driven by VCCB. Customers who have actively participated in creating and shaping a valuable and enjoyable environment in the virtual community want to enjoy the positive outcomes of this environment, and therefore intend to engage with the commercial virtual community also in the future. Moreover, as a commercial virtual community is always built around a commercial activity involving a specific brand, product, or 
service, customers who have the intention to prolong their membership are also likely to purchase more of this brand, product, or service. As Algesheimer et al. (2005, p. 23) put it in the context of brand communities, "a key marker of community membership is ongoing purchase and use of the brand." We find that also in the context of virtual communities for service support, continued membership has the additional positive marketing consequence of increased purchase intentions of the sponsoring company's brands, products, or services.

\subsection{A Perspective on Future Research}

In addition to the specific future research guidelines provided at the end of each chapter, this final section outlines several general directions for future research in marketing regarding commercial virtual communities.

Our last conclusion that continued membership in a commercial virtual community positively influences purchase intentions touches upon the interesting question of how commercial virtual community membership influences the offline behavior of its members. For example, in addition to increasing loyalty to the sponsoring company and its brands, products, or services, to what extent does commercial virtual community membership affect word-of-mouth behavior? How important is the virtual community as a reference group, especially compared to traditional offline reference groups? The influence of the commercial virtual community on marketing-related customer activities, such as consumption, spreading of word-of-mouth, opinion leadership, etc. is not yet well understood.

Furthermore, this dissertation has highlighted the importance of norms in governing the behavior of members in virtual communities. While our study provides interesting first insights into the issue of community management, the whole problem of virtuall community governance is still under-researched. How do normative expectations form in a newly set-up virtual community? Do they just reflect the general norms that dictate behavior in the offline world, or are there specific "online norms" that develop in virtual communitles? How are these norms enforced online? In order to answer these and similar questions, a different research approach than the one employed in this dissertation might afford further insights. First of all, a longitudinal approach would have to be 
taken to observe how norms develop over time. In addition, a study on virtual community governance would benefit from a research method that provides more depth of information, such as netnography.

A related topic concerns the way customers represent themselves in the commercial virtual community. Do they intentionally try to create a certain image or express a certain facet of their personality online, and do they adapt their posting behavior and the wording of their posts accordingly? And if so, is this image correctly perceived by the other community members? How exactly do commercial virtual community members form opinions about the expertise and credibility of their fellow community members in the purely textual online environment? It is important to study these self-perceptions and perceptions for other community members in order to understand how the social dynamics of a commercial virtual community work. From a practical perspective, research into this area would help indicate which types of technical features companies should add to the community in order to support its sociability (e.g, member homepages, point reward systems, icons as visible status symbols, etc.).

Moreover, the research context of commercial virtual communities is particularly interesting because customers provide service to other customers, and as such take over traditional employee functions. This implies that customers are willing to engage in a very active and unusual form of participation in the service delivery process. The customer as a productive resource of the company is not yet utilized to its full potential, and marketers need to understand exactly under which conditions customers are willing to provide "free labor" to the company and how they can "socialize" the customers to their specific organizational context in the most efficient way. Furthermore, customers generate valuable information in virtual communities, and often discover problems and uses of the sponsoring company's products that the company was not even aware of itself. Despite its worth, this important knowledge accumulated in the commercial virtual community is often not structurally absorbed and integrated into the sponsoring company's knowledge base. Research into the area of how to develop a continuous information flow between the virtual community and the sponsoring company is still in its infancy. 
Finally, all academic studies to date, including this dissertation, have studied successful virtual communities. This research has certainly provided many useful insights into the dynamics and functioning of virtual communities. However, important lessons can be learned from commercial virtual community projects that failed. There is a lack of case studies of unsuccessful commercial virtual community ventures which could shed light on the reasons for fallure, such as detrimental management decisions. Furthermore, it would be interesting to examine if the failure of a commercial virtual community negatively affects the brand image or even the corporate image of the sponsoring company.

\subsection{A Final Thought}

A powerful technology such as the Internet, which connects millions of computers and people worldwide, does not come without negative consequences. However, in today's environment in which the Internet gets a lot of negative press due to being misused and abused for criminal and terrorist purposes, it is important to point once again to one of its most positive aspects: its power to unite people from all nationalities, backgrounds, and races in "virtual community." Even though not motivated by pure selflessness, the "kindness of strangers" is still dominant online, evidenced by the millions of people who connect to help and support each other every day. 
REFERENCES 
A

Algesheimer, Rene, Uptal M. Dholakia, and Andreas Hermann (2005). "The social influence of brand community: Evidence from European Car Clubs," Journal of Marketing, 69 (July), 19-34.

Alonzo, Meil and Milam Aiken (2004). "Flaming in electronic communication," Decision Support Systems, 36, 205-213.

Anderson, Stella E. and Larry J. Williams (1996). "Interpersonal, job, and individual factors related to helping processes at work," Journal of Applied Psychology, 81, 282-296.

Anderson, James C. and David W. Gerbing (1988). "Structural equation modeling in practice: A review and recommended two-step approach," Psychological Bulletin, $103(3), 411-423$.

Anonymous (2004), "You're hired," The Economist, published on 18 September 2004.

Ashforth, Blake E. and Fred Mael (1989). "Social identity theory and the organization," Academy of Management Review, 14 (1), 20-39.

B

Babin, Barry J., William R. Darden, and Mitch Griffin (1994). "Work and/or fun: measuring hedonic and utilitarian shopping value," Journal of Consumer Research, 20 (March), 644-654.

Bagozzii, Richard P. and Uptal M. Dholakia (2002). "Intentional social action in virtual communitles," Journal of Interactive Marketing, 16 (2), 2-21.

Balasubramanian, Sridhar and Vijay Mahajan (2001). "The economic leverage of the virtual community," International Journal of Electronic Commerce, 5 (3), 103-138. 
Baron, Reuben M. and David A. Kenny (1986). "The moderator-mediator variable distinction in social psychological research: Conceptual, strategic, and statistical considerations," Journal of Personality and Social Psychology, 51 (6), 1173-1182.

Batson, C. Daniel (1987). "Prosocial motivation: Is it ever truly altruistic?" Advances in Experimental Social Psychology, 20, 65-122.

Bell, Colin and Howard Newby (Eds.) (1974). The Sociology of Community: A Collection of Readings. London: Frank Cass and Co.

Bendapudi, Neeli and Robert L. Leone (2003). "Psychological Implications of customer participation in co-production," Journal of Marketing, 67 (January), 1428.

Bettencourt, Lance A., Matthew L. Meuter, and Kevin P. G winner (2001). "A comparison of attitude, personality, and knowledge predictors of service-oriented organizational citizenship behaviors," Journal of Applied Psychology, 86 (1), 2941.

Blau, Peter M. (1964). Exchange and Power in Social Life. NY: John Wiley \& Sons.

Bloch, Peter H., Daniel L. Sherrell, and Nancy M. Rldgway (1986). "Consumer search: An extended framework," Journal of Consumer Research, 13 (June), $119-126$.

Bolton, Ruth N. and James H. Drew (1991). "A multistage model of customers' assessments of service quality and value," Journal of Consumer Research, 17 (March), 375-384. 
Brady, Michael K. and Christopher J. Robertson (1999). "An exploratory study of service value in the USA and Ecuador," International Journal of Service Industry Management, $10(5), 469-486$.

Bressier, Stacey E. and Charles E. Grantham Sr. (2000). Communities of Commerce. San Francisco, CA: McGraw-Hill.

Brief, Arthur P. and Stephan J. Motowidlo (1986). "Prosocial organizational behaviors," Academy of Management Review, 11 (4), 710-725.

Burgoon, Judee K. (1976). "The unwillingness-to-communicate scale: development and validation," Communication Monographs, 43, 60-69.

Burnett, Gary (2000). "Information exchange in virtual communities: a typology," Information Research, 5 (4), available online at http://informationr, net/ir/5-4/paper82.html.

C

Cohen, Sheldon, Robin 3. Mermelstein, Tom Kamarck, and Harry M. Hoberman (1985). "Measuring the functional components of social support," in Irwin $G$. Sarason and Barbara R. Sarason (Eds), Social Support: Theory, Research and Application. The Hague, Holland: Martinus Nijhoff, 73-94.

Chan, Betty and James C. McCroskey (1987). "The WTC scale as a predictor of classroom participation, "Communication Research Reports, 4, 47-50.

Chen, Xlao-Ping, Chun Hul, and Douglas J. Sego (1998). "The role of organizational citizenship behavior in turnover: Conceptualization and preliminary tests of key hypotheses, ${ }^{\prime \prime}$ Journal of Applied Psychology, 83 (6), $922-$ 931. 
Chen, Zhan and Allan J. Dubinsky (2003). "A conceptual model of perceived customer value in e-commerce: A preliminary investigation, psychology \& Marketing, $20(4), 323-347$.

Churchill, Glibert A. Ir. (1979). "A paradigm for developing better measures of marketing constructs, Journal of Marketing Research, 16 (February), 64-73.

Cialdini, Robert B., Carl A. Kaligren, and Reymond R. Reno (1991), "A focus theory of normative conduct: $A$ theoretical refinement and reevaluation of the role of norms in human behavior," in Leonard Berkowitz (Ed.), Advances in Experimental Social Psychology. New York: Academic Press, 201-214.

Constant, David, Lee Sproull, and Sara Kiesler (1996). "The kindness of strangers: The usefulness of electronic weak ties for technical advice," Organization Science, $7(2), 119-135$.

Cothrel, Joseph P. and Ruth L. Williams (1999). "On-line communities: Helping them form and grow," Journal of Knowledge Management, 3 (1), 54-60.

Cronin, J. Joseph Jr., Michael K. Brady, Richard R. Brand, Roscoe thightower Jr., and Donald 1. Shemwell (1997). "A cross-sectional test of the effect and conceptualization of service value," The Journal of Services Marketing, 11 (G), 375-391.

Cronin, J. Joseph Jr., Michael K. Brady, and Tomas M. Hult (2000). "Assessing the effects of quality, value, and customer satisfaction on consumer behavioral intentions in service environments," Journal of Retailing, $76(2), 193-218$.

Cummings, Janathon N., Lee Sproull, Sara B. Kiesler (2002). "Beyond hearing: Where real-world and online support meet," Group Dynamics: Theory, Research, and Practice, 6 (1), 78-88. 


\section{D}

de Ruyter, Ko and Martin G. M. Wetzels (2000). "With a little help from my fans - Extending models of pro-social behaviour to explain supporters' intentions to buy soccer club shares," Journal of Economic Psychology, 21, 387-409.

Diamond, William D. and Rajiv K. Kashyap (1997). "Extending models of prosocial behavior to explain university alumni contributions," Journal of Applied Social Psychology, 27 (10), 915-928.

Dholakia, Uptal M., Richard P. Bagozzi, and Lisa Klein Pearo (2004). "A social influence model of consumer participation in network- and smail-group-based virtual communities," International Journal of Research in Marketing, 21, 241263.

Downs, A. (1961). "A theory of consumer efficiency," Journal of Retailing, 37 (winter), 6-12.

E

Etzioni, Amital and Oren Etzioni (1999). "Face-to-face and computer-mediated communities: A comparative analysis," The Information Society, 15, 241-248.

$\mathbf{F}$

Fallows, Deborah (2004). The Internet and Daily Life. The Pew Internet \& American Life Project, avallable online at www.pewinternet.org/reports.

Faray, Samer and Lee Sproull (2000). "Coordinating expertise in software development teams," Management Science, 46, 1554-1568.

Feldman, Daniel C. (1984). "The development and enforcement of group norms," Academy of Management Review, 9 (January), 47-53.

Fernback, Jan and Brad Thompson (1995). "Virtual communities: Abort, retry, failure?" available online at www.well.com/user/hlr/texts/Vccivil.html. 
Feick, Lawrence F. and Linda L. Price (1987). "The market maven: A diffuser of marketplace information," Journal of Marketing, 51 (January), 83-97.

Fischer, Elleen, Julia Bristor, and Brenda Gainer (1996). "Creating or escaping community?: An exploratory study of Internet consumers" behaviors, "Advances in Consumer Research, 23, 178-183.

Fisher, Robert 1. and David Ackerman (1998). "The effects of recognition and group need on volunteerism: A social norm perspective, "Journal of Consumer Research, 25 (December), 262-275.

Fornell, Claes and David F. Larcker (1981). "Evaluating structural equation models with unobservable variables and measurement error," Journal of Marketing Research, 18, 19-50.

Freud, Sigmund (1930). Civilization and Its Discontents. London: Hogarth.

G

Garbarino, Ellen C. and Julie A. Edell (1997). "Cognitive effort, affect, and choice," Journal of Consumer Research, 24 (September), 147-158.

Garbarino, Ellen, and Mark S. Johnson (1999). "The different roles of satisfaction, trust, and commitment in customer relationships," Journal of Marketing, 63 (April), 70-88.

George, Don (2003). The Kindness of Strangers - Travelers' Tales of Trouble and Salvation Around the Globe. Lonely Planet Publications.

Gouldner, Alwin W. (1960). "The norm of reciprocity," American Sociological Review, 25, 165-178. 
Grewal, Rajdeep, Raj Mehta, and Frank R. Kardes (2000). "The role of the socialidentity function of attitudes in consumer innovativeness and opinion leadership ${ }_{s}$ Journal of Economic Psychology, 21, 233-252.

Gupta, Sudheer, and Mirjana Vajic (2000). "The contextual and dialectical nature of experiences," in James A. Fitzsimmons and Mona J. Fitzsimmons (Eds), NeW Service Development: Creating Memorable Experiences. Thousand Oaks, CA: Sage Publications, 33-51.

\section{H.}

Hammond, Michael (2000). "Communication within on-line forums: The opportunities, the constraints and the value of a communicative approach," Computers \& Education, 35 (4), 251-262.

Hagel, John III and Arthur G. Armstrong (1997). Net Gain: Expanding Markets Through Virtual Communities. Boston MA: Harvard Business School Press.

Harris, Kimberly (2001). Community Technologies: Something Old, Something New. SPA-13-8989, Gartner Group, July.

Hillery, George A. Jr. (1955). "Definitions of community: Areas of agreement," Rural Sociology, 2, 111-123.

Hoffmann, Donna L. and Thomas P. Novak (1996). "Marketing in hypermedia computer-mediated environments: Conceptual foundations," Journal of Marketing, 60 (July), 50-68.

Holbrook, Morris B. and Elizabeth Hirschman (1982). "The experiential aspects of consumption: Consumer fantasies, feelings and fun," Journal of Consumer Research, 9 (September), 132-140. 
Jöreskog, Karl and Dag Sörbom (1999). LISREL 8: User's Reference Guide. Chicago: Scientific Software International.

\section{$\underline{K}$}

Kraut, Robert, Sara B. Kiesler, Bonka Boneva, Jonathon N. Cummings, Vicki Helgeson, and Anne Crawford (2002). "The Internet paradox revisited," Journal of Social Issues, 58, 49-74.

Kreijns, Karel, Paul A. Kirschner, Wim Jochems, and Hans van Buuren (2004), "Determining sociability, social space, and social presence in (a)synchronous collaborative groups," CyperPsychology \& Behavior, 7 (2), 155-172.

Krishnamurthy, Sandeep (2002). "Cave or community?: An empiricall examination of 100 mature open source projects," First Monday, 7 (6), available online at http://firstmonday.org/issues/lssue7 6/krishnamurthy/index.html.

\section{$\underline{\mathbf{L}}$}

Lambert, Susan J. (2000). "Added benefits: The link between work-life benefits and organizational citizenship behaviour," Academy of Management Journal, 43 (5), 801-815.

Lenhart, Amanda, John Horrigan, and Deborah Fallows (2004). Content Creation Online. The Pew Internet \& American Life Project, avallable online at www.pewinternet.arg/reports.

Liu, Yuping (2003). "Generating value through online interaction: individual and situational differences," Presented at the 2003 Academy of Marketing Science Annual Conference, Washington, D.C.

Lovelock, Christopher H. and Robert F. Young (1979). "Look to consumers to increase productivity," Harvard Business Review, 57 (3), 168-178. 
M.

Machiavelii, Niccolò (1515). The Prince.

Mathwick, Charla, Naresh Malhotra, and Ed Rigdon (2001). "Experiential value: Conceptualizaion, measurement and application in the catalogue and Internet shopping environment, Journal of Retailing, 77 (1), 39-56.

Maxham III, James G. and Richard G. Netemeyer (2003). "Firms reap what they sow: The effect of employee shared values and perceived organizational justice on customer evaluations of complaint handling," Journal of Marketing, 67 (January), 46-62.

McAlexander, James H., John W. Schouten, and Harold F. Koenig (2002). "Building brand community," Journal of Marketing, 66 (January), 38-54.

McCroskey, James C. and Virginia P. Richmond (1985). "Willingness to communicate and interpersonal communication," Presented at the West Virginia Symposium on Personality and Interpersonal Communication, Morgantown, WV.

McLure Wasko, Molly and Samer Faraj (2000). "It is what one does: Why people particlpate and help others in electronic communities of practice," Journal of Strategic Information Systems, 9, 155-173.

McWilliam, Gil (2000). "Building stronger brands through online communities," Sloan Management Review, (Spring), 43-54.

Menon, Geeta (1997). "Are the parts better than the whole? The effects of decompositional questions on judgments of frequent behaviors," Journal of Marketing Research, 34 (August), 335-346.

Meuter, Matthew L. and Mary Jo Bitner (1998). "Self-service technologies: Extending service frameworks and identifying issues for research," in Dhruw 
Grewal and Connie Pechmann (Eds.), AMA Winter Educators' Conference. Chicago, IL: American Marketing Association.

Mills, Peter K. and James H. Morris (1986). "Clients as partial employees of service organizations: Role development in client participation;" Academy of Management Review, 11 (4), 726-735.

Moon, Jae Yun and Lee Sproull (2000). "Essence of distributed work: The case of Linux Kernel," First Monday, 5 (1), available online at http://firstmonday.org/issues/issues $7 /$ moon/index.html.

Muniz, Albert M. Jr. and Thomas C. O'Guinn (2001). "Brand community," Journal of Consumer Research, 27 (March), 412-432.

Nietzsche, Friedrich W. (1910). The Complete Works of Friedrich Nietzsche. Oscar Levy (Ed.). Edinburgh: T. N. Foulis.

\section{N}

Nunnally, Jum C. and Ira H. Bernstein (1994). Psychometric Theory. McGraw Hill.

o

Oklleshen, Cara and Sanford Grossbart (1998). "Usenet groups, virtual community and consumer behaviours," Advances in Consumer Research, 25, 276-282.

Organ, Dennis W. (1988). Organizational citizenship behavior: the good soldier syndrome. Lexington, MA: Lexington Books.

\section{$\underline{P}$}

Papadakis, Maria C. (2003). Computer-Mediated Communities: The Implications of Information, Communication, and Computational Technologies for Creating Community Online. Arlington, VA: SRI International. 
14 It

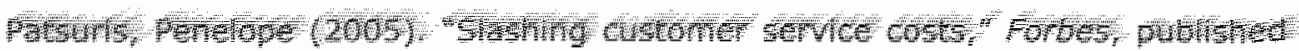
mistome 2005

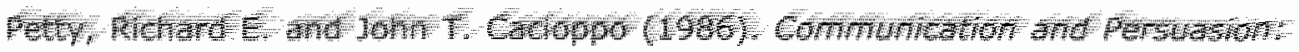

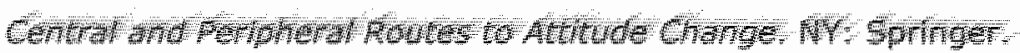

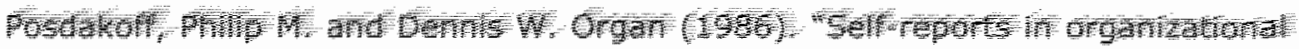

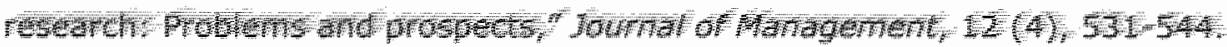

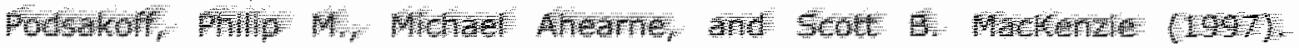

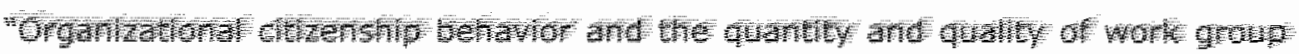

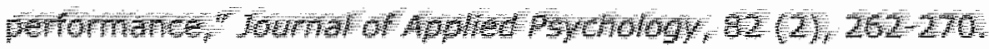

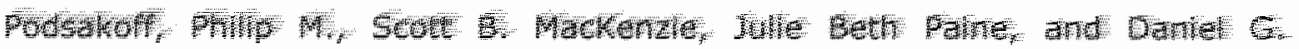

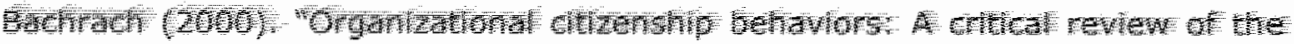

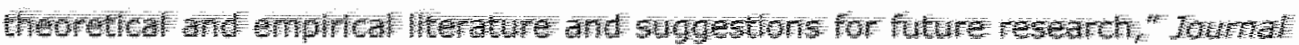

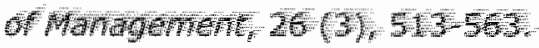

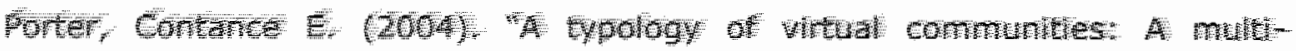

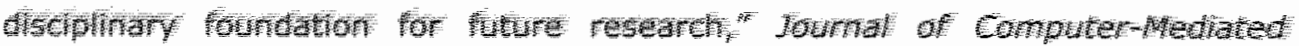
Comureator. 10 (1)

Prahalad, C. K, and Venkat Ramaswamy (2004). "Co-creation experiences: The next practice in value creation," Journal of Interactive Marketing, 18 (3), 5-14.

Preece, Jennifer (2000). Online Communities: Designing Usability, Supporting Sociability. Chichester, UK: John Wiley \& Sons.

Preece, Jennifer, Yvonne Rogers, and Hellen Sharp (2002). Interaction Design: Beyond Human-Computer Interaction. New York, NY: John Wiley \& Sons.

Preece, Jennifer (2004). "Etiquette online: From nice to necessary," Communications of the ACM, 47 (4), 56-61. 
Price, Linda L., Lawrence F. Felck, and Audrey Guskey (1995). "Everyday market helping behaviour," Journal of Public Policy and Marketing, 14, 255-266.

Puddifoot, John E. (1995). "Dimensions of community identity," Journal of Community \& Applied Social Psychology, 5, 357-370.

R

Rainie, Lee and John Horrigan (2005). How the Internet Has Woven Itself Into American Life. The Pew Internet \& American Life Project, avallable online at Www.pewinternet, org/reports.

Rheingold, Howard (1993). The Virtual Community: Homesteading on the Electronic Frontier. MA: Addison-Wesley.

Ridings, Catherine M., David Gefen, and Bay Arinze (2002). "Some antecedents and effects of trust in virtual communities," Journal of Strategic Information Systems, 11, 271-295.

Ridings, Catherine M. and David Gefen (2004). "Virtual community attraction:

Why people hang out online," Journal of Computer-Mediated Communication, 10 (1), available online at

thttps://jomc.indiana. edu/vol10/issue1/ridings gefen, html.

Risch Rodle, Amy and Susan Schultz Klelne (2000) "Customer participation in services production and deliver," in Teresa A. Swartz and Dawn Iacobucci (Eds), Handbook of Services Marketing and Management. Thousand Oaks, CA: Sage Publications, 111-125.

Rothaermel, Frank $T$. and Stephen Sugiyama (2001). "Virtual Internet communities and commercial success: Individual and community-level theory grounded in the atypical case of TimeZone.com," Journal of Management, 27, 297-312. 
Ruch, Wiltibald and Franz-Josef Hehl (1993). "Humour appreciation and needs: Evidence from questionnalre, self-, and peer-rating data," Personality and Individual Differences, 15 (4), 433-445.

s

Schwartz, Shalom H. (1977). "Normative influences on altruism," Advances in Experimental Social Psychology, 10, 222-280.

Settoon, Randall P. and Kevin W. Mossholder (2002). "Rellationship quality and relationship context as antecedents of person- and task-focused interpersonal citizenship behavior," Journal of Applied Psychology, 87 (2), 255-267.

Shuman, Jeffrey and Janice Twombly (2001). Collaborative Communities: Partnering for Profit in the Networked Economy. Chicago, IL: Dearborn Trade Publishing.

Swinyard, William R. (1993). "The effects of mood involvement and quality of store experience on shopping intentions," Journal of Consumer Research, 20 (2), 271-280.

T

Teigland, Robin and Molly McLure Wasko (2003). "Integrating knowledge through Information trading: Examining the relationship between boundary-spanning communication and individual performances," Decision Sciences, 34 (2), 261286.

Tönnies, Ferdinand (1887). Gemeinschaft und Gesellschaft: Abhandlung des Kommunismus und des Sozialismus als Empirische Kuiturformen. Leipzig: Reisland. 
Utz, Sonja (2000). "Social information processing in MUDs: the development of friendships in virtual worlds," Journal of Online Behavior, 1 (1), avallable online at www.behavior, net/JoB/v1n1/utz.html.

W

Wiesenfeld, Batia M., Sumita Raghuram, and Raghu Garud (2001). "Organizational identification among virtual workers: The role of need for affiliation and perceived work-basd social support," Journal of Management, 27 (2), 213-230.

Williams, Larry J. and Stella E. Anderson (1991). "Job satisfaction and organizational commitment as predictors of organizational citizenship and in-role behaviors," Journal of Management, 17, 601-617.

Williams, Ruth L. and Joseph Cothrel (2000). "Four smart ways to run online communities," Sloan Management Review, 41 (4), 81-91.

Woodruff, Robert B. (1997). "Customer value: The next source for competitive advantage," Journal of the Academy of Marketing Science, 25 (2), 139-153.

$x$

Xue, Mel, Gregory R. Heim, and Patrick T. Harker (2005). "Consumer and coproducer roles in e-service: Analyzing efficiency and effectiveness of e-service designs," International Journal of Electronic Business, 3 (2), 1-24.

$\underline{Z}$

Zeithaml, Valarie A. (1988). "Consumer perceptions of price, quality, and value: A means-end model and synthesis of evidence," Journal of Marketing. 52 (July), $2-22$. 


\section{APPENDICES}


Appendix A: Scale Items and CFA results for Chapter 2

\begin{tabular}{|c|c|c|c|}
\hline \\
\hline \multicolumn{4}{|c|}{$\begin{array}{l}\text { Measurement padel Fit } \gamma^{2}=510.84(224 \text { df }) \text {. RMSEA }=0.057 \text { CFI }=0.95 \\
\text { Constiruct }\end{array}$} \\
\hline Information & I usually gather a lot of information about the $X$-car. & 0.72 & $(*)$ \\
\hline Seeking & I am always on the lookout for more information about the $X$ - & & \\
\hline \multirow[t]{2}{*}{$\left(\mathrm{CR}^{4}=0.82\right)$} & car. & 0.79 & 13.55 \\
\hline & I am very interested in information about the $\mathrm{X}$-car. & 0.82 & 13.89 \\
\hline Opinion & In general, I'm the one who talks about the $X$-car in my circle & & \\
\hline Leadership & of friends. & 0.78 & $\left({ }^{*}\right)$ \\
\hline \multirow[t]{3}{*}{$(C R=0.87)$} & I inform my friends about new developments concerning the & & \\
\hline & $x$-car. & 0.85 & 17.31 \\
\hline & $\begin{array}{l}\text { When I talk with my friends about the } X \text {-car, I give a great } \\
\text { deall of information. }\end{array}$ & 0.86 & 17.52 \\
\hline Social Ldentity & I feel as a member of the group of X-car drivers. & 0.80 & $(*)$ \\
\hline \multirow{2}{*}{$(C R=0.93)$} & I feel closely connected to the group of X-car drivers. & 0.96 & 22.86 \\
\hline & I have strong feelings towards the group of $X$-car drivers. & 0.94 & 22.37 \\
\hline Expected & Likely, it will be uncomplicated to use the $X$-car community. & & \\
\hline Cognitive Effort & (r) & 0.42 & $(*)$ \\
\hline \multirow[t]{2}{*}{$(C R=0.70)$} & $\begin{array}{l}\text { Likely, it will take a lot of effort to use the } X \text {-car community. } \\
\text { I believe it will be difficult to learn how the } X \text {-car community }\end{array}$ & 0.73 & 6.85 \\
\hline & works. & 0.81 & 6.50 \\
\hline \multirow{5}{*}{$\begin{array}{l}\text { Expected } \\
\text { Informational } \\
\text { Benefits } \\
(C R=0.92)\end{array}$} & The $X$-car community will be useful to get information about & & \\
\hline & the $\mathrm{X}$-car. & 0.88 & $\left(^{*}\right)$ \\
\hline & The $X$-car community will enable me to find information about & 0.91 & 25.11 \\
\hline & With the $x$-car community, I will have better access to & & \\
\hline & information about the $X$-car. & 0.90 & 24.87 \\
\hline \multirow{3}{*}{$\begin{array}{l}\text { Expected Social } \\
\text { Benefits } \\
(C R=0.85)\end{array}$} & Participating in the $X$-car community will be entertaining. & 0.91 & $(*)$ \\
\hline & Surely, it will be fun to use the $X$-car community. & 0.94 & 28.49 \\
\hline & $\begin{array}{l}\text { I believe that it will be nice to get into contact with other } \\
\text { members in the } X \text {-car community. }\end{array}$ & 0.77 & 19.66 \\
\hline \multirow{3}{*}{$\begin{array}{l}\text { Expected Overall } \\
\text { Value } \\
(\mathrm{CR}=0.89)\end{array}$} & $\begin{array}{l}\text { How would you describe your overall evaluation of the } x \text {-car } \\
\text { community? }\end{array}$ & 0.86 & $\left({ }^{*}\right)$ \\
\hline & I think positively about the value of the $X$-car community. & 0.89 & 22.67 \\
\hline & I bellewe that the $X$-car community is a valuable resource. & 0.79 & 18.88 \\
\hline \multirow[t]{3}{*}{$\begin{array}{l}\text { Intentions to Join } \\
(C R=0.76)\end{array}$} & $\begin{array}{l}\text { If I have the opportunity, I intend to participate in the } X \text {-car } \\
\text { community. }\end{array}$ & 0.86 & $(*)$ \\
\hline & It is improbable that I will join the X-car community. ( $r)$ & 0.57 & 11.46 \\
\hline & $\begin{array}{l}\text { If I need information about the } X \text {-car, I will join the } X \text {-car } \\
\text { community in order to get it. }\end{array}$ & 0.69 & 14.40 \\
\hline
\end{tabular}

(") indicates scale item set to "1.00" to establish the scale.

"CR $=$ Composite reliability 


\section{Appendix B: Scale Iterns and CFA results for Chapter 3}

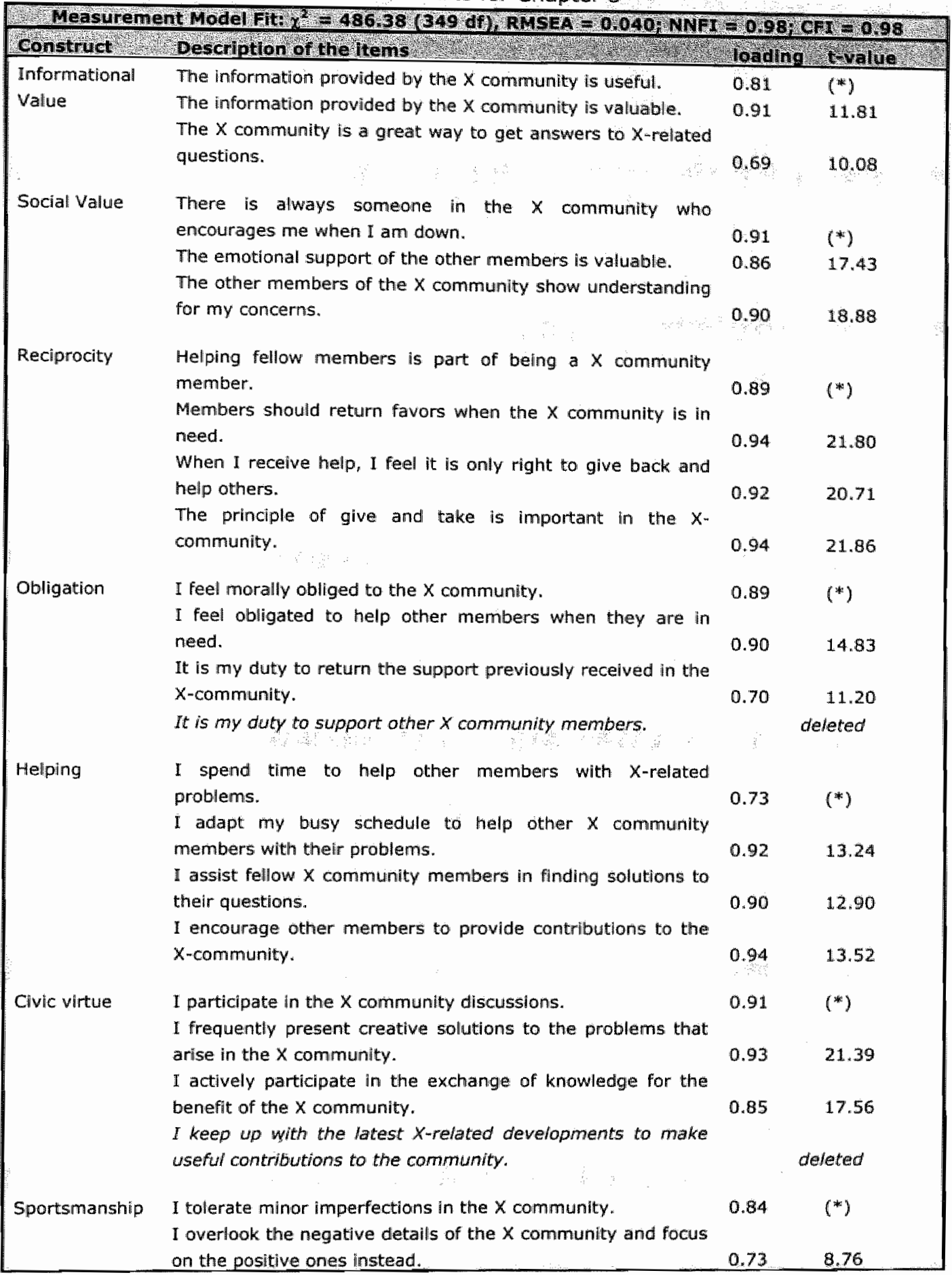


112 Appendices

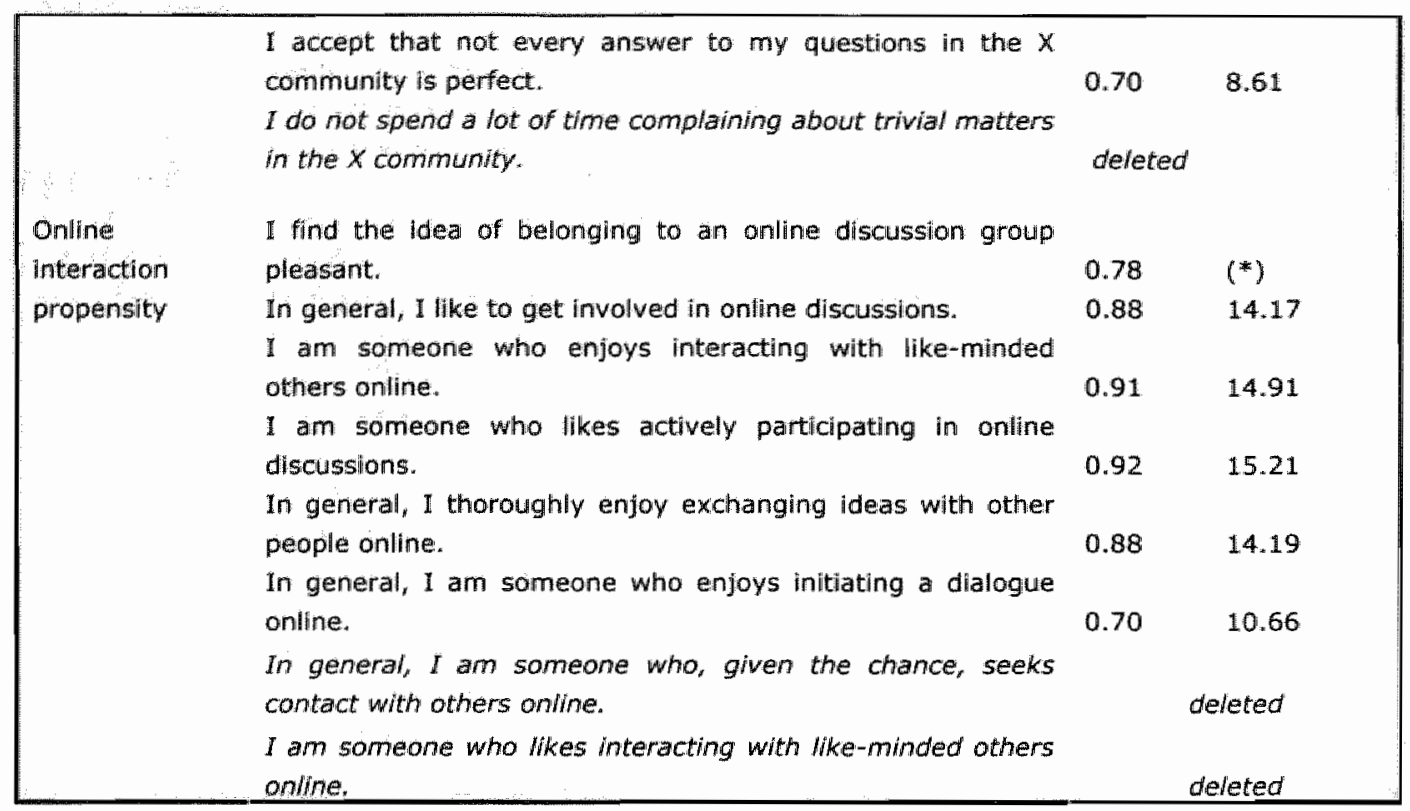

$\left({ }^{*}\right)$ indicates scale item set to " $1.00 "$ to establish the scale. 
Appendix C: Scale Items and CFA results for Chapter 4

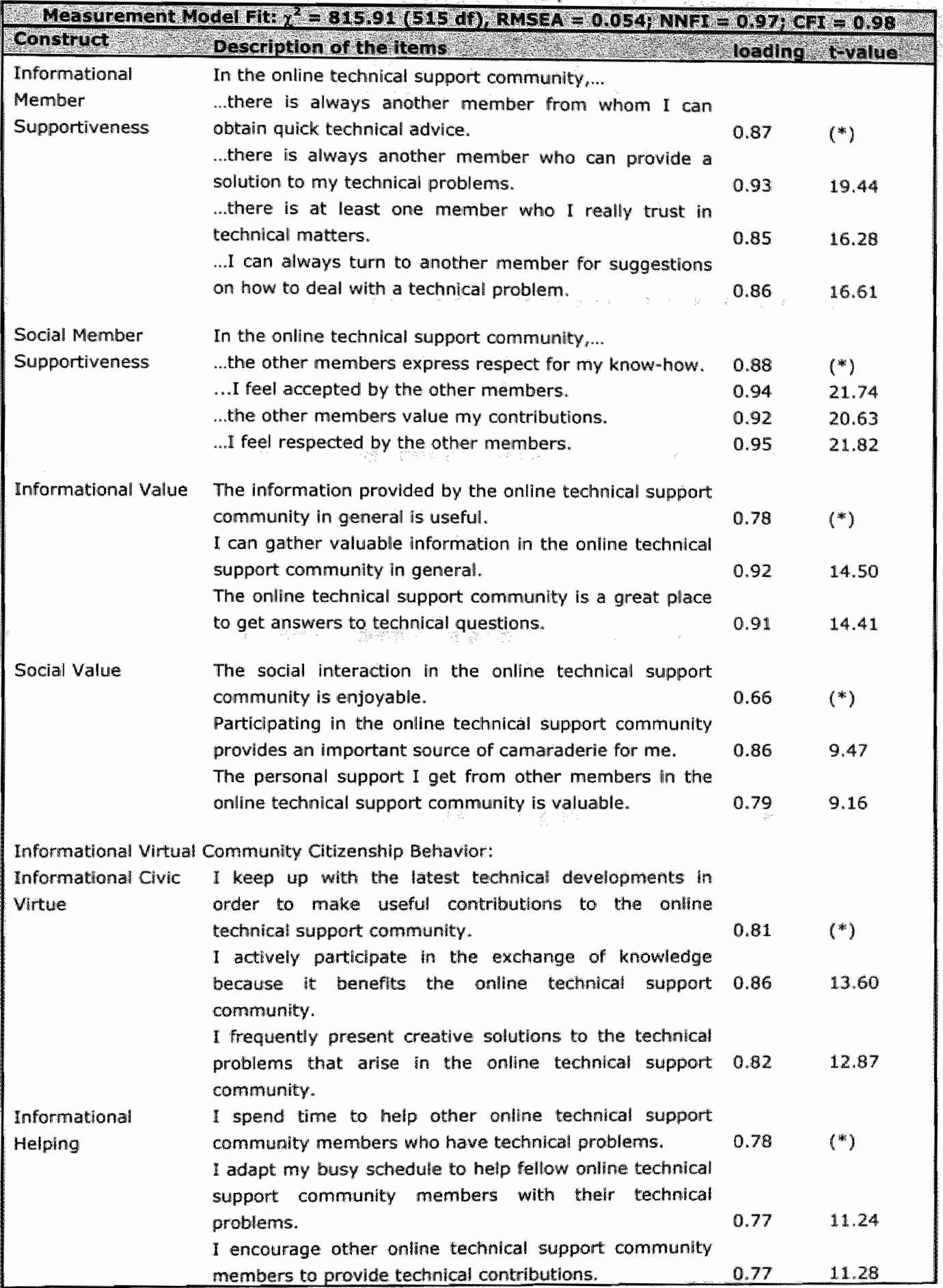


1 assist fellow online technical support community members in finding sollutions to their technical quiestions.

$0.79 \quad \mathbb{1 1 . 4 8}$

Social Virtual Community Citizenship Behavior:

Social Crvic virtue I particlpate in the oniine techinical support community discussions that are about a non-technical topic. $\quad 0.70$

I prowde suggestions about how the online technical support community could improve socially.

I frequently present creative suggestions to other members about the appropriate behavior in the online technical support community.

1 keep up with social dewelopments in the online technical support community.

Social Helping 1 adapt my busy schedule to help fellow online technical support community members with their personal problems.

I encourage aniline technical support community members to help other members also with their personal problemsix

I spend time to help other online technical support community members who hawe non-technical problems.

Membership Continuance Intentions

I plan to attend the discussions in the online technical support community in the future.

I will definitely contact members in the online technical support community agailn.

I will still spend time in the online technical support community in the future.

I expect to stay an active member of the online technical support community also in the future.

Purchase Intentions I comsider purchasing $X Y Z$ products and services in the futurie.

I plan to use $X Y Z$ products and services in the future.

I expect to buy at least one (more) $X Y Z$ product or service sooner or later. 
Curriculum Vitae 

Caroline Wiertz was born on the $23^{\text {rd }}$ of May 1977 in Aachen, Germany. She attended the Rhein-Maas Gymnasium in Aachen and obtained a FrenchGerman secondary school diploma. During this time, she also spent an exchange semester at a US high school in Rochester, New York. In September 1996, she started studying International Business at the Faculty of Economics and Business Administration of Maastricht University, the Netherlands. She was awarded her Masters degree (cum laude) in September 2000. During her studles, she worked as a research assistant at Maastricht University's Department of Marketing. In addition, she spent eight month in Paris executing a llarge-scale marketing research project for the company Océ. She formally joined the Department of Marketing as a PhD candidate in September 2000. Her maín research interests incllude online consumer behavior, especially in virtual communities, as well as services marketing. She has presented her work at varlous international conferences and has published in the Journal of Business Research. Furthermore, her work has been reported in the commercial press, such as De Telegraaf, Telecommerce Magazine, and The Economist.

Currently, she works as an Assistant Professor of Marketing at Cass Business School, City University London. In addition to her research on online consumer behavior, she has recently started work in the area of movie marketing. 